\title{
Elementary Educators' Attitudes about the Utility of Educational Robotics and Their Ability and Intent to Use It with Students
}

Todd I. Ensign

Follow this and additional works at: https://researchrepository.wvu.edu/etd

\section{Recommended Citation}

Ensign, Todd I., "Elementary Educators' Attitudes about the Utility of Educational Robotics and Their Ability and Intent to Use It with Students" (2017). Graduate Theses, Dissertations, and Problem Reports. 5546.

https://researchrepository.wvu.edu/etd/5546

This Dissertation is protected by copyright and/or related rights. It has been brought to you by the The Research Repository @ WVU with permission from the rights-holder(s). You are free to use this Dissertation in any way that is permitted by the copyright and related rights legislation that applies to your use. For other uses you must obtain permission from the rights-holder(s) directly, unless additional rights are indicated by a Creative Commons license in the record and/ or on the work itself. This Dissertation has been accepted for inclusion in WVU Graduate Theses, Dissertations, and Problem Reports collection by an authorized administrator of The Research Repository @ WVU.

For more information, please contact researchrepository@mail.wvu.edu. 
Elementary Educators' Attitudes about the Utility of Educational Robotics and Their Ability and Intent to Use It with Students

Todd I. Ensign

\author{
Dissertation submitted \\ to the College of Education and Human Services \\ at West Virginia University \\ In partial fulfillment of the requirements for the degree of \\ Doctor of Education in \\ Curriculum and Instruction \\ James Rye, PhD, Chair
M Cecil Smith, PhD
John Oughton, EdD
Earl Scime, PhD
Jennifer Robertson-Honecker, PhD
Department of Curriculum \& Instruction/Literacy Studies
}

Morgantown, West Virginia

2017

Key words: robotics, elementary education, science, technology, engineering, mathematics, STEM, LEGO, WeDo, programming, constructionism, Papert, FIRST

Copyright 2017 Todd I. Ensign 


\begin{abstract}
Elementary Educators' Attitudes about the Utility of Educational Robotics and Their Ability and Intent to Use It with Students
\end{abstract}

\title{
Todd I. Ensign
}

Educational robotics (ER) combines accessible and age-appropriate building materials, programmable interfaces, and computer coding to teach science and mathematics using the engineering design process. ER has been shown to increase K-12 students' understanding of STEM concepts, and can develop students' self-confidence and interest in STEM. As educators struggle to adapt their current science teaching practices to meet the new interdisciplinary nature of the Next Generation Science Standards, ER has the potential to simultaneously integrate STEM disciplines, engage and inspire students in mathematics and science, and build connections to STEM careers. One challenge is a lack of documented models for preparing educators, particularly at the elementary level, to effectively use robotics in their classrooms. The lack of scholarship on appropriate robotics platforms for elementary learners, reliable techniques of delivering professional development in ER, or standardized instruments that can reliably measure elementary educators' self-efficacy with robotics suggests there is a need for such research. The primary purpose of this study was to investigate the impact of a four-hour, hands-on, ER professional development workshop on K-5 ${ }^{\text {th }}$ grade educators' attitudes about their ability to teach ER, the value (utility) of the technology, and their desire to use it (intent). An 18question survey was administered before (pre-) and after (post-) the workshop, as well as a third time after educators had an opportunity to use robotics with students (post-post). In order to extend and explain the quantitative data, $60 \%$ of the educators who completed all three surveys were also interviewed. This study sought to determine if any of the trained educators also participated in after-school robotics competitions, and if so what impact that had on their attitudes of using ER. Results comparing the pre to post workshop means determined that there were statistically significant differences with large effect sizes in educators' attitudes across all three subscales. The interviews supported the conclusion that the workshop and classroom kits are important for successful implementation of ER in classrooms. Post use surveys did not result in statistically significant differences in educators' attitudes, demonstrating persistence of attitudes consistent with the interview results that revealed educators value the "hands-on" nature of ER which they believe increases student engagement in STEM and cross-curricular learning. A case-study of one educator suggests that participation in FIRST ${ }^{\circledR}$ LEGO $^{\circledR}$ League Jr. increased the skills, confidence, and engagement of both the teacher and students which led to the integration of engineering practices, and school-wide interest in ER. This study demonstrates the importance of high-quality professional development in increasing educators' self-efficacy with using ER with elementary students, and suggests that new tablet-based, wireless robotics platforms, such as the $\mathrm{LEGO}^{\circledR}$ WeDo 2.0 enable younger learners to engaged with this technology. Additional research is necessary to better understand the impact of ER on students, and to identify and study schools where ER helped lead a transformation of the teaching toward constructionism. It is vital for the success of our children and our nation that we engage and inspire students in STEM subjects and career pathways at an early age if we are to meet the needs of the $21^{\text {st }}$ century job market, reduce disparities in STEM fields, and maintain our place in the global economy. 


\section{Acknowledgements}

I wish to acknowledge my committee members Jim Rye, M Cecil Smith, John Oughton, Earl Scime, and Jennifer Robertson-Honecker for their support and belief in my ability to achieve this goal. Without a doubt, I could never have reached this point without the selfless gifts of guidance, mentorship, collaboration, prodding, editing, and coffee (lots of coffee) from the chair of my committee Jim Rye, whom I have known for over 14 years. Jim invited me into his classroom when I had first moved to West Virginia, engaged me in NSF grants and projects, believed in me when I had doubts, encouraged me when I fell behind, and was available anytime to answer questions from statistics to soil types. Enjoy your retirement, Jim!

I give my thanks and appreciation to my wife Jessika and son Ian who loved, supported, and sacrificed for me in more ways than I will never know, allowing me the chance to follow through on yet another (over) commitment I made. Likewise, all my colleagues at the NASA Educator Resource Center cheerfully accepted the challenge to help me through this process by covering my workshops, meetings, and much more throughout my coursework and dissertation. I especially wish to thank Pam Casto for leading the baker's dozen workshops and overseeing the data collection necessary for this study to exist. Finally, many thanks to NASA, Fairmont State, and WVU for providing the classroom kits of robots necessary to conduct this research, which will continue to inspire and engage students for many years to come. 


\section{Table of Contents}

List of Figures ........................................................................................................... viii

List of Tables .............................................................................................................

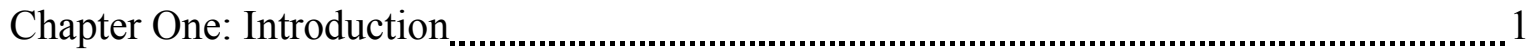

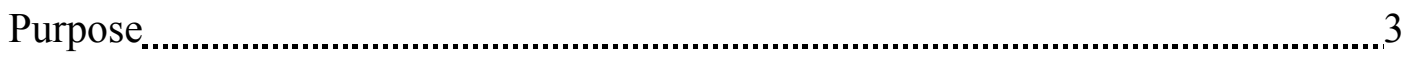

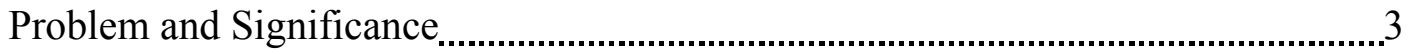

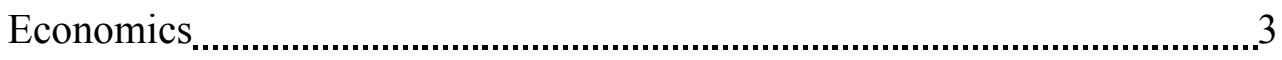

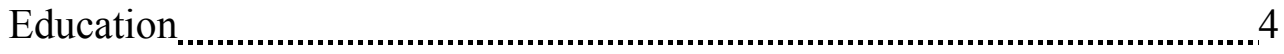

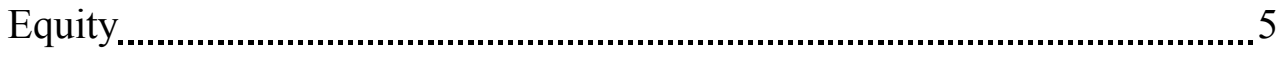

Delivery of STEM Educator Professional Development..............................6

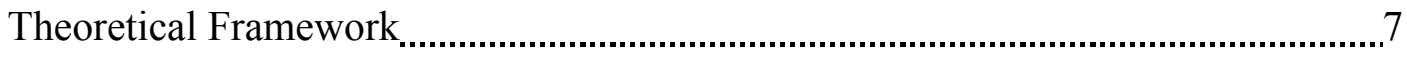

Scope of Study

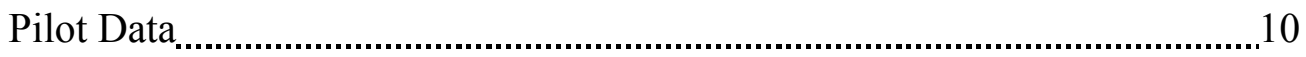

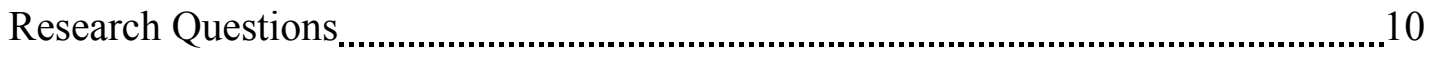

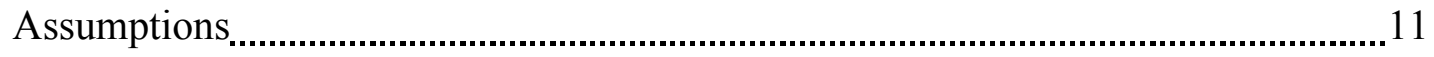

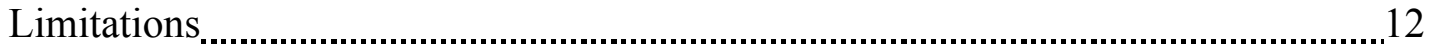

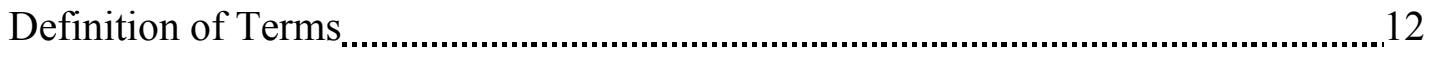

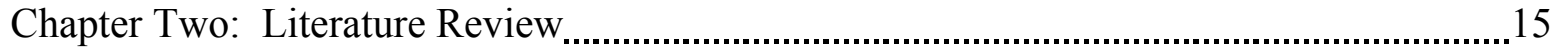

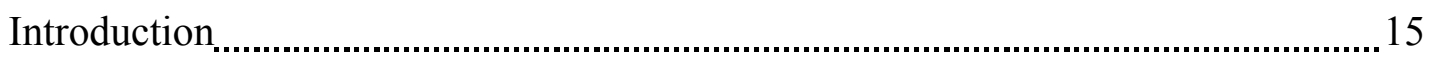

Pedagogical Approaches for Educational Robotics ...............................................

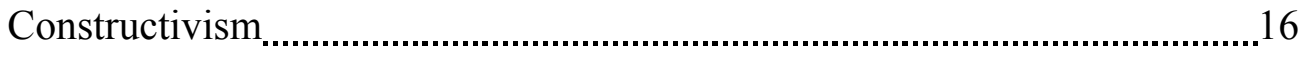

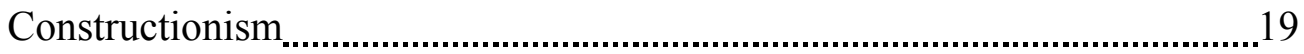

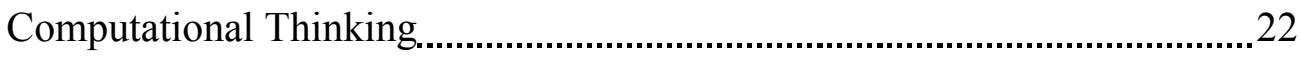




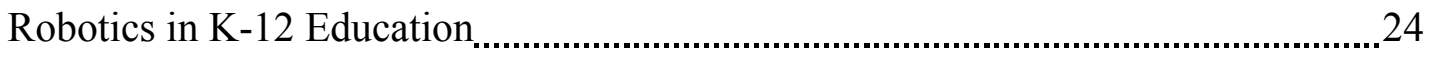

Evaluating K-12 Robotics Programs.....................................................................2

Teacher Professional Development........................................................................3

Attitudes, Perceptions and Beliefs ........................................................................... 31

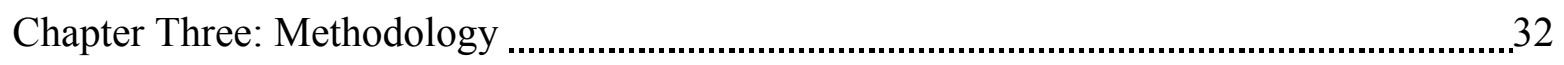

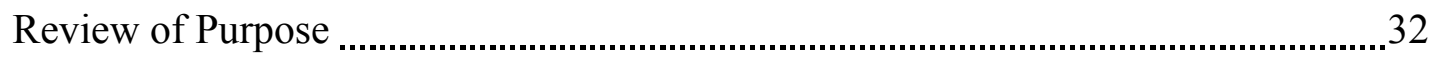

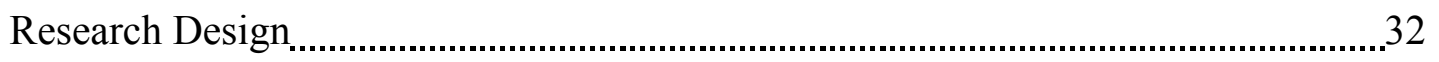

Institutional Review Board......................................................................................

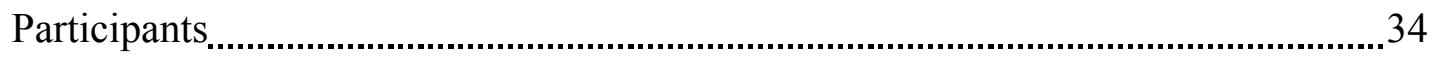

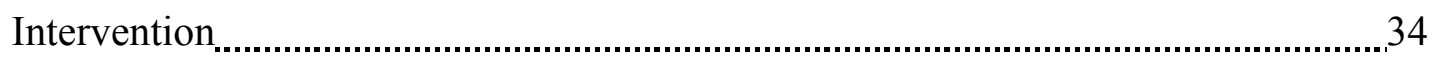

Workshop.

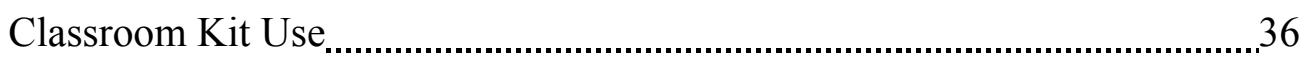

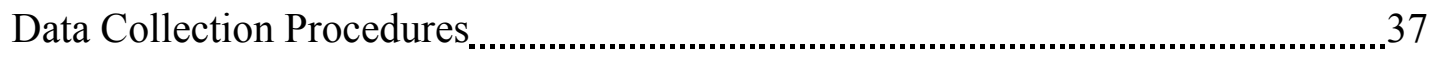

Technology Integration Survey ................................................................... 38

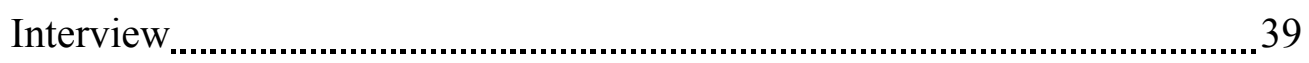

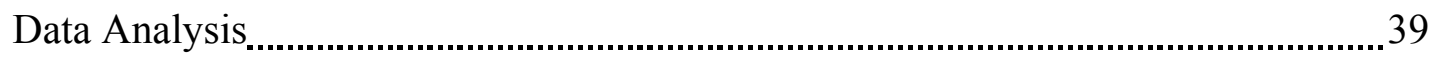

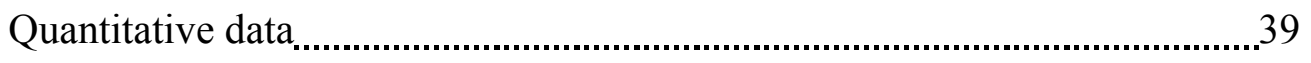

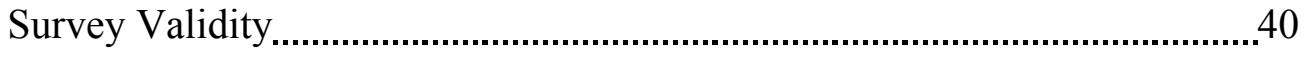

Qualitative data

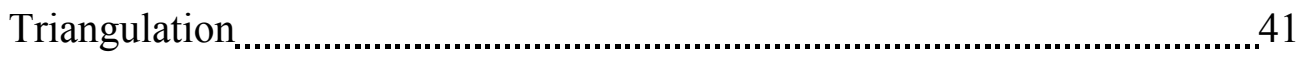

Research Question One

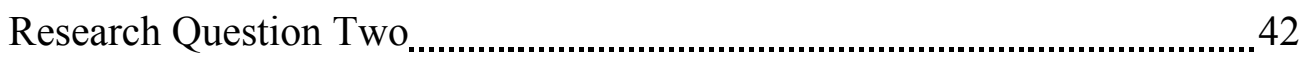

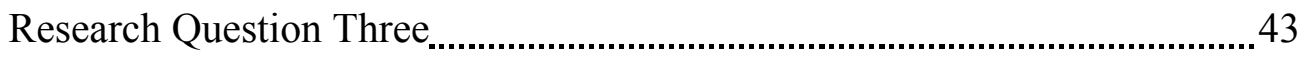


Chapter Four: Findings and Discussion ......................................................................... 44

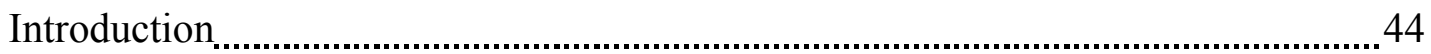

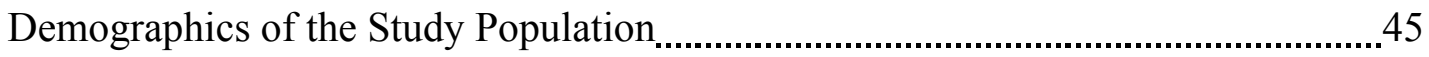

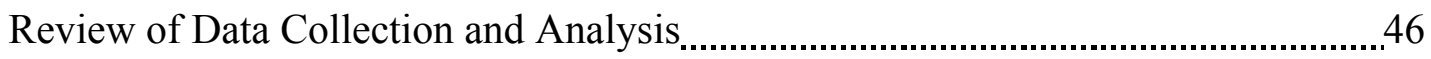

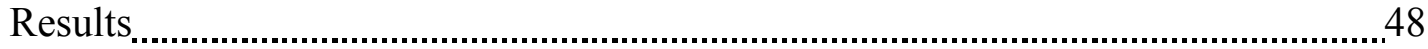

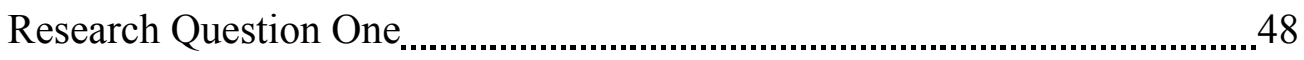

Research Question Two............................................................................. 50

Post Hoc One .................................................................................. 52

Post Hoc Two ........................................................................ 53

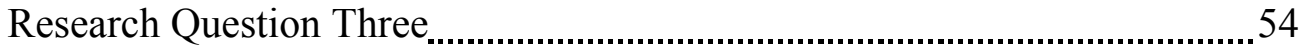

Categories

Themes

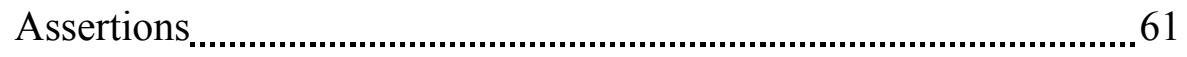

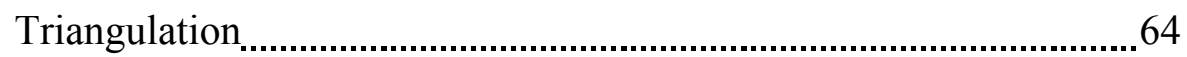

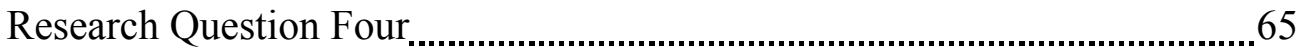

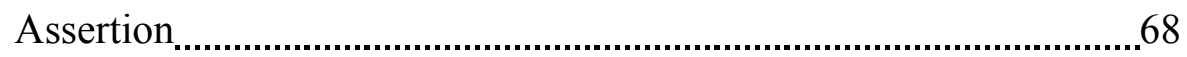

Retrospective Question One .................................................................... 72

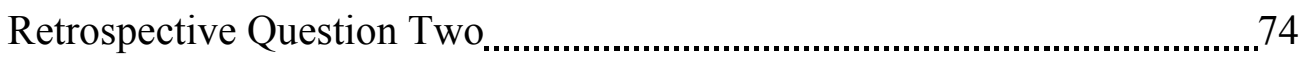

Chapter Five: Conclusions, Implications, and Recommendations ....................................... 76

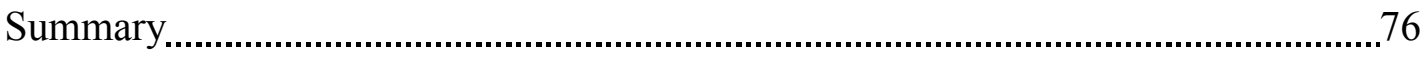

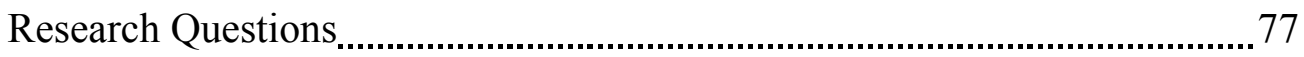

Methodology 
Findings 80

Conclusions 83

Research Question One

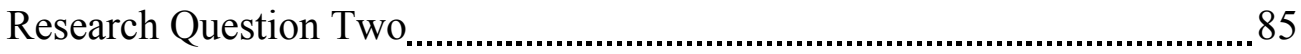

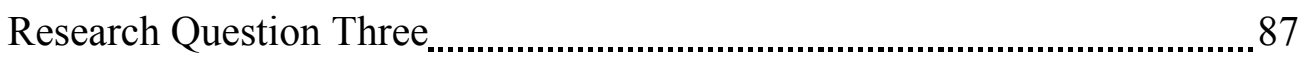

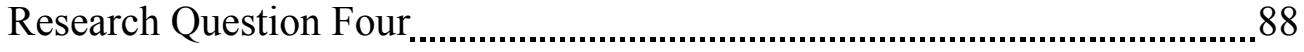

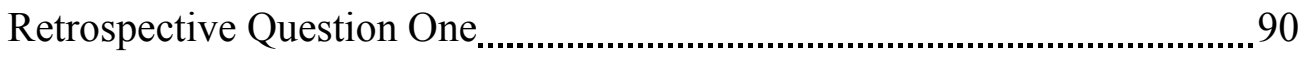

Retrospective Question Two ................................................................. 91

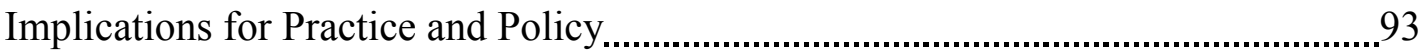

Professional Development Workshop...................................................... 93

Educational Robotics Classroom Kit ..................................................... 95

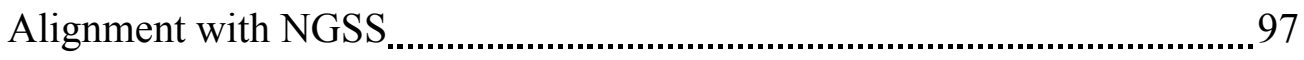

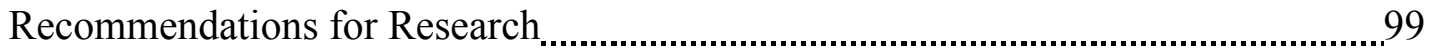

Research Instruments ...................................................................... 100

Case Studies of Transformational Schools ................................................. 102

References

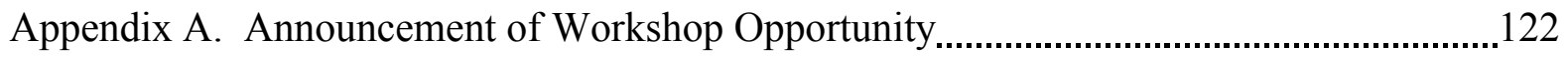

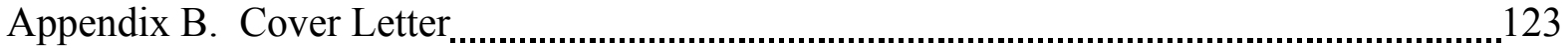

Appendix C. Demographical Information Collected About Subjects ..................................124

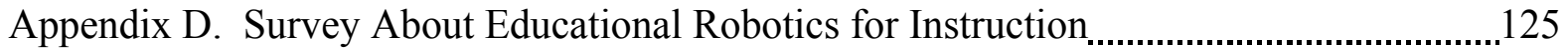

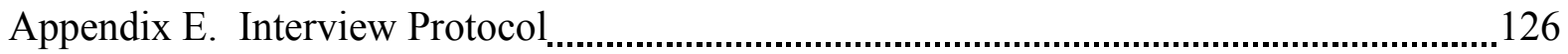

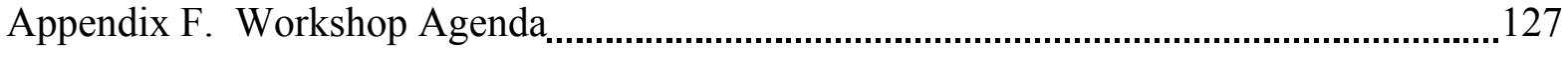

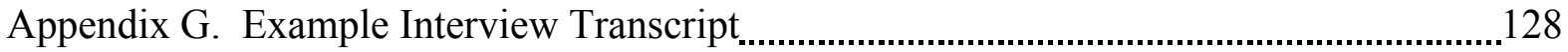




\section{List of Figures}

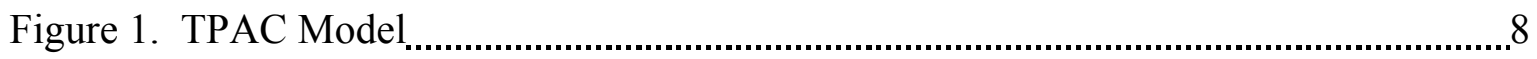

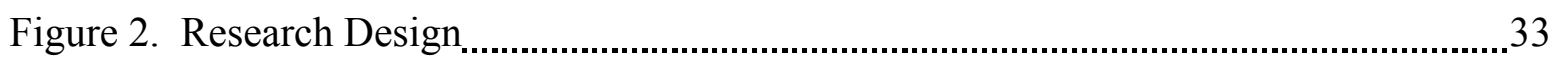

Figure 3. LEGO $^{\circledR}$ WeDo 2.0 Platform, Software, and Milo............................................... 36

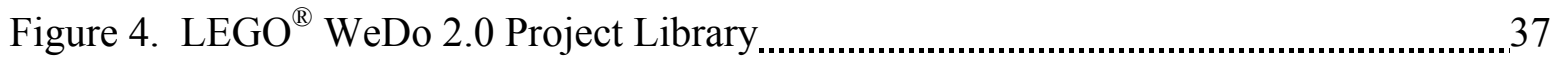

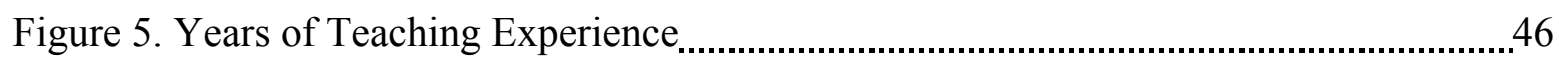

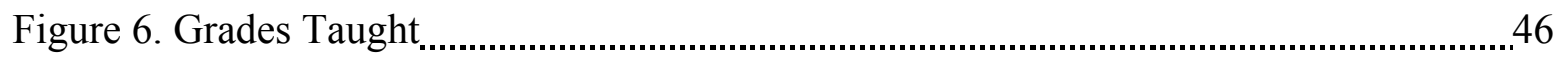

Figure 7. Pre to Post Workshop Survey Results......................................................... 48

Figure 8. FIRST ${ }^{\circledR}$ LEGO $^{\circledR}$ League Jr. Impact Chart ....................................................... 71

Figure 9. Educational Robotics Workshop Objectives with TPACK ..................................95 


\section{List of Tables}

Table 1. Research Question Organizer......................................................................... 44

Table 2. Cronbach Alpha for 18-Question Survey ........................................................... 47

Table 3. Pre/Post Workshop Values and One-Way ANOVA with Repeated Measures.......49

Table 4. Wilcoxon Signed-Rank Test for Ability, Utility, and Intent..................................50

Table 5. Post/Post-Post-Workshop Users/Non-Users Values and One-Way ANOVA........53

Table 6. Categories from Interviews of Users and Non-Users of ER ..................................55

Table 7. Emergent Themes from Interviews with Educators ...............................................59

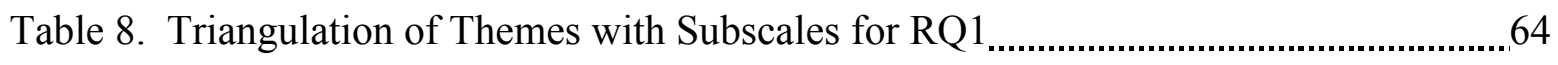

Table 9. Themes and Assertions of Case Study on After-School Robotics Program............67

Table 10. Mean Scores for Pre-Workshop Survey Comparing Prior Use/Non-Prior Use..... 73

Table 11. Pre/Post Workshop Mean Values and One-Way ANOVA with Repeated Measures

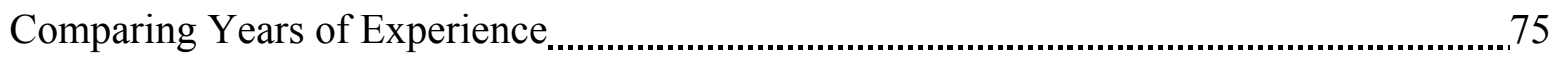




\section{Chapter One: Introduction}

For the United States (U.S.) to continue developing innovative products, discovering medical advancements, and producing products which enhance the quality of life, we must engage and inspire our students to excel in science, technology, engineering, and mathematics (STEM). Over the past decade, growth in STEM occupations have grown at a rate six times faster than non-STEM occupations and are projected to continue outpacing non-STEM careers

over the next decade (Noonan, 2017). These careers also command higher wages, experience lower unemployment, and they can help our nation stay competitive in the increasing knowledge-based economy (Economics and Statistics Administration, 2011). In 2014, foreign companies filed over half of U.S. technology patent applications while the United States' portion of high-tech exports have declined leaving the country with a high-tech trade deficit which continues to grow (National Science Board, 2016).

Despite the increased need for STEM jobs, U.S. higher education institutions are not increasing their number of STEM graduates at an adequate rate (Doerschuk, Bahrim, Daniel, Kruger, Mann \& Martin, 2016). This shortfall can be attributed partially to K-12 students' lack of adequate preparation to enter post-secondary STEM degree programs, and K-12 systems' failure to motivate students in math and science (Thomasian, 2011). In response to this growing need, President Obama's Committee on STEM Education (CoSTEM) released a five-year strategic plan in 2013 which included the ambitious goal of adding 100,000 new K-12 STEM teachers by 2021, and to leverage the resources of thirteen federal programs to support the current STEM teacher workforce (CoSTEM, 2013). In his address to the attendees of the 2013 White House Science Fair, President Barack Obama declared: 
One of the things that I've been focused on as President is how we create an all-handson-deck approach to science, technology, engineering, and math. We need to make this a priority to train an army of new teachers in these subject areas, and to make sure that all of us as a country are lifting up these subjects for the respect that they deserve (CoSTEM, 2013, p. vi).

The President's goals cannot be met by merely adding new teachers. The United States must also focus on building the skills of our existing K-12 workforce through high-quality, effective, professional development on the use of STEM-based content, curriculum, and tools. Teaching STEM is a critical component of competitiveness for federal grant funding. There is pressure on states, school districts, and K-12 educators to prepare students for $21^{\text {st }}$ century jobs through student-centered, technology-enabled, science and mathematics curriculum that connects learning to the real-world. Educational robotics has the potential to engage K-12 students in the STEM disciplines while inspiring students to consider careers in STEM.

Educational robotics (ER) combines accessible and age-appropriate building materials, programmable interfaces, and computer coding to teach science and mathematics using the engineering design process. ER has been shown to increase K-12 students' understanding of STEM concepts, and can develop students' self-confidence and interest in STEM (Nugent, Barker, Welch, Grandgenett, Wu \& Nelson, 2015). As educators struggle to adapt their current science teaching practices to meet the new interdisciplinary nature of the Next Generation Science Standards (NGSS), ER has the potential to simultaneously integrate STEM disciplines, engage and inspire students in mathematics and science, and build connections to STEM careers. One challenge is a lack of documented models for preparing educators, particularly at the elementary level, to use robotics in their classrooms (Jaipal-Jamani \& Angeli, 2017). The lack of 
scholarship on appropriate robotics platforms for elementary learners, reliable techniques of delivering professional development in ER, or standardized instruments that can reliably measure elementary educators' self-efficacy with robotics suggests there is a need for such research.

\section{Purpose}

The primary purpose of this study was to investigate the impact of a four-hour, hands-on, educational robotics professional development workshop and subsequent implementation of activities on $\mathrm{K}-5^{\text {th }}$ grade formal and informal educators' attitudes about their ability to teach ER, the value (utility) of ER, and their desire to use it (intent). This study delved deeper into understanding how the variables (ability, utility, and intent) are affected by using educational robotics with students through the application of a survey administered before and after the workshop, as well as a third time after educators had an opportunity to use robotics with students. In order to extend and explain the quantitative data, $60 \%$ of the educators who completed all three surveys were also interviewed. The findings of this mixed-methods study are strengthened by using both instrument (survey and interview) as well as analyst (author and independent researcher) triangulation. This study also sought to determine if any of the trained educators also participated in after-school robotics competitions, and, if so, what impact participation had on their attitudes of using ER with students.

\section{Problem and Significance}

The case for leveraging educational robotics to engage and inspire young learners in STEM can be viewed through the lens of economics, education, and equity.

Economics. From 2005 to 2015, the growth in STEM jobs was $24.4 \%$ versus $4.0 \%$ for that of non-STEM jobs, and the U.S. Department of Commerce estimates that in the coming years (2014-2024), STEM occupations will grow 8.9\% compared to 6.4\% for non-STEM 
occupations (Noonan, 2017). Additionally, these emerging careers paid 29\% higher wages than non-STEM occupations in 2015, although just holding a STEM degree commands higher earnings regardless of occupation (Langdon, McKittrick, Beede, Khan \& Doms, 2011; Noonan, 2017). Another concerning statistic is that over half of U.S. patents are now filed by foreign competitors (Fischetti, 2014), and almost one-third of all patents awarded to American interests are from California, Oregon, and Washington - states known as leaders in the new STEM economy. Some states in our nation are leading the development of new STEM industries while others, such as West Virginia, are being left behind (Dill, 2016; Bloom, 2017). It is more important than ever to get our students interested in career pathways different from their parents. In places like rural Appalachia, the need to reinvent the local economy has never been more acute.

Education. U.S. students performed poorly compared to their peers in the 65 OECD (Organisation for Economic Co-operation and Development) countries, ranking $23^{\text {rd }}$ in science and $30^{\text {th }}$ in mathematics on the 2010 Program for International Student Assessment (Fleischman, Hopstock, Pelczar \& Shelley, 2010). Even on domestic measures of performance, U.S. students are falling behind, with over one-third of eighth-graders scoring below basic competency on the 2011 National Assessment of Educational Progress (NAEP) Science assessment (NCES, 2012); $54 \%$ of high school graduates failed to meet the ACT's college readiness benchmarks in math; and, $69 \%$ of graduates failed to meet the benchmarks in science (ACT, 2012). To address these concerns in student readiness, nationwide attempts to strengthen and expand our standards -such as the NGSS -- have embedded engineering practices within science objectives. Unfortunately, in addition to concerns over student gaps in math and science readiness, there 
continues to be a nationwide shortage of qualified mathematics and science teachers (Sutcher, Darling-Hammond \& Carver-Thomas, 2016).

Equity. While the nation as a whole is slipping behind our peers, a closer examination of our student performance illustrates the growing disparity in academics and degrees awarded between white male students and their minority and female counterparts (Martin, Mullis, Foy \& Stanco, 2012) Data from the Trends in International Math and Science Study (TIMSS) show the science scores for white American students are in the top four, below only Singapore, Chinese Taipei, and S. Korea, while Hispanic and African American scores fell to the bottom third of the 45 countries completing the $8^{\text {th }}$ grade assessment (Martin et al., 2012). "Although women and members of minority groups now constitute approximately $70 \%$ of college students, they are underrepresented among students receiving undergraduate degrees in STEM subjects (approximately 45\%)," (PCAST, 2012, p. 5) and hold less than 25\% of STEM jobs (NSF, 2011). The Pew Research Center projects that by 2055 there will be no single racial or ethnic majority (Cohn \& Caumont, 2016). Given that our nation's minority populations continue to grow, if the U.S. fails to engage minorities and women in STEM fields, we risk undermining one of the fastest growing engines of our nation's economy and perpetuating inequities which should not exist in an open and democratic society.

While these inequities are troubling, there is a promising, and growing set of data which indicates that early STEM engagement with under-represented populations (particularly females, minorities, and non-native speakers) has the potential to influence their future academic and career choices (Bandura, Barbaranelli, Caprara, \& Pastorelli, 2001; Bouvier, 2011; Eccles, 2005; Tai, Qi, Maltese, \& Fan, 2006). Students that indicate early expectations for a career in science by the eighth grade are much more likely to complete a college degree in a STEM field than 
students without those expectations (Tai et al. 2006). Compiled research from the University of Massachusetts' Donahue Institute examined dozens of K-12 STEM programs that demonstrated children develop strong attitudes of their own future occupations as early as grades 3-5 (Bouvier, 2011). This suggests it may be important to reach under-represented populations in elementary school with programs such as robotics to help influence these students' self-efficacy in STEM courses and careers before they develop negative stereotypes of STEM which can limit their potential. Programs such as For the Inspiration and Recognition of Science and Technology $\left(\right.$ FIRST $^{\circledR}$ ) have demonstrated through longitudinal studies that after-school teams lead to statistically significant increases in STEM careers, knowledge, and interest (Melchior, Burack, Hoover, \& Marcus, 2017).

Delivery of STEM educator professional development. NASA's Independent Verification and Validation (IV\&V) Program Educator Resource Center (ERC) is managed through a highly successful collaboration with Fairmont State University (FSU) that results in significant benefits to educators and students across West Virginia. The goal of the ERC is to provide resources and training opportunities to make a significant educational impact in the classroom, and it accomplishes this by hosting over 1,000 teachers at 100 or more educator professional development programs annually. The ERC provides in-service, pre-service, home school, and informal educators with an easily accessible source of materials that reflect NASA's current research and technology in the core areas of STEM. The ERC delivers workshops on a variety of topics, including ER, to supplement school curriculum and help educators exceed national and state educational standards. Additionally, educators participating in ERC workshops are eligible to reserve classroom sets of equipment, allowing students immediate access to over a million dollars of equipment -- including four classroom kits of twelve LEGO $^{\circledR}$ 
WeDo 2.0 robotics sets paired with Apple ${ }^{\circledR} \mathrm{iPad} \mathrm{Mini}^{\circledR}$ tablets that have specific programming software installed. Workshops are advertised and offered at the ERC's STEM laboratory in Fairmont, or are customized to meet the needs of the audience and delivered at no cost to any school or organization in West Virginia.

The ERC program has been funded for almost 20 years, and has grown from one graduate level college intern to a staff of four full-time employees, three full-time AmeriCorps VISTA volunteers, and up to six part-time undergraduate interns. Given the wide spectrum of educational opportunities provided through the ERC, the objective of this research project is to investigate the effectiveness of one of the ERC's most popular and best organized workshops the educational robotics (ER) workshop for K-5 educators. Although summative evaluations have been gathered for this workshop throughout the program, no research involving pre- and post- workshop data collection has been conducted. Data has also never been collected and analyzed on educators after they use ER with students. This in-depth study makes the findings unique and relevant to K-12 educators and STEM professional development providers.

\section{Theoretical Framework}

The most common conceptual framework for describing technology integration is the Technological Pedagogical Content Knowledge Model (TPACK, 2012; Mishra \& Koehler, 2006). TPACK is best illustrated (Figure 1) by a Venn diagram showing the interactions between content, pedagogy, and technology knowledge. Remhat and Bailey (2014) emphasize that "Technology skill training alone leaves teachers without the knowledge of how to use technology to teach more effectively, disregards the relationship between technology and content knowledge, and does not address curriculum content standards with students while using technology" (p 745). In essence, it is not enough to provide training on ER without also 
modeling appropriate pedagogical approaches for its use and combining the training with science, engineering, and mathematics content. This is the approach used by the ERC, during the delivery of ER trainings, through a series of hands-on activities that are appropriate for elementary classrooms. For effective utilization of ER, educators need to understand how this technology works, the science, mathematics, and engineering practices that can be taught with it, and how it is best used with students. This research explored the attitudes of educators participating in the workshop about the utility of ER, their ability to use it with students, their intent to implement this technology in their future classrooms, and what, if any, impact borrowing and implementing the ER kits had on their classrooms.

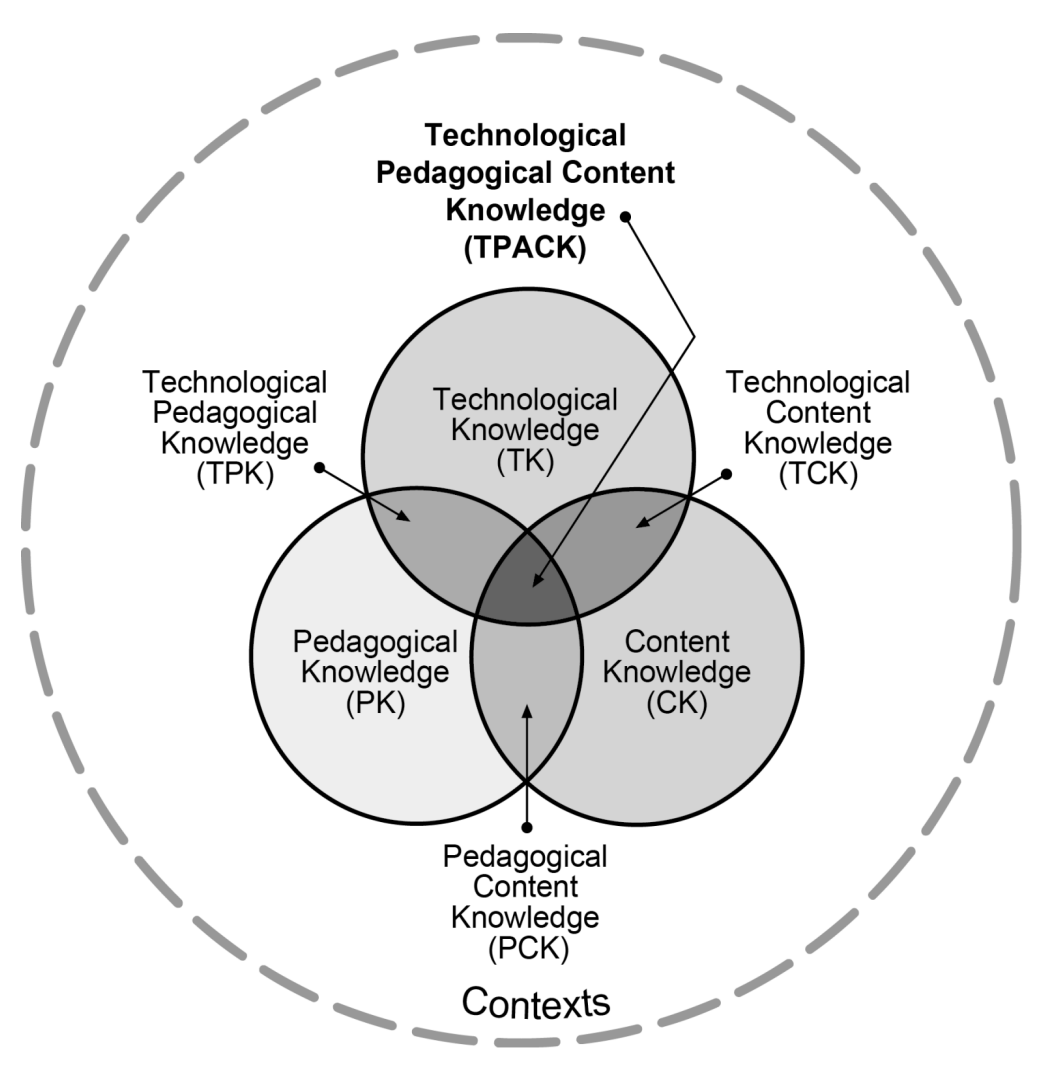

Figure 1. TPACK Model. Adapted from “TPACK Model” by TPACK.org, 2012, Retrieved April 17, 2016 from http://tpack.org. (Reproduced by permission of the publisher, (C) 2012) 


\section{Scope of Study}

The mixed-method study employed a convenience sample of one hundred participants who provide instruction to $\mathrm{K}-5^{\text {th }}$ grade students in formal educational settings (school day) or informal settings (out-of-school time). The participants self-selected to attend a three hour elementary-level ER workshop which covered (a) the LEGO ${ }^{\circledR}$ WeDo 2.0 robotics platform, (b) associated software, (c) curriculum and activities, (d) classroom management, and (e) best utilization practices for the ERC's classroom kit of twelve robots, iPads, and other supplies. All the workshops were conducted by a NASA Education Specialist. The workshops were conducted at the NASA IV\&V ERC training laboratory and at six additional locations (three elementary schools, one intermediate school, a science center, and a university extension office) based on requests made by educators or principals. In total, 13 workshops were conducted between September 13, 2016 and March 16, 2017, and all participants completed a pre-workshop and post-workshop 18-question survey. Between March 15 and March 31, 2017, an online version of the instrument was distributed via email to all of the participants which resulted in 33 completed (post-post) surveys. Of those educators who completed the post-post survey, 16 educators indicated they were able to implement the ER activities with elementary students by borrowing a classroom kit from the NASA ERC, or in several cases were able to use their school's own robots and iPads, purchased after the workshop. Twenty-one of the 33 educators who completed the post-post survey participated in a 15-20 minute telephone interview which was recorded and transcribed for the qualitative analysis. Of the 21 participants who completed the interview, 10 had used the LEGO ${ }^{\circledR}$ WeDo 2.0 and iPads with students and 11 had not yet had the opportunity. 
Pilot Data. A pilot study was conducted to determine if the interview questions were soliciting the right type of information to inform the researcher about the participant's opinions of the workshop, robotics platforms suitability for elementary students, their attitudes of their own ability to use ER, how useful they found ER for instruction in STEM, and their intent to use ER with students. Three volunteers who were not in the study but had been trained on the use of LEGO $^{\circledR}$ WeDo 2.0, completed the pilot study, and several questions were added to the questionnaire as a result.

\section{Research Questions}

1. Research Question One (pre/post survey): Does the elementary level educational robotics professional development workshop result in statistically significant $(p<.05)$ gains in K-5 $5^{\text {th }}$ grade educators' attitudes about the educational utility of the technology and their ability and intent to use it? Partial eta squared $\left(\eta_{\text {partial }}^{2}\right)$ will be examined as a measure of effect size: Will at least a medium $\left(\eta_{\text {partial }}^{2}>.06\right)$ effect size be realized (Richardson, 2011)?

2. Research Question Two (post/post-post survey): Does implementation of the elementary level educational robotics activities using the ERC's LEGO ${ }^{\circledR}$ WeDo 2.0 classroom kit result in statistically significant $\left(p<.05 ; \eta_{\text {partial }}^{2}>.06\right)$ gains in $\mathrm{K}-5^{\text {th }}$ grade educators' attitudes about the educational utility of the technology and their ability and intent to use it compared to their post professional development attitudes? Partial eta squared $\left(\eta_{\text {partial }}^{2}\right)$ will be examined as a measure of effect size: Will at least a medium $\left(\eta_{\text {partial }}^{2}>.06\right)$ effect size be realized?

3. Research Question Three (interview): What themes emerge from the interviews with K-5 ${ }^{\text {th }}$ grade educators who did/did not implement the robotics activities with students, and in what ways do they illuminate findings from the survey? 
4. Research Question Four (interview): Did any elementary educators also participate in an after-school experience, such as $F I R S T^{\circledR}$ LEGO $^{\circledR}$ League Jr., and if so what impact, if any, did that have on their attitudes compared to educators who did not participate in such a program?

\section{Assumptions}

1. The workshop experience is consistent across the various locations and audiences during the study period. It should be recognized that workshops such as these are never identical due to differences in the attendees, physical location, and whether or not the educators self-selected to attend the workshop or were required to attend (such as by their principal). Efforts were made to ensure that the workshops were as similar as possible.

2. The attendees are formal or informal educators serving students in grades K-5 in either the classroom or out of school time who self-selected to attend the ER workshop.

3. The survey data are valid. The survey was adapted with permission from Gado, Ferguson, \& Van 'T Hooft (2006), who reported that it was cross-validated. The adapted 18-item survey was previously administered to preservice teachers $(N=60)$ in 2011 to study the impact of scientific probeware which had been integrated in a science methods course. The survey was used to measure pre to post changes in preservice teacher attitudes about the utility of science probeware as well as their ability and intent to use it. Data analysis of the post survey results from the probeware study revealed that the Cronbach alpha for each of these three subscales was greater than .8 , suggesting that the items comprising each subscale have high internal consistency (Rye, 2011). 


\section{Limitations}

1. The study duration is only six months. The likelihood that educators will be able to borrow and implement the activities they are trained in is not as high as it would be for a longer study.

2. The population of educators will likely self-select to participate in the ER workshop due to a high-level of interest in STEM activities. This will bias the level of interest in the pre-survey results and decrease potential gains in the pre to post comparison.

3. There is a risk of researcher bias because the subject of the study is one of the 33 workshops conducted by the NASA IV\&V ERC, for which the author is the Program Manager. This specific workshop is presented by the author's colleague, not himself. The workshop is also the most popular training offered, providing the largest sample size of educators and highest likelihood of identifying educators who attempt to implement the activities.

\section{Definition of Terms}

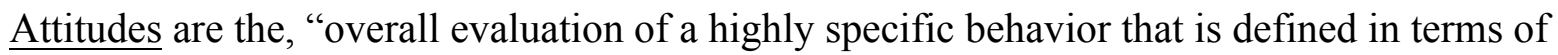
action, target, context and time" (Koballa \& Glynn, 2007, p. 79). Koballa and Glynn also note that beliefs are the cognitive basis for attitudes, and are a "significant determinant of intention to engage in the behavior" (p. 79). Attitudes and beliefs are tied to self-efficacy (defined below). In the context of this study, the constructs of the subscales ability and intent to use the technology are a function of the educators' attitude, that has been demonstrated to be measurable via instruments such as STEBI (also defined below).

Educational Robotics (ER) is a specific application of $\mathrm{K}-12$ engineering education and offers students physical manipulatives that are familiar and easy to work with as they participate in the engineering design process (Ortiz, Bos, and Smith, 2015). 


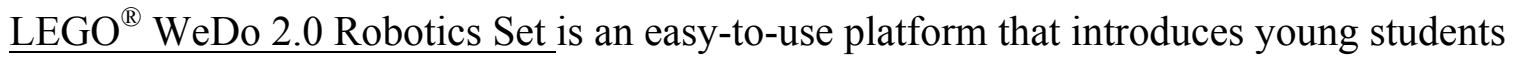
(grades K-5) to robotics when combined with the WeDo Software and Activity Pack. Students build models featuring working motors and sensors. The students program their models using a intuitive drag-and-drop software on a desktop or tablet computer. They also explore a series of cross-curricular, theme-based activities while developing their skills in science, technology, engineering, and mathematics as well as language, literacy, and social studies. (LEGO ${ }^{\circledR}$ WeDo, n.d.)

NASA IV\&V ERC is the acronym for the National Aeronautics and Space Administration's Independent Verification and Validation Program's Educator Resource Center. The NASA IV\&V ERC conducts workshops for educators and students, manages the classroom kit loan program, and is the official partner for 12 robotics competitions in the state of West Virginia. Self-efficacy is defined by Bandura (1994) as “people's beliefs about their capabilities to produce designated levels of performance that exercise influence over events that affect their lives" (p. 2). Bandura identified two types of expectancy beliefs: outcome expectations and efficacy expectations. The self-efficacy construct has served as a predictor of subsequent performance in academics and other fields. Four means of improving self-efficacy are: performance accomplishments, vicarious experience, verbal persuasion, and psychological states (Bandura, 1997).

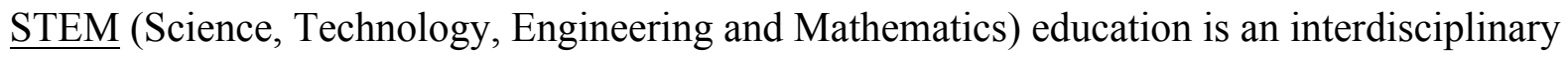
approach to learning where rigorous academic concepts are coupled with real-world lessons. Students apply science, technology, engineering, and mathematics in contexts that make connections between school, community, work, and the global enterprise enabling the 
development of STEM literacy and with it the ability to compete in the new economy (Tsupros, Kohler, \& Hallinen, 2009).

$\underline{\text { STEBI }}$ is the Science Teaching Efficacy Belief Instrument that was developed and used by Riggs and Enochs (1990) to measure science teaching self-efficacy and outcome expectancy in preservice teachers' (version B) and in-service teachers (version A). This 25-item instrument uses a 5-point Likert scale confidence in providing instruction on a subject or topic to students. $\underline{\text { TPACK }}$ is the acronym for Technological Pedagogical Content Knowledge, an educational framework for describing technology integration. It is visually depicted as a Venn diagram illustrating the interplay between the three forms of knowledge. (Mishra \& Koehler, 2006). 


\section{Chapter Two: Literature Review}

\section{Introduction}

A review of educational robotics literature could begin with the latest advancements and studies, but the history of the movement itself is grounded in the educational theory that students learn best when constructing, and sharing their own knowledge (Papert, 1991). Therefore, the logical approach is to begin with the theoretical frameworks that underpin this emerging area of educational technology. A review of educational robotics in K-8 classrooms moves from the first LEGO ${ }^{\circledR}$ platform (Watters, 2015) to the current model used in this research, highlighting research into classroom and after-school applications. The availability of scholarship about robotics in K-12 education is sparse, but growing, with numerous studies examining programs outside the U.S. An overview of evaluation techniques for K-12 robotics programs reveals which methods are most appropriate for, and should guide this research, which supports the mixed-method approach used. The participants of this study are educators, and the final review of literature recognizes the importance of best practices in STEM professional development.

\section{Pedagogical Approaches for Educational Robotics}

The current educational robotics (ER) movement evolved from Piaget's constructivist pedagogy, 1972, which was founded on the notion that knowledge is based in experience. As such, knowledge must be constructed or reconstructed (Ackerman, 1996). Most scholarship (Alimisis, 2012; Barker, 2012; Bonarini \& Romero, 2013; Cristóforis, Pedre, Nitsche, Fischer, Pessacg \& Di, 2013; Somyûrek, 2015; Ucgul \& Cagiltay, 2014; Welch \& Huffman, 2011) cites cognitive constructivism as the theoretical framework that undergirds the teaching and study of ER. There is evidence that Papert's constructionism, which highlights the importance of a public demonstration, is a more relevant model (Papert and Hargel, 1991). Constructionism relates 
closely to Piaget's constructivism in that learners must actively engage with the world to construct knowledge. However, constructionism adds to the theory that leaners are also consciously constructing learning for public displays. Papert's work in the field of educational robotics also led to the development of the $\mathrm{LEGO}^{\circledR}$ Mindstorms product line and spawned one of the most successful ER platforms in the world ("Global educational robots market 2016-2020," 2016). When ER is effectively used in learning environments, students are inherently solving problems using data, simulations, and computer programming. An emerging model for describing this approach is Computational Thinking (Cuny, Snyder, \& Wing, 2010). Given the relevance to the evolution of ER, constructivism, constructionism, and computational thinking in the literature will be examined.

Constructivism. Piaget is most famously known for his theory of cognitive development and the various developmental stages children move through as they mature. The cornerstone of his epistemology is constructivism theory.

Knowledge is not a commodity to be transmitted. Nor is it information to be delivered from one end, encoded, stored and reapplied at the other end. Instead, knowledge is experience, in the sense that it is actively constructed and reconstructed through direct interaction with the environment. (Ackerman, 1996, p.27)

One of the great ironies of educational research is that the classrooms of the 1900's look shockingly like the classrooms of today. Over one hundred years ago, children were viewed as vessels to be filled with knowledge. Piaget was instrumental in changing that view to one in which children were active analysts of the world around them; children need experiences to build their own knowledge. Modern educators understand the most meaningful learning is active, 
collaborative, and constructed by the students rather than being told to them, yet many classrooms have not changed a great deal through this time.

Constructivism theory posits that students have strongly held worldviews, and despite what they may be told, they rarely abandon them. The now famous study by Gardner (1991) exemplifies this. Gardner asked Harvard students at their graduation, why the Earth experiences summer (Gardner, 1991). Although this fundamental concept of the tilt of the Earth bring primarily responsible for the seasons was certainly taught to these students, most of the students responded with their persistent and original misconception that the Earth was closer to the sun. The act by a teacher of devising situations which will confront a student's current misconceptions and force them to re-conceptualize the concept at hand, and construct their own knowledge is at the heart of the constructivist pedagogical theory.

According to Ackermann (2004), constructivism provides clear guidelines for learning: (a) teaching should not be direct because students do not simply take in information presented to them, they try to relate it to their own prior knowledge and experience; (b) knowledge is not gained by listening to an instructor, it is constructed through interactions and experiences that allow students to connect meaning of the content to their worldview; and, (c) students will hold onto their own worldviews despite what they are told unless they are encouraged to interact with, confront, and express their beliefs. Educational robotics provides an ideal platform for students to interact with STEM concepts, receive instant feedback, and to construct their own understanding of the world.

Bonarini and Romero (2013) use constructivist theory applied to a robotics program. In an effort to explore the question "How can robots communicate emotions?", researchers recruited engineering and design students to participate in a two-day course. The intent of the 
class was to be practical with the students using a micro-processor, motors, and a variety of materials to create robots with facial expression capability. They also implemented the school's traditional pedagogy with the students working in interdisciplinary groups, learning-by-doing, and employed constructivist principles. All of the groups had to produce a prototype robot able to communicate four given emotions: pleasure, surprise, rage, and terror. In addition, some groups were tasked with creating an abstract object rather than a face. While the final goal was defined, methodology and group leadership were left open-ended to foster a constructivist approach. Bonarini and Romero briefly reflect on the pedagogy demonstrating that the framework clearly was a consistent theme. The outcome of their course was the development of a seven-day for-credit class, which intentionally groups interdisciplinary teams of engineers and designers to complete similar tasks using robotics as the base-technology and constructivism as the pedagogy. This research demonstrated the interdisciplinary nature of ER and how it can be used to foster a constructivist teaching and learning approach.

Alimisis (2012) highlighted the role of constructivist pedagogy when using robotics to teach physics and informatics (computer science) in both the classroom and teacher professional development environments. While many authors in the field of educational robotics reference educational theory, Alimisis explicitly explored its importance: "The robot is just another tool, and it is the educational theory that will determine the learning impact coming from robotic applications (p. 7)." The methodology in his paper clearly refers to Piaget's emphasis on student-driven knowledge creation.

To engage students in activities requiring designing and manufacturing of real objects, i.e. robotic structures that make sense for themselves and those around them, we should devise activities that will encourage students to construct robots 
but also to encourage them to experiment and explore ideas that govern their constructions (Alimisis, 2012, p. 8).

The educational program which was evaluated by Alimisis involved teaching elementary preservice teachers and in-service physics secondary teachers how to teach physics using robotics. They then implemented the robotics curriculum with students. Of the four groups described in the paper, it was the elementary pre-service cohort that most closely aligned with a constructivist framework because the lesson was more self-directed and reflective. One particularly interesting comment made by a student in their journal, indicated their favorite exercise was not the guided activities, but the open-ended robotic competition.

I liked most when we pulled the battle carts and although ours is the heaviest it came out first. . learning is easier, faster and more effective when combined with the game and turns education into a fun activity" (Alimisis, 2012, p. 12).

Alimisis designed his research around the examination of constructivism, but the student's obvious engagement when required to compete a team project demonstrates the role of performance in learning, which leads to the expanded theory of constructionism.

Constructionism. Evolving from constructivism is the theory of constructionism. In the late 1950s and early 1960s, Papert moved to Switzerland to study under Jean Piaget. In his 1993 book Mindstorms: Children, Computers, and Powerful Ideas, Papert reflected, "In 1964, after five years at Piaget's Center for Genetic Epistemology in Geneva, I came away impressed by his way of looking at children as the active builders of their own intellectual structures'” (p.19). According to Papert (1999), constructionism includes and extends far beyond learning by doing, and can be succinctly described as learning by making. Papert and Harel (1991) define constructionism in the first chapter of their book by the same name: 
Constructionism — the N word as opposed to the V word — shares constructivism's connotation of learning as "building knowledge structures" irrespective of the circumstances of the learning. It then adds the idea that this happens especially felicitously in a context where the learner is consciously engaged in constructing a public entity, whether it's a sand castle on the beach or a theory of the universe. (p. 1) Papert joined MIT in 1963 and formed what would come to be known as the MIT Media Laboratory. He is incredibly relevant to the field of ER, inventing the Logo programming language which was used by students in schools in the 1970's to teach computer programming and geometry. The LEGO ${ }^{\circledR}$ Mindstorms robotic product line is named after his seminal book, Mindstorms: Children, Computers, and Powerful Ideas. Papert (1993) has said that robots are one of the best tools for implementing constructionist learning principles.

Ucgul and Cagiltay (2014) used a qualitative case study approach to describe critical factors for the design and development of an educational robotics training camp for secondary students. The goal was to illustrate how each factor affects the success of the camp, and to enlighten researchers as to how these factors should be implemented. Data resulted in seven critical robotics training camp design themes: Instruction, Group Issues, Competition, Coaching, Technical Issues, Challenges, and Camp Duration. For each of these themes, the authors provide numerous suggestions to aid in the construction of effective robotic camps. The learning style that was most successful was classified under the theme of Coaching. "During the camps, the instructors avoided direct instruction, especially when children worked at learning stations or on projects; they encouraged children to find their own solutions to their design or programming problems" (Ucgul \& Cagiltay, 2014, p. 213). The study concluded that effective robotics instruction requires a paradigm shift from teacher-centered to learner-centered, from simple to 
complex, and should emphasize learners' active roles in building "unique intellectual structures" (Ucgul \& Cagiltay, 2014, p. 214) according to Papert's constructionism.

When approaching large paradigm shifts in education such as the integration of ER, training teachers already in the classroom often proves to be challenging. Another factor is that while there is growing acceptance of the importance to provide engaging STEM educational experiences to elementary students, most early childhood educators rarely receive enough preparation to feel confident implementing technology-dependent programs such as ER while also moving toward a constructionist pedagogical approach. To address the growing need for effective models of training that can be replicated, Bers and Portsmore (2005) chose to prepare early childhood pre-service teachers before they entered the workforce. Unique to their project was the pairing of engineering students with small groups of early childhood pre-service teachers. The rationale for this partnership is that early childhood educators are not adequately prepared to teach STEM topics, and that most new teachers resort to an instructionist teaching model while they are fully aware that constructivism is the appropriate pedagogy (Bers \& Portsmore, 2005). Unfortunately, they are not comfortable enough with the content to employ a student-centric approach. Underlying the entire project was a set of philosophical tenants by which the class would run: (a) Belief in the constructionist approach; (b). The importance of objects for supporting the development of concrete ways of thinking; (c) Powerful ideas empower the individual; and (d) The importance of self-reflection. These tenants are founded on Papert's constructionist model. Although somewhat dated, this 2005 research provided the undergirding for the current DevTech Research Group at Tufts University that continues to study the role of computational thinking, constructionist theory, and developmentally appropriate robotic platforms play in early childhood education. 
Computational thinking. Scratch is a free educational programming language that was developed by the Lifelong Kindergarten Group at MIT. The programming is referred to objectoriented or drag-and-drop and was designed to be fun, educational, and easy to learn (Faloon, 2016). As Scratch has grown in popularity over the past five years - there are currently over eight million users - Harvard researchers Brennan \& Resnick (2012) have developed an educational framework they refer to as computational thinking, which has three components:

(1) knowing certain computational concepts,

(2) being able to employ those concepts using computational practices, and

(3) developing new computational perspectives, an awareness of self, others, and world. A more technical definition of computational thinking was posited by Carnegie Mellon University faculty, "Computational Thinking is the thought processes involved in formulating problems and their solutions so that the solutions are represented in a form that can be effectively carried out by an information-processing agent" (Cuny, et al., 2010, p. 2). While this model is the newest to emerge in the field of STEM and ER, it is rapidly gaining popularity to describe and measure the thinking and learning that is now possible. These boundless possibilities are due to the evolution of easy-to-use computer languages allowing K-12 students to develop games, tell interactive stories, and program robots. Finally, as the constructionist approach envisions, individuals then share their creations with the world.

Although developed at MIT and used often by Harvard researchers through their ScratchEd project, Scratch is also a key tool being used to program LEGO ${ }^{\circledR}$ robots by the TangibleK Robotics Project at Tufts University (Flannery \& Bers, 2013). Tufts University is also the developer of the $\mathrm{LEGO}^{\circledR}$ ROBOLAB programming software. Programing a robot to perform the "Hokey Pokey" was the student goal of a single-case study conducted by Flannery 
and Bers (2013) intended to explore what kindergarteners can understand about programming and robotics and if developmentally appropriate tools, such as physical programming blocks, can support technology learning in early childhood classrooms. The researchers blended two bodies of theoretical work: computational thinking, "which addresses problem solving with computers," and technological literacy and fluency, which examine expressivity with new technologies" (Flannery \& Bers, 2013, p. 82).

According to Barr and Stephenson (2011), the Computer Science Teachers Association (CSTA) and the International Society for Technology in Education (ISTE) initiated a long-term project to develop an operational definition of computational thinking for K-12 education in 2009. A committee of invested K-12 educators developed a set of computational thinking concepts and capabilities that could be applied not only to computer science, but to math, science, social studies and language arts. The concepts included: data collection, data analysis, data representation, problem decomposition, abstraction, algorithms and procedures, automation, parallelization, and simulation. Given this educational paradigm is still evolving, it is not as readily recognized as constructivism or constructionism. However, its utilization by the Carnegie Mellon Robotics Academy, a popular and successful K-12 training program for numerous ER platforms (http://education.rec.ri.cmu.edu), will likely result in increased use in the literature.

Building on Brennan and Resnick’s (2012) framework for computational thinking, Falloon (2016) analyzed data from five and six year olds using Scratch Jnr. to explore basic shapes and numbers. The author concluded that computational learning in early childhood education, "strongly supports the efficacy of coding for promoting broadly-based cognitive, collaborative, team work and self-management objectives. . . seen as important outcomes for 
21st century education” (p. 591). The LEGO ${ }^{\circledR}$ WeDo 2.0 programming language, although not identical to Scratch used in this study is another example of a drag-and-drop, visual approach to coding known as object oriented. Falloon provides evidence that using coding with kindergarten and first graders can result in a technologically literate society.

The 2013 Next Generation Science Standards (NGSS) that are being adopted by an increasing number of states (Jacobson, 2016) include the teaching of computational thinking skills. While computational thinking is currently used as a broad term to include many reasoning and problem solving strategies, computational thinking at the elementary curriculum level involves teaching strategies for organizing and searching data, creating sequences of steps called algorithms, and using and developing new simulations of natural and designed systems (JaipalJamani \& Angeli, 2016). As educators learn to adapt their teaching to meet the expectations of the new standards, educational robotics may serve as a valuable tool to increase student-directed learning, data-driven decision making, and inclusion of engineering practices, all components of NGSS.

\section{Robotics in K-12 Education}

According to Watters (2015), in 1984 Kjeld Kirk Kristiansen, CEO of LEGO ${ }^{\circledR}$ and Papert met at the MIT Media Lab where they formed a partnership to create an educational LEGO ${ }^{\circledR}$ robot platform modeled off Papert's LOGO Turtle programming language. In January, 1998, the Mindstorms RCX was released, which coincided with the founding of the FIRST ${ }^{\circledR}$ LEGO $^{\circledR}$ League competition, and the product "caught fire" according to President Emeritus of LEGO ${ }^{\circledR}$ Education (Watters, 2015). Since that time, LEGO ${ }^{\circledR}$ has updated its original platform several times with the NXT released in 2006 and the EV3 released in 2013, all aimed at the middleschool age range. Their newest iteration is the WeDo for elementary learners, originally released 
in 2009 and WeDo 2.0 was released at the beginning of 2016. WeDo 2.0, is an elementary level robotics platform designed to work across mobile and desktop platforms and communicate wirelessly between the robot and computer.

The benefits of STEM education in early childhood include cognitive, social, psychomotor, and may influence career decisions (Tai et al. 2006). Early research on the Logo programming language has shown that computer programming can help young children with the development of number sense, language skills, and visual memory (Clements 1999). More recently, the use of ER in early childhood education has been shown to increase cognitive and fine motor skills and social development (Bers, Seddighin, \& Sullivan, 2013). Sullivan and Bers (2016) concluded that, "As early as pre-kindergarten, children are able to master foundational concepts regarding programming a robot and that children as young as seven years old are able to master concepts as complex as programming a robot using conditional statements" (p. 18). Because ER doesn't simply involve sitting alone at a computer but working with peers to build, test, and manipulate a robot, it improves hand-eye coordination, teamwork skills, and allows students to work collaboratively to experience STEM's interdisciplinary nature (Lee, Martin, Denner, Coulter, Allan, et al., 2013). LEGO $^{\circledR}$ robotics, specifically, is widely used in K-8 settings as an authentic and kinesthetic way to improve children's problem-solving skills, reinforcing science applications and concepts, while building upon informal learning activities often done at home (Karp \& Maloney 2013). In a study examining how engagement with ER developed students' self- efficacy in technology and their attitudes toward STEM, Leonard, Buss, Gamboa, Mitchell, Fashola, Hubert, \& Almughyirah (2016), noted that LEGO $^{\circledR}$ robotics can improve both spatial visualization and proportional reasoning skills. Grubbs (2013) noted, "Not only does the design and hands-on component of technology stay intact, but students also 
enjoy solving a realistic engineering scenario, role playing...and constructing physical components through an open-ended design challenge" (p. 12).

There is further evidence suggesting that children exposed to STEM curriculum, such as ER at an early age demonstrate fewer gender-based stereotypes regarding STEM careers (Metz 2007; Steele 1997). Additionally, programming robots helps students to engage in scientificinquiry (Linn \& Hsi, 2000): (a) science is made accessible by engaging with physical models; (b) thinking is made visible through construction and design principles; (c) students learn from each other through collaboration; and (d) autonomous learning skills are developed through selfdirected learning.

A growing body of recent research has demonstrated that ER can provide opportunities for elementary school students to learn STEM concepts earlier than expected. This earlier acquisition can increase students' confidence and interest in math, science, and engineering (Nugent at al. 2015; Park 2015; Rogers \& Portsmore, 2004). A study commissioned by Microsoft found nearly four in five STEM college students say that they decided to study STEM in high school or earlier, and their parents indicated that their child's STEM interest began at an early age (Harris Interactive, 2011). The study also found that $68 \%$ of females surveyed indicated that a teacher or class got them interested in STEM before college. As society works to expand opportunities in STEM fields for under-represented populations such as women, minorities, and individuals with disabilities, implementation of ER in elementary grades takes on an increased importance.

Despite the potential for ER in the classroom, the majority of robotics programs have been implemented as after-school programs and as robotics competitions (Barker \& Ansorge 2007; Chung, Cartwright \& Cole, 2014; Karp \& Maloney, 2013; Nugent, Barker, Grandgenett \& 
Adamchuk, 2010; Williams, Prejean, \& Ford, 2007). While robotics in formal elementary classrooms is neither consistent nor widespread, the inclusion of engineering practices in the Next Generation Science Standards (NGSS) may increase the use of ER platforms, such as the $\mathrm{LEGO}^{\circledR}$ WeDo 2.0, to increase the opportunities for students to solve real-world problems. A meta-analysis (Benitti, 2012) of studies where robotics were used to promote STEM learning showed that the use of educational robotics increased student learning of specific STEM concepts. Additional cognitive benefits of ER have been reported for elementary-aged students, including improvement in sequencing skills (Kazakoff, Sullivan \& Bers, 2013) and causal reasoning (Mioduser et al., 2009). ER may also improve systems understanding (the relationships between parts and their functions) in upper elementary and middle school children (Sullivan, 2008). ER may be promoted as a stand-alone subject area to provide students with the opportunity to learn engineering practices and technology education (Grubbs, 2013).

Whether it is through the engaging process of constructing robots or the excitement of after-school competitions, numerous robotics programs have resulted in an increase in students' comfort level with applications of STEM (Melchior, et al., 2017), development of twenty-firstcentury skills, and increased interest in pursuing STEM-related programs beyond high school (Brand, Collver \& Kasarda, 2008; Caron, 2010; Grubbs, 2013; Ivey \& Quam, 2009; Matson DeLoach \& Pauly, 2004).

\section{Evaluating K-12 Robotics Programs}

To better understand the impact of educational robotics programs, it is necessary to follow the students into the workforce or post-secondary education. Unfortunately, longitudinal studies of K-12 students face challenges such as a lack of long-term funding and the Family Educational Rights and Privacy Act (FERPA, 1974) that adds additional requirements and 
challenges for tracking students. Furthermore, much of the data about the effectiveness of ER programs is anecdotal or lacks appropriate pre- and post-test, any comparison group, or has insufficient numbers to support their conclusions a large enough effect (Benitti, 2012). One exception is the work conducted by Brandeis University on behalf of FIRST ${ }^{\circledR}$ (For the Inspiration and Recognition of Science and Technology), which released their most recent long-term study, the FIRST Longitudinal Study: Findings at 36 Month Follow-Up (Melchior, et al., 2017). The research by Brandeis of over 1,000 participants, including a paired comparison group, indicates that FIRST participants were significantly more likely to show a gain on STEM-related measures than comparison students between baseline and the 36-month follow-up. According to Melchior et al.,

After adjusting for differences in baseline characteristics and baseline scale scores, FIRST participants were:

- 2.9 times more likely than comparison students to show gains on STEM interest;

- times more likely to show gains in involvement in STEM activity;

- 2.3 times more likely to show gains on interest in STEM careers;

- 2.4 times more likely to show gains in STEM identity; and

- 2.7 times more likely to show gains in understanding of STEM.

One key difference between the FIRST ${ }^{\circledR}$ study, and other ER programs is that competition programs occur almost exclusively after-school with limited numbers of students, while this study is primarily examining school-day utilization of robotics with entire classrooms of students as a function of a specific training model and use of a standardized classroom kit (2017, p 4).

Ortiz, et al. (2015) completed a qualitative analysis using both observational techniques along with reflective essays to study the impact of ER in graduate-level math, science, and 
technology methods classes with a mixed group of 25 pre-service and in-service teachers. The authors described five major themes from the essays: 1. ER is fun and motivating, 2. ER is significant and important, 3. ER is a good way to integrate technology, 4. ER develops pedagogical skills in teachers, and 5. ER develops cross disciplinary skills in students (p. 45). The coding scheme developed for this research is a valuable resource for this current study as it provides a possible comparison of emergent themes and a validation of the qualitative techniques used by the researcher.

Although students in an elementary-level robotics summer camp were the subjects of Somyürek's (2015) study, his mixed-methods evaluation approach provides a valuable example of method and analyst triangulation. Grounding his research in the constructivist learning approach, Somyürek concluded that $\mathrm{LEGO}^{\circledR}$ Mindstorms robotics kits enable student-centered, active learning experiences that encourage multiple perspectives and collaborative learning. Importantly, he suggests that, “a teacher's role is to provide a problem that is related to real-life, various information resources, and an environment which allows collaboration among the learners" (p. 35). While the focus of the current study is on the educators, these key concepts are ones that will be observed by the educators implementing ER with their students.

The current study of elementary educators attitudes towards ER measures the impact of an educator workshop (pre, post, post-post), on participants' attitudes toward the technology and builds off the research by Gato, Ferguson, \& Van 'T Hooft (2006) into the attitudes and selfefficacy of educator toward technology integration in classrooms. Instruments such as the

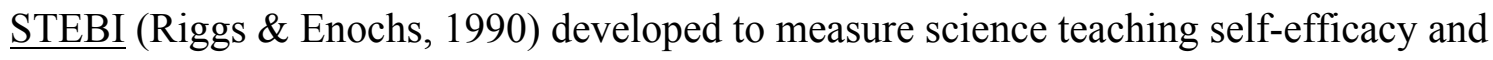
outcome expectancy for students. Riggs and Enochs (1990) found that although science is a required subject, many elementary teachers do not give science as a high priority as other 
subjects. Teacher belief systems are a likely contributor to classroom instruction, which is the underlying rationale for measuring educator's attitudes of the utility of the technology, their ability to use it, and their intent to utilize educational robotics in their learning environments. The most effective approach to evaluate K-12 ER is to utilize multiple methods, allowing overlap and explanation of the data. It is for this reason the study will use a quantitative survey instrument which has been in validated and used by the researcher since 2013 , in combination with interviews which will aid in the interpretation of the survey data.

\section{Teacher Professional Development}

As the need for STEM instruction in K-12 classroom environments increases, the need to prepare teachers to deliver STEM-based learning also increases. Because most teachers are inclined to teach what they were taught (Llinares \& Krainer, 2006), and with limited personal experience, teachers may feel unprepared to integrate STEM (Skamp \& Mueller, 2001).

However, as Levitt (2002) reported, when provided with useful models, teachers tend to be open to modifications in their teaching. The need for and influence of effective models of STEM teaching provided the motivation for the NASA ERC's K- $5^{\text {th }}$ grade elementary educational robotics professional development (NASA Education Specialist, personal communication, June $6,2016)$.

Despite the national movement for K-12 STEM education and its corresponding push to develop STEM educators, comparatively little attention has been given to the content of STEM teacher preparation or professional development (Rinke, Gladstone-Brown, Kinlaw, \& Cappiello, 2016). A recent review of the research on STEM education found that most current scholarship focused on the STEM learning of K-12 students, with relatively little attention paid to STEM teachers (Brown, 2012). Although some literature has highlighted the importance of 
teachers to STEM education and called for teachers to cultivate their STEM thinking, in general STEM teacher development has not yet been well-defined or carefully studied (Reeve, 2015; National Research Council, 2011). This study aims to fill a critical gap in research and literature. Currently there is lack of scholarship on how to effectively prepare teachers for including ER during the school day and a growing need for information about how to best inspire young learners to consider STEM career pathways. This research seeks to fill those gaps as well to demonstrate how to provide opportunities for $\mathrm{K}-5^{\text {th }}$ educators to gain confidence using robotics with their students.

\section{Attitudes, Perceptions and Beliefs}

This study seeks to quantify educators' belief in their competence (ability) to use ER, their motivation (intent) to use ER, and their attitudes toward ER (utility) as an appropriate educational tool for elementary students. According to Eccles and Wigfield (2002), "Modern theories of motivation focus more specifically on the relation of beliefs, values, and goals with action" (p. 110) and relate directly to self-efficacy. Bandura (1997) proposed that self-efficacy can be an indicator for confidence in one's ability to "organize and execute a given course of action to solve a problem or accomplish a task" (Eccles \& Wigfield, 2002, p. 110). Attitudes are the "overall evaluation of a highly specific behavior that is defined in terms of action, target, context and time" (Koballa \& Glynn, 2007, p. 79). Koballa and Glynn also note that beliefs are the cognitive basis for attitudes, and are a "significant determinant of intention to engage in the behavior" (p. 79). Through the 18-question survey and interviews, the researcher hopes to gain insights into the motivation, attitudes, and beliefs of educators to use ER with students. 


\section{Chapter Three: Methodology}

\section{Review of Purpose}

The purpose of this study is to investigate the impact of a four-hour educational robotics (ER) professional development workshop and subsequent implementation of activities on K-5 formal and informal educators' attitudes about the value of this technology, and their self-rated ability and desire to use ER. Both quantitative and qualitative methods will be used to understand the impact of the workshop on participants and their utilization of the technology with students. Analyst and method triangulation will be employed to increase the trustworthiness and meaningfulness of the findings.

\section{Research Design}

The data sources for this mixed method study are both quantitative and qualitative. The data was collected as follows: First, an 18-item survey (Appendix D) was administered prior to (pre) and at the completion of (post) a workshop on ER; then, the same survey was administered approximately three months after (post-post) workshop completion, which allowed participants a timespan during which they could implement ER with students; second, interviews (Appendix E) were conducted with workshop participants who did, and or did not implement ER (Figure 3). The interviews were coded by content and inductive and frequency analyses were completed. Two forms of triangulation were employed: analyst (author and independent researcher) for the qualitative data; and method (survey and interview). The overall design of the study is diagrammed in Figure 2. 


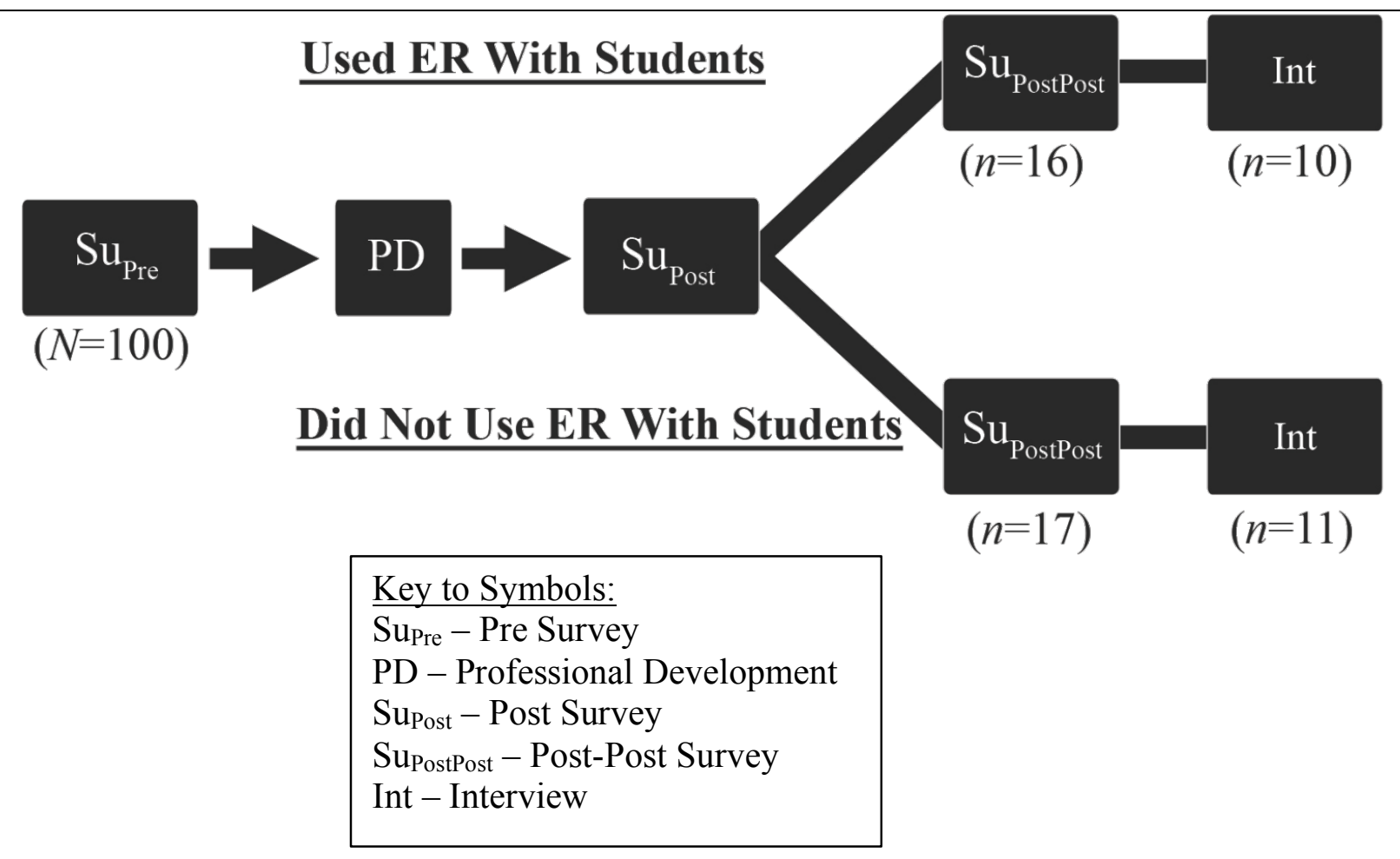

Figure 2. Research Design for mixed methods study of educators participating in robotics workshop. Subjects $(N=100)$ completed a pre- and post-workshop survey and a subset completed a post-use survey $(n=33)$. A portion of educators completing the post-use survey who also used robots with students completed an interview. An approximately equivalent number of educators who had not used robotics also completed an interview.

\section{Institutional Review Board}

WVU Institutional Review Board (IRB) approval for human subjects was sought prior to conducting the research, including the piloting of the instrument and recruitment of any participants. The research was deemed exempt and approved on June 6, 2016 (Protocol \# 1605112098). Letters of approval to conduct research were obtained for the seven locations where the workshops took place: the NASA IV\&V ERC, a university extension office, a science center, one intermediate school, and three elementary schools. All participants received and were read a cover letter (Appendix B) approved by the IRB which explained that participation was strictly voluntary. Only two attendees of all the workshops chose not to participate in the 
study because they were a pre-service teacher or a substitute, although they did complete the workshop.

\section{Participants}

One hundred participants $(N=100)$ were recruited for this study from a convenience sample of educators who provide instruction to $\mathrm{K}-5^{\text {th }}$ grade students in either formal (school day) or informal (out-of-school time) settings. Subjects self-selected to attend an elementary-level ER workshop conducted by the NASA IV\&V ERC between September 13, 2016 and March 16, 2017 on the new LEGO ${ }^{\circledR}$ WeDo 2.0 platform. The opportunity to attend a workshop was advertised (Appendix A) on the NASA IV\&V ERC's email listserv which reaches over 7,000 members, and workshops were hosted at the ERC or at a school site if there was sufficient interest. Of the 100 participants in the workshops who completed the pre- and post-workshop survey, 33 additionally completed the post-use (post-post) survey. Approximately half of the participants who completed the post-use survey $(n=16)$ indicated they either borrowed one of the NASA ERC LEGO ${ }^{\circledR}$ WeDo 2.0 kits, or their school purchased their own identical kits which were used with students. Semi-structured phone interviews (Appendix E) were conducted with 21 of the post-post participants and, of those, 10 indicated they had used ER with students with the remaining indicating they had not been able to yet.

\section{Intervention}

The intervention was comprised of a single four-hour professional development workshop for all participants. The majority of the 16 ER kit users were able to borrow one of the NASA ERC's LEGO ${ }^{\circledR}$ WeDo 2.0 classroom kits, although several schools had purchased their own set of identical equipment that participants were able to use, which for the purposes of this study were considered to be the same treatment. 
Workshop. The workshop agenda (Appendix F) started with an introduction to the NASA ERC and an overview of the 33 other professional development topics that could be requested, the classroom kit loan program, student STEM experiences at NASA, and how to get involved in STEM competitions such as IIRST $^{\circledR}$ LEGO $^{\circledR}$ League Jr. that requires the use of the LEGO $^{\circledR}$ WeDo 2.0 robot. After reading aloud the cover letter (Appendix B) required by the Institutional Review Board (IRB) and completing the demographics form (Appendix C), the preworkshop survey (Appendix D) was administered. Subsequently, participants were paired up to complete the workshop activities in partnerships, and they were introduced to the WeDo 2.0 curriculum and how to perform assessments using the portfolio tool embedded in the software. Portfolios are able to capture images of the software code programmed by the student, a photo or video of the constructed robot, and student reflections in a journal format. Kit and classroom management topics covered included:

- importance of keeping numbered robot and iPads together;

- demonstration of how to charge and replace batteries;

- how to clear prior student portfolios;

- importance of working in pairs and ensuring students change roles and adds to portfolio;

- recommended activities; and

- $\quad$ strategies for both younger and older learners.

Next, partners built Milo (Figure 3), the first activity designed to introduce the building platform and materials. In completing this build, the partners learned how to pair the WeDo 2.0 with the iPad, how to program the robot so that it moved a specified number of rotations before playing a sound file, and documented their build using the portfolio tool. After completing the first model, the instructor then let participants complete a different one of the eight guided models (Figure 4) 
using the included curriculum, programed the model, modified their program, and shared their experience with the class. The workshop concluded by completing the post-workshop survey and letting the educators schedule a time to borrow classroom kits.

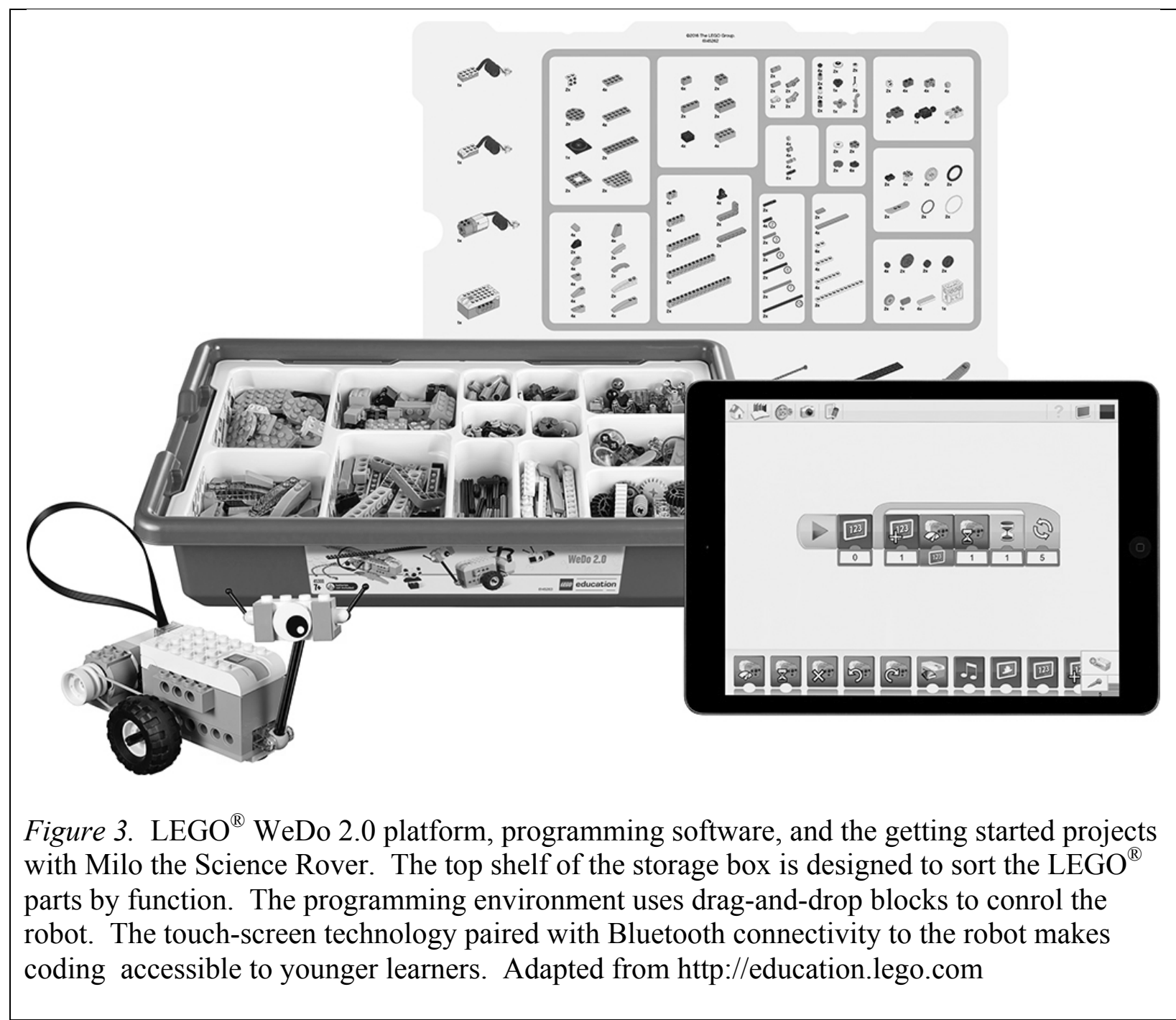

Classroom kit use. Given the limited duration of the study and limited number of kits available to be loaned, only 16 of the 33 participants who completed the post-post survey were also able to implement the ER activities with students. Classroom use varied at each site from a single classperiod to week-long unit. While not all participants were able to use the kit during the study, 


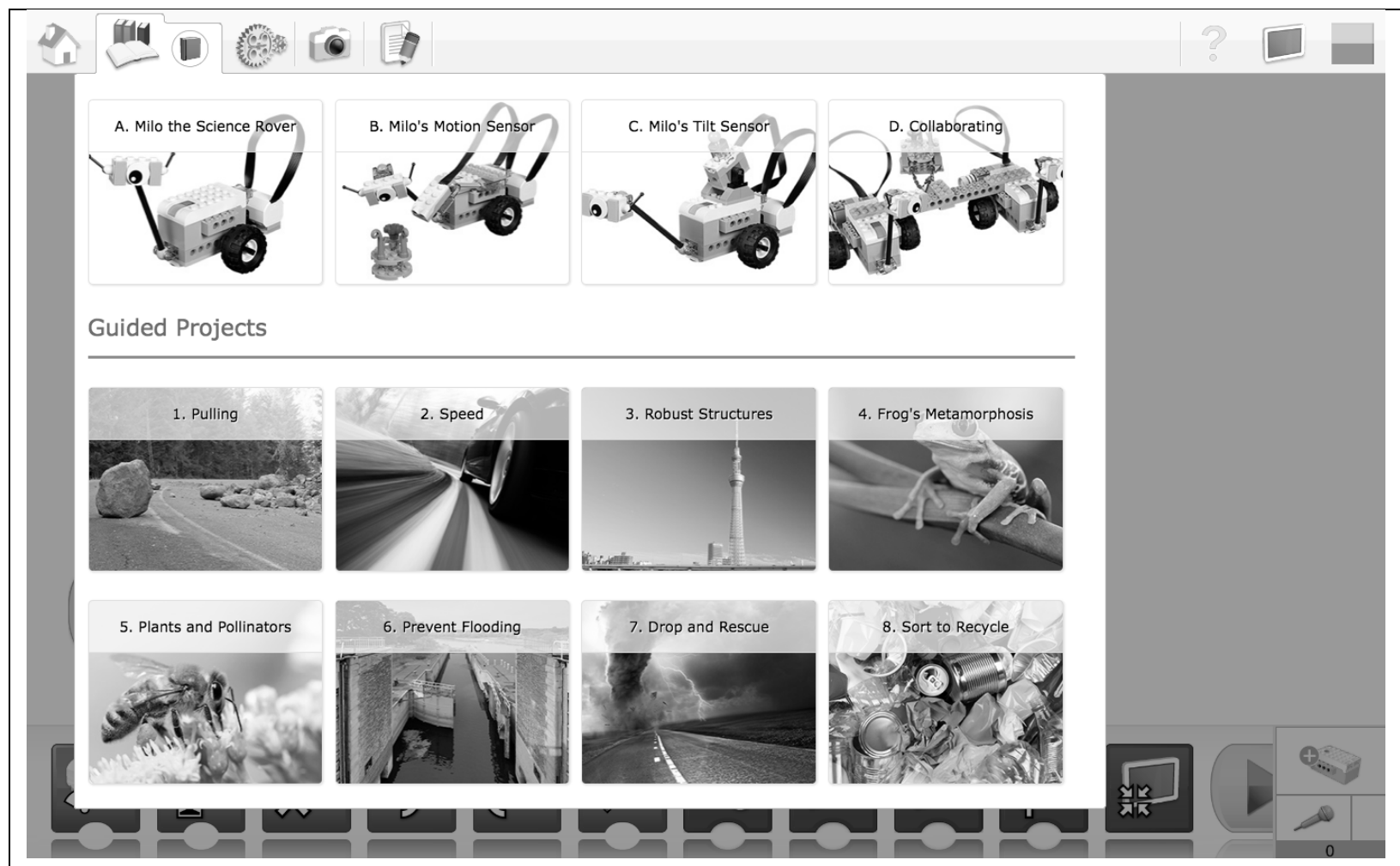

Figure 4. LEGO $^{\circledR}$ WeDo 2.0 tablet application opened to the Project Library depicting Milo the Science Rover along with eight Guided Projects. Image captured by researcher on Apple iPad 2, June 6, 2017.

every one of the 33 who completed the post-post survey was already scheduled to borrow a kit, or planned to do so in the coming school year.

\section{Data Collection Procedures}

All volunteers were asked to participate in every component of the study. As described earlier, the survey was administered before and after the four-hour workshop, and after using robotics with students. To provide the researcher with greater understanding of participant attitudes, a 15-20 minute interview was conducted with those who did and did not use the robotics kit with students. 


\section{Technology integration survey.}

The instrument for this study (Appendix D.) is based on a cross-validated 24-item survey (Gado, Ferguson, and Van 'T Hooft, 2006) that investigated "how the integration of hand- heldbased science activities affect preservice teachers' attitudes and self-efficacy toward handheldbased activities in their classrooms" (p. 504). A more recent 18 question version of the of the survey instrument was adapted and used with permission by Rye (2011) who administered it to 60 pre-service teachers to measure pre to post changes in "their attitudes and feelings of selfefficacy" (Gado et al., 2006, p. 502) of integrating science probeware. Data analysis of the post survey revealed that the Cronbach alpha for each of the three subscales of ability, utility and intent was greater than .8 , suggesting that the items comprising each subscale have high internal consistency (Rye, 2011). Most recently, the instrument was used with elementary pre-service teachers to determine the change in attitudes of probeware when presenting a climate change thematic unit (Ensign, Rye, \& Luna, 2015; Ensign, Rye \& Luna, in press).

Prior to administration of the survey, the workshop participants were apprised by the instructor of what constitutes "Educational Robotics" and the survey also contained a brief explanation as part of the instructions for completing it. The investigator was not present during data collection, and educators were informed that their responses would be kept confidential. The 18 statements on the survey target educator attitudes about the utility of this technology as well as their ability to use the technology, and their intent to use it in their own teaching. The survey employs a Likert-type scale (5 possible responses) that ranged from "strongly disagree" (1) to "strongly agree" (5). At the bottom of the post-workshop survey, an additional openended question was asked. "Please provide suggestions/ideas for improving the robotics experiences in this course." 
Interview. The researcher followed a semi-structured interview protocol (Appendix E) to gain insight into why the participants may have indicated that robotics would be easy to implement, why their confidence increased, and what obstacles they faced in utilizing the classroom kit. The interview questions are set forth in Appendix E and address the educators' attitudes, what they learned, what they liked/disliked about the ER training, plans for future use, and suggestions for making ER more useful. All 21 interviews were conducted by the researcher, recorded digitally, and transcribed to facilitate analysis. Transcriptions were checked against the audio file and corrected as needed.

\section{Data Analysis}

Quantitative data. Survey responses for each participant were entered into Microsoft Excel (v. 15.26) as 1, 2, 3, 4, or 5. Because questions 1, 2, 7-11, and 16 used reverse coding, the data were entered with $1=$ the least desirable and $5=$ the most desirable response. For example, a "strongly agree" response to survey item three, "Someday, I will use ER in my classroom" was coded 5 (and "strongly disagree" was coded 1) whereas a "strongly agree" response to survey item 10, "I think that integrating ER with teaching would take too much time" was coded 1 (and "strongly disagree" was coded 5). The data were averaged and the means for each participant, and sub-measure were entered into IBM's Statistical Package for the Social Sciences (SPSS v. 24) to ascertain if there were statistically significant differences in the mean of responses to all (18) items as well the mean to subsets of the items that were intended to measure attitudes about utility of the technology (items 1, 5, 15, 17, 18), ability to use the technology (items 2, 6, 9, 13, 14, 16), and intent to use the technology (items $3,4,7,8,10,11,12$ ). A one-way ANOVA with repeated measures was performed three times for each dependent variable (subscale) measure: attitudes about the utility of ER, ability to use ER, and intent to use ER, for both the pre- and the 
post-survey data $(N=100)$ as well as the post/post-post data $(n=33)$. One-way repeated measures ANOVA is an appropriate statistical test to perform when comparing the same group(s) on a parameter (dependent variable) at two or more points in time (independent variables), provided that the study design and population meet specified assumptions (Laerd Statistics, 2013). Quantitative findings were used to answer research questions one and two.

Survey Validity. The survey was adapted with permission from Gado, Ferguson, \& Van 'T Hooft (2006), who reported that it was cross-validated by the authors. Gado et al., do not describe their cross-validation process or related statistics. However, in prior research (Ensign, et al., 2015; Ensign, et al, in press), the researchers reported that the 18-item instrument had an acceptable level of reliability (Cronbach alpha $\geq .7$; Frankfort-Nachmias \& Machmias, 1996), based on survey data from preservice teachers $(n=60)$. For the entire instrument and each of the three subscales - utility, ability, intent - Cronbach alpha levels for the pre and post data were, respectively, .891, .739, .721, .800; and $.930, .847, .799, .840$. A variety of measures were taken to ensure the validity of the quantitative data from design of the instrument to the analysis conducted.

The survey utilizes both a midpoint response and reverse coding which have been shown to increase validity (Weems \& Onwuegbuzie, 2001). A midpoint Likert scale option provides respondents a choice when they truly do not have an opinion, rather than forcing them to create artificial opinions. The instrument utilized a five-point scale with "strongly disagree," “disagree," "not sure," "agree," and "strongly agree" as possible responses. Reverse coding protects against respondents who are either unable to understand the questions (e.g. possibly due to a language barrier or learning disability), or due to low interest may choose not to read the questions, and simply respond to all items with "strongly agree" (DeCoster, 2005). When data 
were initially entered into Excel in the original order recorded (before re-coding), standard deviation was calculated across all 18 items for each participant, and if the value was zero (indicating all 5's for example), that participant was removed. Rules were also applied to all surveys from all participants and, if violated, led to their removal from the quantitative analysis. participants were removed if they:

- missed or skipped either the pre or the post assessment;

- missed or skipped three or more items on any survey;

- $\quad$ missed or skipped two or more items in any subscale (ability, utility, intent).

These thresholds were determined after consultation with the WVU Program Evaluation and Research Center in order to ensure the results from statistical analysis were valid.

Qualitative data. Research questions three and four are qualitative in nature and were answered using the interview data. According to the well-established techniques of grounded theory (Charmaz, 2008), the entries were analyzed inductively in an iterative manner through open coding to generate the codes and respective categories (Fraenkel, Wallen, \& Hyun, 2015). Data were reduced by collapsing similar categories and through the formation of themes. A quantitative rule was established to determine when a category became a theme: A theme had to represent more than $50 \%$ of the participants who completed the interviews. The themes are inclusive, though more complex, than categories. Assertions are inclusive of the themes, but are the most complex and attempt to capture the broad outcomes of the workshop and ER implementation with students, as expressed by the participants.

Triangulation. Two forms of triangulation were employed in this study: methodological and analyst. By employing both a quantitative Likert scale survey instrument (RQ1-RQ2) and a qualitative interview (RQ3-RQ4), the two methods will complement and 
inform the other (Cresswell, Plano Clark, Gutmann \& Hanson, 2003) while increasing internal validity of the study (Merriam, 1998). Analyst triangulation by the researcher and an independent researcher was employed to increase the trustworthiness of the qualitative findings (Patton, 2002). After initial coding, the researchers compared and discussed their emergent categories and themes, noted categories that emerged with a much greater frequency for one but not the other researcher, and they independently reanalyzed the data using code definitions (closed coding) in order to ascertain if greater agreement between the researchers could be identified (Saldana, 2011).

Research question one. Research Question One (pre/post survey) asked: Does the elementary level educational robotics professional development workshop result in statistically significant $(p<.05)$ gains with at least a medium effect size, $\left(\eta_{\text {partial }}^{2}>.06\right)$ in $\mathrm{K}-5^{\text {th }}$ grade educators' attitudes about the educational utility of the technology, and their ability, and intent to use it? The survey data was analyzed in SPSS using a one-way ANOVA with repeated measures with the pre to post survey data. Partial Eta Squared $\left(\eta_{\text {partial }}^{2}\right)$ was examined as the measure of effect size.

Research question two. Research Question Two (post/post-post survey) asks: Does implementation of the elementary level educational robotics activities using the LEGO ${ }^{\circledR}$ WeDo robotics result in statistically significant $(p<.05)$ gains with at least a medium effect size, $\left(\eta_{\text {partial }}^{2}>.06\right)$, in K-5 ${ }^{\text {th }}$ grade educators attitudes about the educational utility of the technology, and their ability, and intent to use it compared to their post professional development experience? The survey data were analyzed in SPSS using a one-way ANOVA with repeated measures with the post to post-post survey data. Partial Eta Squared $\left(\eta_{\text {partial }}^{2}\right)$ was examined as the measure of effect size. 
Research question three. Research question three asks: What themes emerge from the interviews with $\mathrm{K}-5^{\text {th }}$ grade educators who did or did not implement the robotics activities with students, and in what ways do they illuminate findings from the survey? To answer this question, inductive and frequency content analysis was applied to the transcribed interview questions. To determine themes in the data, the researcher initially analyzed using open-coding to determine emergent categories as well as to generate the code definitions (for categories) and rules. Analyst triangulation was used to increase trustworthiness of the findings (Patton, 2002). The independent analyst was from a research university with over 30 years of qualitative research experience.

Research question four. Research question four asked: Did any elementary educators also provide an after-school experience, such as FIRST $^{\circledR}$ LEGO ${ }^{\circledR}$ League Jr., and if so what impact if any did that have on their attitudes compared to educators who did not participate in such a program? To answer this question, the transcript underwent content analysis through open coding to generate the codes and respective categories (Fraenkel, et al., 2015). The codes were reduced by collapsing similar categories to form themes, from which assertions were developed. An independent researcher who is a NASA Education Specialist and LEGO ${ }^{\circledR}$ League Jr. trainer, discussed, and (a) examined the open coding and emergent categories to determine if the categories were reflective of codes, (b) verified the consolidated themes maintained the essential elements found in the emergent themes, and (c) discussed the assertions identified by the researcher, and how they reflected the themes. 


\section{Chapter Four Findings and Discussion}

\section{Introduction}

The purpose of this study was to investigate the impact of a four-hour educational robotics (ER) professional development workshop and subsequent implementation of activities on $\mathrm{K}-5^{\text {th }}$ grade formal and informal educators' attitudes about the value of this technology, and their ability and desire to use ER. Both quantitative and qualitative methods were used to understand the impact of the workshop, utilization of the technology with students, as well as increasing the meaningfulness of the data. The findings for each research question (RQ) are organized by reporting the data relating to the impending question. RQ1-RQ2 utilize quantitative data from the 18-question survey, followed by RQ3-RQ4 which utilize qualitative

Table 1

Research Question Organizer.

\begin{tabular}{|c|c|c|c|}
\hline $\begin{array}{l}\text { Research } \\
\text { Question }\end{array}$ & Population & Data Source & Analysis Method \\
\hline RQ1 & ALL workshop participants & $\begin{array}{l}\text { Attitudes survey } \\
\text { (pre- and post-) }\end{array}$ & $\begin{array}{l}\text { One-Way ANOVA with } \\
\text { Repeated Measures }\end{array}$ \\
\hline RQ2 & $\begin{array}{l}\text { Workshop participants who } \\
\text { subsequently used ER }\end{array}$ & $\begin{array}{l}\text { Attitudes survey } \\
\text { (post- and post- } \\
\text { post) }\end{array}$ & $\begin{array}{l}\text { One-Way ANOVA with } \\
\text { Repeated Measures }\end{array}$ \\
\hline RQ3 & $\begin{array}{l}\text { Subset of RQ2 Subjects } \\
\text { who agreed to interview }\end{array}$ & $\begin{array}{l}\text { Semi-Structured } \\
\text { Interview protocol }\end{array}$ & $\begin{array}{l}\text { Inductive Analysis } \\
\text { followed by closed coding }\end{array}$ \\
\hline RQ4 & $\begin{array}{l}\text { Workshop Participants who } \\
\text { ran After-School ER }\end{array}$ & $\begin{array}{l}\text { Above plus } \\
\text { Informal Interview }\end{array}$ & $\begin{array}{l}\text { Inductive Analysis } \\
\text { followed by closed coding }\end{array}$ \\
\hline Retro1 & $\begin{array}{l}\text { All Workshop Participants } \\
\text { (Prior Experience vs. No } \\
\text { Prior Experience) }\end{array}$ & $\begin{array}{l}\text { Attitudes Survey } \\
\text { (pre) }\end{array}$ & $\begin{array}{l}\text { Three Independent } \\
\text { Samples } t \text {-tests for Ability, } \\
\text { Utility, Intent }\end{array}$ \\
\hline Retro2 & $\begin{array}{l}\text { All Workshop Participants } \\
(0-10 ; 11-20 ; 21+\text { Years of } \\
\text { Teaching Experience })\end{array}$ & $\begin{array}{l}\text { Attitudes survey } \\
\text { (pre- and post-) }\end{array}$ & Mixed Methods ANOVA \\
\hline
\end{tabular}


data from the interview transcripts. Two retrospective questions (Retro1-Retro2) emerged from the data analysis process, the first utilized quantitative data to determine what impact prior experience with robotics has on participants' overall pre/post workshop attitudes of ER. The second retrospective question sought to determine if years of teaching experience can serve as an indicator for positive attitudes toward ER when examining the pre/post workshop data. Table 1 depicts the population studied, data source, and analysis method for each research question.

\section{Demographics of the Study Population}

One hundred two participants attended the 13 elementary ER workshops, and of those, 100 completed the demographics questionnaire and pre-workshop survey, indicating their participation in the study. Four individuals failed to submit or complete the post-workshop survey, consequently the pre/post workshop comparison group was comprised of 96 participants. All participants $(N=100)$ were invited to complete the online version of the post-post survey which resulted in 33 participants who had completed all three qualitative assessments. Twentyone of the 33 completed the phone interview. Only one individual was identified through the phone interviews as an after-school IIRST $^{\circledR}$ LEGO $^{\circledR}$ League Jr. coach, and that participant completed a second separate unstructured phone interview.

Demographics information was collected at the beginning of the workshop (Appendix C.) and documented that the majority of the 100 participants were female $(n=95)$ and taught in a formal educational setting $(n=87)$; the greatest percentage $(30 \%, n=30$; Figure 5 .) of participants fell into the $0-5$ years teaching experience category; and grade four was the grade most often taught $(18 \%$, Figure 6$)$. Sixteen participants $(n=16)$ indicated they had previously been trained by the NASA ERC and had prior experience with another robotics platform such as 
LEGO $^{\circledR}$ WeDo 1 or LEGO ${ }^{\circledR}$ NXT. Only one $(n=1)$ educator was identified as participating in the FIRST $^{\circledR}$ LEGO $^{\circledR}$ League Jr. program during the study period.

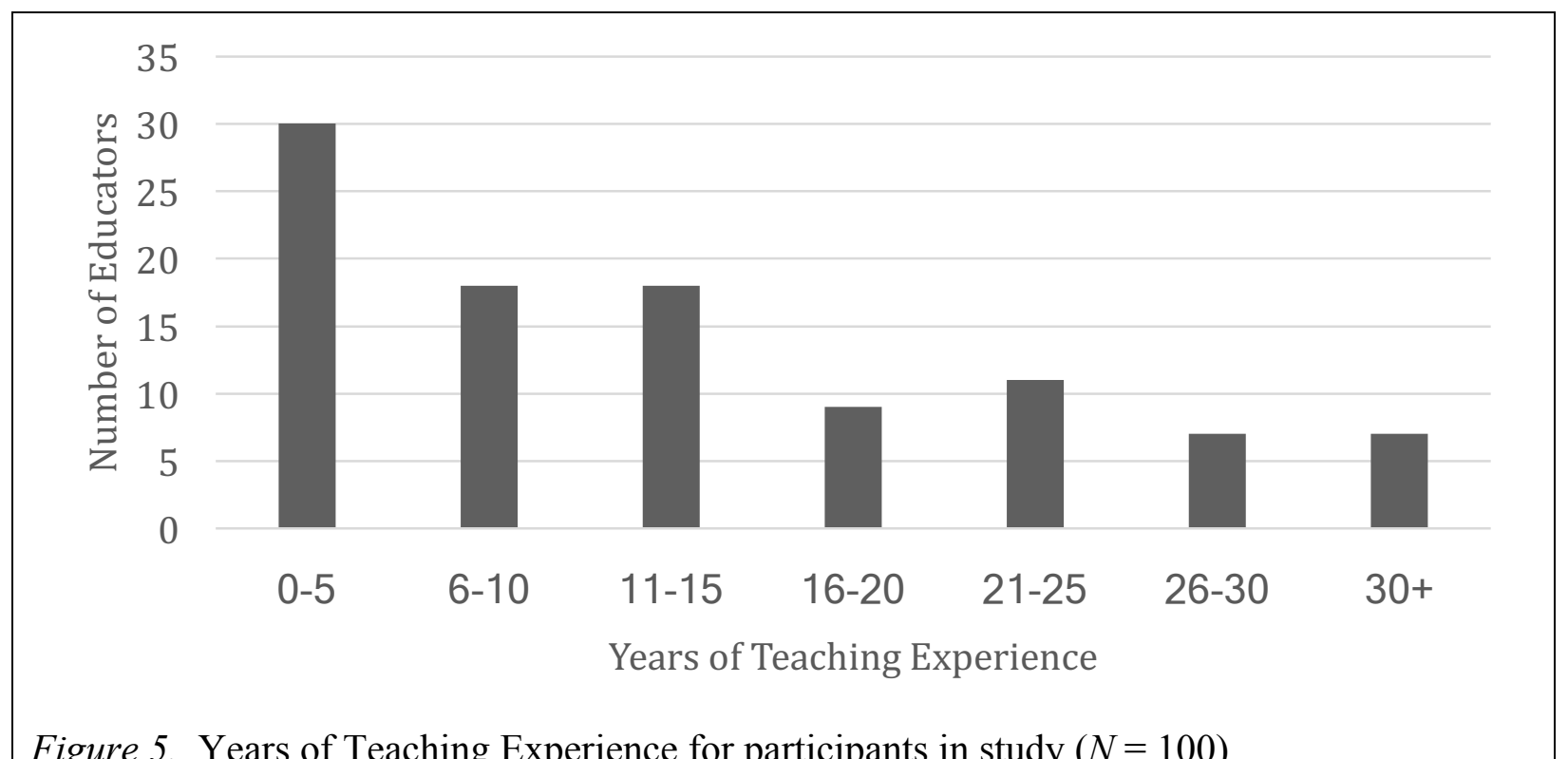

Figure 5. Years of Teaching Experience for participants in study $(N=100)$.

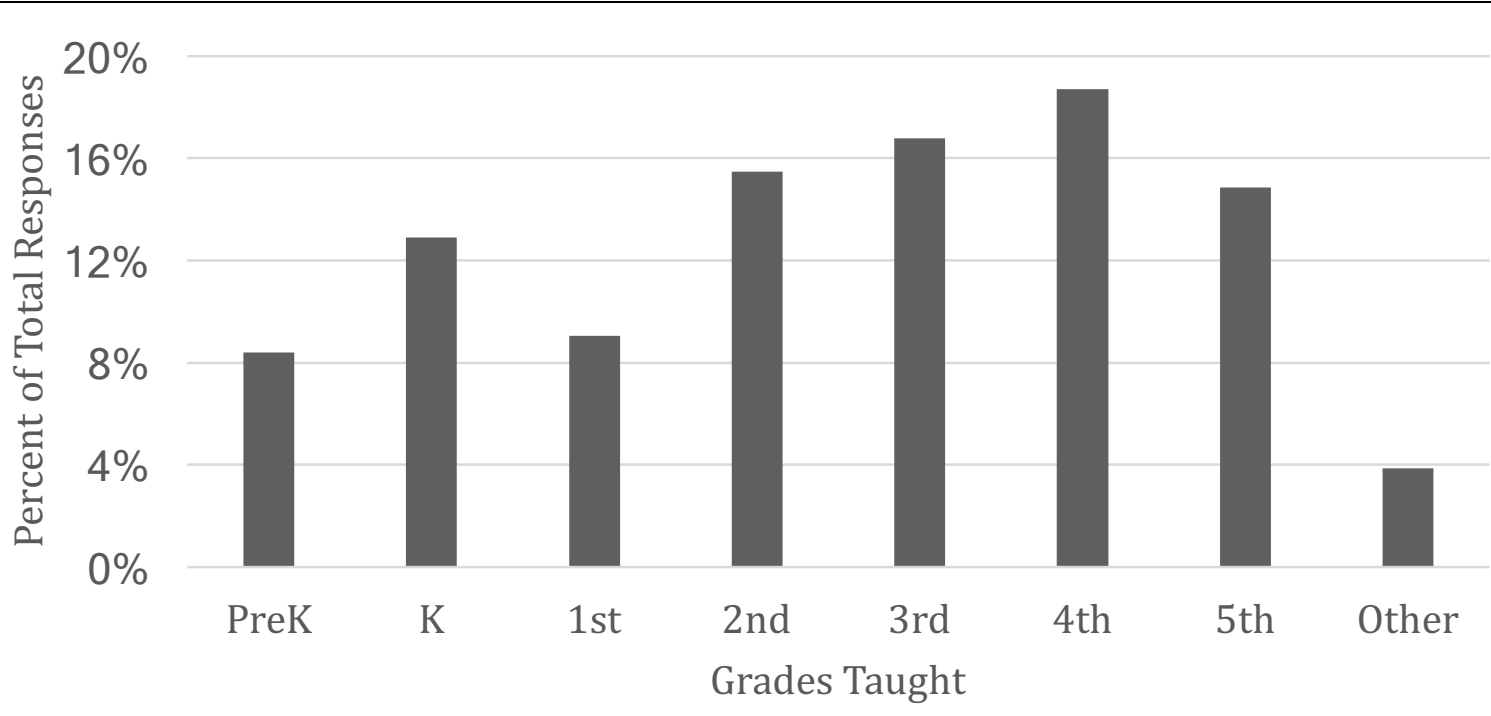

Figure 6. Grades taught by participants. Each grade taught was recorded for educators who covered more than one grade.

\section{Review of Data Collection and Analysis}

Subject demographics questionnaire, pre- and post-workshop surveys were completed inperson, on paper, and collected at the workshop by the lead instructor at all 13 trainings. Seven 
of the workshops took place at the NASA IV\&V ERC training laboratory, three took place at elementary schools, and one each took place at an intermediate school, university extension office, and a science center. Although the venue changed, the arrangement of the classroom, equipment, use of audio/visual, handouts, and all other controllable variables of the training environment remained as constant as possible. The post-post survey was distributed via email to each participant individually and completed as an online form. All survey data were tabulated, re-coded, and averaged by subcategory using Microsoft Excel (Version 15.26), with statistical analysis using SPSS (Version 24) to conduct a one-way ANOVA with repeated measures and comparing within groups for RQ1-RQ2. Two post hoc tests for RQ2 used SPSS to conduct a one-way ANOVA comparing differences in the mean in users and non-users for all three subscales on their post and post-post survey results.

The Cronbach alpha levels based on the data from this study for the subscales of ability, utility, intent for the pre-workshop $(N=100)$ ranged from .60 to .91 . Generally, reliability was high for each measure for each time (see Table 2 for each value). However, Cronbach alpha for the post-post measure of utility was unreliably low at .60, and conclusions based upon this measure should be assessed critically. This low reliability may indicate that utility as a construct has a wider range of variance than what is captured by this assessment.

Table 2

Cronbach alpha for 18-Question ER Survey.

\begin{tabular}{llll}
\hline Subscale & Pre-Workshop & Post-Workshop & Post-Use (post-post) \\
\hline Ability & 0.86 & 0.91 & 0.74 \\
Utility & 0.81 & 0.77 & $0.60^{\mathrm{a}}$ \\
Intent & 0.89 & 0.85 & 0.863 \\
\hline
\end{tabular}

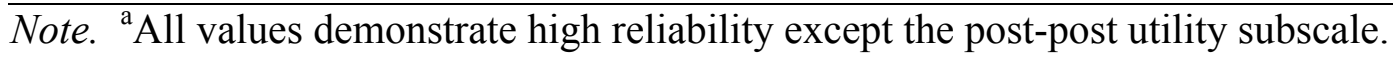


The qualitative data (RQ3-RQ4) was collected via a recorded phone call which was saved digitally as an .MP3 file, transcribed to Microsoft Word (Version 15.26), and coded using Microsoft Excel. The retrospective question used SPSS to conduct an independent samples (between subjects) $t$-test comparing the participants with and with-out prior experience with robotics.

\section{Results}

Research question one (RQ1). Does the elementary level educational robotics professional development workshop result in statistically significant $(p<.05)$ gains with at least a medium effect size $\left(\boldsymbol{\eta}_{\text {partial }}^{2}>.06\right)$ in $K-5^{\text {th }}$ grade educators' attitudes about the educational utility of the technology, and their ability, and intent to use it? A one-way ANOVA with repeated measures comparing the pre to post means for the 96 participants completing both surveys (Figure 7.) determined that there were statistically significant differences in attitudes of ability $(p<.001)$, utility $(p<.001)$, and intent $(p<.001)$.

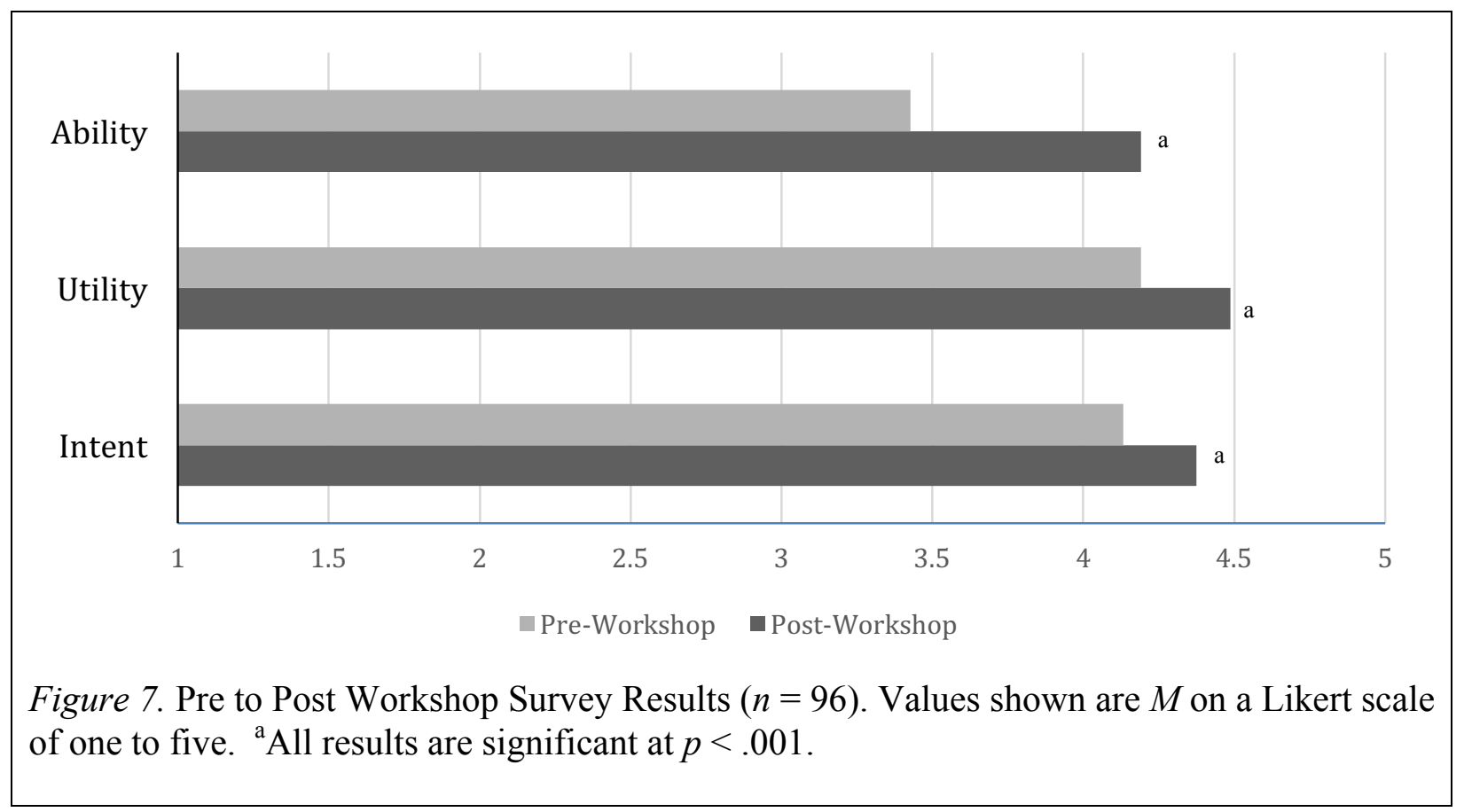


These differences were associated with large effect sizes: $\eta_{\text {partial }}^{2}=.50, .23$, and .16 respectively

(Table 3). The largest gains and effect size were observed in the subscale, ability to use ER ( $M$ $=3.43$ to $M=4.19$ ), which was an expected response to a four hour, hands-on training, particularly when the majority of the participants $(n=84)$ were using robotics for the first time. Table 3

Pre/Post Workshop Mean Values and One-Way ANOVA with Repeated Measures for Ability, Utility and Intent.

\begin{tabular}{llllll}
\hline & $M$ pre & $M$ post & $F$ & $p$ & $\eta_{\text {partial }}^{2}$ \\
\hline Ability & 3.43 & 4.19 & 96.70 & $\leq .001$ & .50 \\
Utility & 4.19 & 4.48 & 27.64 & $\leq .001$ & .23 \\
Intent & 4.13 & 4.37 & 18.67 & $\leq .001$ & .16 \\
\hline
\end{tabular}

Note. One-way ANOVA with repeated measures, significant at $p<.05$.

Utility of ER and intent to use ER showed smaller, although significant increases, which is expected for participants who self-selected to attend a workshop on robotics (utility) that advertised the ability to become certified to borrow the kit for use with students (intent).

The Shapiro-Wilk test did reveal that there was a violation of the normality assumption on the pre and post-survey data for all the subscales, with the exception of the post-workshop ability subscale. However, one-way repeated measures can withstand some violation to normality (Laird Statistics, 2013). The primary factor contributing to the violation of normality is that the participants disproportionally scored "strongly agree," resulting in a skewed distribution (Cramer \& Howitt, 2004).

Wilcoxon matched-pairs signed-ranks tests were also performed for all subscales as a non-parametric alternative. This non-parametric test does not assume data are normally distributed, and instead uses a rank-order system comparing different scores from each sample. This test was used as a follow-up to the repeated-measures ANOVA, to provide more evidence that the significant differences detected by the ANOVA are statistically valid. This test is 
interpreted by a $Z$-test which uses the standardized scores of the pre-post differences. Results of the test are presented in a lower-, higher-, or tied-scores fashion by subtracting the pre- from the post- scores for each subscale and classifying them accordingly (see Table 4 for subscale outcomes). The Wilcoxon matched pairs sign-rank test found statistically significant differences in the pre-post values for each subscale, corroborating the findings of the repeated measures ANOVA described above for ability $(Z=-7.25, p<.001)$; utility $(Z=-5.10, p<.001)$; and intent $(Z=-4.03, p<.001)$.

Table 4

Wilcoxon Signed-Rank Test for Ability, Utility and Intent.

\begin{tabular}{llll}
\hline Subscale & $\begin{array}{l}\text { Number of } \\
\text { participants with a } \\
\text { lower score }\end{array}$ & $\begin{array}{l}\text { Number of } \\
\text { participants with a } \\
\text { higher score }\end{array}$ & $\begin{array}{l}\text { Number of } \\
\text { participants with the } \\
\text { same score. }\end{array}$ \\
\hline Post ability - Pre ability & 9 & 83 & 4 \\
Post utility - Pre utility & 14 & 64 & 18 \\
Post intent - Pre intent & 23 & 58 & 15 \\
\hline
\end{tabular}

Research question two (RQ2). Does implementation of the elementary level educational robotics activities using robotics result in statistically significant $(p<.05)$ gains with at least a medium effect size $\left(\boldsymbol{\eta}_{\text {partial }}^{2}>\right.$.06) in $K-5^{\text {th }}$ grade educators attitudes about the educational utility of the technology, and their ability, and intent to use it compared to their post professional development experience? Fifteen of the 32 participants who completed both the post and the post-post survey indicated they had either borrowed the NASA ERC LEGO ${ }^{\circledR}$ WeDo 2.0 robotics kit or their school had purchased their own set of robots and iPads, which they were able to use with students. For the purposes of this study, either of these options allowed the participants to use the same ER platform they were trained on with students, and are counted together as "users." A one-way ANOVA with repeated measures determined that the use of ER with students does not result in statistically significant differences in educators attitudes of 
ability $(F(1,14)=.26, p=0.621)$, utility $(F(1,14)=2.55, p=0.132)$, or intent $(F(1,14)=.72, p$ $=0.410)$. The Shapiro-Wilk test did reveal that there was one violation of the normality assumption on the post-post survey for the subscale ability, while all other subscales had a normal distribution. Fortunately, one-way repeated measures can withstand some violation to normality (Laird Statistics, 2013).

The lack of significance with the educators who used ER with students may be the result of several possible factors:

1. The participants' attitudes were accurately measured in the post-workshop survey and simply had not changed significantly. This could be because the workshop had adequately prepared the participants for their experience, and their attitudes post-workshop were very close to their experience.

2. The instrument was unable to measure change due to a ceiling effect which occurs when there is a bunching of dependent variable scores at the upper level of the instrument (Cramer \& Howitt, 2004).

3. The small sample size $(n=15)$.

A lack of significant change is most likely a combination of the above factors, but may also be a strength of the ER program if it documents the workshop had the appropriate balance of demonstration, cooperative learning, and discussions on pedagogical approaches. Importantly, the results also document that participants maintained, post- to post-post, their attitudes of the utility of educational robotics as well as their ability and intent to use it. With respect to the latter, this suggests that these users intended to continue using it beyond their most recent implementation. However, none of the five questions that measured this parameter used the word "continue" in association with intent. 
RQ2 Post hoc one. Although there were no statistically significant differences in the post-workshop to post-post scores for the subgroup who used robotics with students, a post hoc test comparing users $(n=16)$ with the similar size group who had also completed the post-post survey but had not used robotics with students $(n=17)$ was conducted. To determine if these two groups (users and non-users) varied in any significant way at the conclusion of the workshop and at the time of the post-post, a one-way ANOVA (see Table 5) comparing these two groups was conducted. The one-way ANOVA determined these groups were significantly different for the post-workshop test across all three subscales (at the $p<.05$ level) with non-users' mean scores higher for all three subscales. The post-utility subscale violated Levene's test of homogeneity but was significant using the Welch test (which corrects for violations of homogeneity), for post ability $(F(1,30)=5.63, p=.024)$, post utility $(F(1,23.23)=6.77, p=$ $.023)$, and post intent $(F(1,30)=6.26, p=.018)$. This result is contrary to expectations, as it was assumed that those who were motivated to borrow the robotics kit (or use their school's kit) shortly after their training would score higher for the intent subscale, or indicate no significant difference between the groups. The post-post assessment comparison across all three subscales revealed no violations of homogeneity, and the groups (users and non-users) were not statistically different, for post-post ability $(F(1,30)=.85, p=.365)$, post-post utility $(F(1,30)=$ $1.42, p=.243)$, and post-post intent $(F(1,30)=2.64, p=.115)$ Any differences that existed between the user and non-user groups normalized by the post-post assessment, as the participants' post-post scores were not significantly different. The following subscales failed the Kolmogorov-Smirnov test of normality: post utility, post intent, post-post utility, and post-post intent for non-users; post-post ability for users. The one-way ANOVA is a robust test against the normality assumption and can tolerate data that is non-normal (Laerd Statistics, 2013). 
Table 5

Post- and Post-Post-workshop Users and Non-Users Mean Values and One-Way ANOVA

\begin{tabular}{llllll} 
& $M$ users & $M$ non-users & $d f$ & $F$ & $p$ \\
\hline Post-Ability & 4.08 & 4.58 & 1,30 & 5.63 & $0.024^{\mathrm{b}}$ \\
Post-Utility & 4.29 & 4.79 & $1,23.23^{\mathrm{a}}$ & 6.77 & $0.016^{\mathrm{b}}$ \\
Post-Intent & 4.28 & 4.71 & 1,30 & 6.26 & $0.018^{\mathrm{b}}$ \\
Post-post- & 4.19 & 4.36 & 1,31 & .845 & $0.365 \mathrm{n} / \mathrm{s}$ \\
$\begin{array}{l}\text { Ability } \\
\text { Post-post- }\end{array}$ & 4.53 & 4.71 & 1,31 & 1.42 & $0.243 \mathrm{n} / \mathrm{s}$ \\
$\begin{array}{l}\text { Utility } \\
\text { Post-post- }\end{array}$ & 4.39 & 4.66 & 1,31 & 2.64 & $0.115 \mathrm{n} / \mathrm{s}$ \\
Intent & & & & \\
\hline
\end{tabular}

Note. Mean values for Users $(n=15)$ versus Non-Users $(n=17)$.

${ }^{a}$ Post-Utility violated Levene's test of homogeneity, but was significant using the Welch test. ${ }^{\mathrm{b}}$ One-way ANOVA results are all significant at $p<.025$.

$\mathrm{n} / \mathrm{s}=$ not significant

RQ2 Post hoc two. Do non-users of the elementary level ER activities result in statistically significant $(p<.05)$ differences with at least a medium effect size $\left(\eta_{\text {partial }}^{2}>.06\right)$, in $K-5^{\text {th }}$ grade educators' attitudes about the educational utility of the technology, and their ability, and intent to use it compared to their post professional development experience? A one-way ANOVA with repeated measures was used to determine whether there were any significant differences $(\mathrm{p}<.05)$ between the non-users post and post-post scores, and how that compared to the users. Although RQ2 demonstrated there were no statistically significant differences for users on any subscale, there was a statistically significant difference in the non-user subscale of ability between the post and post-post scores, but not utility or intent. One possible explanation is that the users attitudes and self-efficacy toward ability decreased after working with children, while non-users maintained an elevated sense of ability. The non-users: post/post-post for utility $(F(1,16)=1.53, p=.234)$, and intent $(F(1,16)=0.72, p=0.50)$, were not significant. The nonusers post/post-post for ability was significant at ability at $(F(1,16)=0.40, p=.031)$. 
Research question three (RQ3). What themes emerge from the interviews with $K-5^{\text {th }}$ grade educators who did/did not implement the robotics activities with students, and in what ways do they illuminate findings from the survey? Twenty-one $(n=21)$ of the participants completed phone interviews and of those, $10(48 \%)$ indicated they had the opportunity to implement ER with students, while 11 had not (example transcript located in Appendix G). Inductive analysis in which the researcher and independent analyst applied open coding revealed over 150 codes each, which were combined independently to generate categories for each group, user and non-user. The researchers then compared their categories identified those which overlapped, or were present for only one or the other analyst. From the initial categories, 14 were agreed upon and checked against the transcripts. Further examination of the 14 categories revealed six emergent themes, consistent with the recommended number of final categories, or themes, of three to seven (Saldana, 2011). Themes are, "general propositions that emerge from diverse and detail-rich experiences of participants and provide recurrent and unifying ideas regarding the subject of inquiry" (Bradley, Curry, \& Devers, 2007, p. 1). The six emergent themes were observed to represent $50 \%$ or greater of the participants, although this is not a rule or rationale. These themes and were used by the researcher to complete the closed coding, a process of re-examining the transcribed interviews and quantifying and comparing the most prevalent perspectives of the users and non-users (Table 6). A final process by both the researcher and independent analyst was conducted to derive two overarching assertions through a review of the 14 categories and six themes. The assertions are grounded in the data, validated by two researchers, reflect the perspectives of the 21 participants interviewed, and were used to illuminate the survey results via data triangulation. 
Categories. The participants' responses to the survey questions (Appendix E) for both groups (users and non-users) revealed an almost universal enthusiasm for implementing educational robotics with elementary students (Table 6). Every participant interviewed stated clearly that even if they had not borrowed the robotics kit, they had already signed up to do so by the end of the school year or would do so soon. Several sites had submitted grants to purchase their own classroom kits, and more than one had implemented the activities covered in the workshop using their own equipment (identical to the NASA ERC kit). While the majority of the interviews were with traditional elementary classroom teachers, unique perspectives were provided by a retired school psychologist who volunteers in a school, an after-school provider, a home-school parent, a county technology integration specialist, and a principal.

\section{Table 6}

Categories From Interviews of Users and Non-Users of ER Users

Teachers are able to implement robotics easily, due to increased confidence from workshop.

Classroom management and strategies are critical to teachers (educators) use of robotics.

Robotics increases student engagement through hands-on learning.

Students enjoy doing STEM activities with robotics

Robotics kits are organized and/or easy to use.

Robotics increases cross-curricular student learning.

Robotics engages students through cooperative learning.
Non-Users

Workshop was a very positive experience and increased teachers' confidence with robotics.

Teachers valued the practical classroom strategies presented, and experiencing the same innovative activities they will use with students.

Teachers valued the hands-on activities covered during workshop.

Robotics engages students in STEM and science learning.

Students' technology skills increase their engagement.

Robotics motivates and engages students.

Robotics engages students by providing opportunities for creative expression, asking questions, and through problem-based

learning.

Note. Agreed upon categories from interviews of participants who used or didn't use LEGO ${ }^{\circledR}$ WeDo 2.0 robotics with students. 
The 14 agreed-upon categories that emerged from the open coding of both users and nonusers (Table 6) indicate that hands-on learning was both an essential element of the workshop and an important aspect of successful implementation of robotics activities with students.

Although apprehension for programming was expressed, those fears were quickly dispelled, and participants indicated a much higher confidence in their ability to use ER in elementary settings by the end of the workshop. Subject 25 stated that the workshop "also eliminated my fears and so I thought, that's pretty good, because now I could eliminate the students' fears when they tackled these things." Of the many activities and topics addressed, classroom management was both a concern and an area that participants felt was addressed with clear and tested strategies. Subject 72, a principal in one of the participating schools said "The one thing that I heard a lot about from many educators is that they tend [to] feel overwhelmed - more so with the classroom management part of implementing the robotics kit than the kit itself." While Subject 74 (a teacher) reflected, "It's totally doable and the kids are very excited about it. It just takes that classroom management piece in the beginning so that it's not a free for all - and you can do amazing things with elementary school students." Not represented in the categories are several suggestions for improvement of the workshop to include more hands-on time earlier in the training ( $28 \%$ of all participants), a suggestion to add evaluation tools such as rubrics aligned with the activities and local standards (14\% of all participants), and a trouble-shooting guide to address unexpected issues that may arise relating mostly to technology glitches (1 participant).

Themes. The most consistent and pervasive theme across both groups (Table 7) is that the workshop experience was positive and led to increased educator confidence as well ability to implement robotics activities. 
I think that was the biggest part - whether I could build something, whether I could understand how it works, and her taking us through that you know, letting us play with instead of just talking to us about it - we had the kit in our hands, we had the iPad in our hands. We were able to build and see what it did. I think that (a) it motivated me to say, "Oh my kids will love this!" and (b) took the away the fear of doing it (Subject 55). Ninety-one percent of non-users and $80 \%$ of users clearly indicated the training was effective. One hundred percent of users and 64\% of non-users indicated that Robotics increases student motivation and engagement through "hands-on" STEM and/or cross curricular learning activities. "It's also STEM, you can see the hands-on, it gets them thinking and problem solving - it's hands on, it's tangible, and in the moment (Subject 61)". One participant, illustrated the ability of robotics to also address English, language arts (ELA):

...the cross curricular that comes along with the writing portion, you know, so that the kids can kind of work on ELA and explaining, you know, what they're doing and how they're doing that. I thought that was another great aspect of the WeDo 2.0 specifically, you know they can take pictures of what they're doing and then also to write on it. So not only using, you know technology and math, but they're also using their ELA. So I thought that was a really great aspect of the WeDo 2.0 (Subject 40).

The ability to address science and math standards through technology to complete activities that encouraged students to engineer, using $\mathrm{LEGO}^{\circledR} \mathrm{s}$, their own unique solutions to problems is an example of effective STEM education.

"Hands-on," was also identified in the context of the effective nature of the workshop for $64 \%$ of non-users and $70 \%$ of users. Educators valued the practical classroom management strategies, and experiencing the "hands-on" robotics activities they can use with students 
covered during the workshop. This theme illustrated the instructor's approach of modeling effective classroom practices, including how to manage student roles and expectations as well as address the practical issues of working with small pieces and young learners. Directly responding to reflections about the workshop, Subject 66 stated:

[The instructor] kept us moving and we went through things and she talked about the different ways that teachers were using it, which was really helpful because any time you're starting something new as a teacher - you know you love it, you know your kids are going to love it - but how can you work it into the curriculum? How can you work it into your classroom? How do you manage it? - Those kinds of things [the instructor] had some of those tips (Subject 66).

Another participant reflected, "Of course she started her class in the same way that you would do that with your children" (Subject 102). More than one school teacher reported that despite the workshop directly addressing classroom management, it persisted as a challenge for integration of robotics, and the use of volunteers, technology integration specialists or Title 1 teachers helped overcome this obstacle.

One thing that I heard a lot about from many educators is that they tend to feel overwhelmed - more so with the classroom management part of implementing the robotics kit...So one thing that we did at our school is we tried to get the Title One teacher or volunteers or anyone actually that we had to come into the classroom whenever the teacher was using the kit (Subject 72).

Fifty-five percent of non-users and $70 \%$ of users observed that Robotics engages students in cooperative learning, which is highly valued by educators. This perspective was stated in a variety of ways, but Subject 67 clearly said robotics increased, "their level of interest and in 
cooperating because they had to work together - so that was a success. They actually had to learn to work together and follow the directions." The terms "group" and "teams" were used often to describe observations of how robotics were used, "I like the aspect that you can work on it as a group, in pairs, even using it as a team building exercise beyond what we used it for" (Subject 64). One participant described a phenomenon that was observed in numerous classrooms, "I have several who are just anxious to teach other students which I just find interesting because they like that - helping others" (Subject 62). What many participants described was actually peer-mentoring, with students helping one another in the same class, or even assisting with implementation of robotics throughout the school.

Table 7

Emergent Themes from Interviews with Educators

\begin{tabular}{|c|c|c|c|c|}
\hline \multirow[b]{2}{*}{ Emergent Themes } & \multicolumn{2}{|c|}{$\underline{\text { Non-Users }}^{\mathrm{a}}$} & \multicolumn{2}{|c|}{$\underline{\text { Users }}^{\mathrm{b}}$} \\
\hline & Count & Percent & Count & Percent \\
\hline $\begin{array}{l}\text { Workshop experience was positive and led to } \\
\text { increased educator confidence as well as ability to } \\
\text { implement robotics activities. }\end{array}$ & 10 & $91 \%$ & 8 & $80 \%$ \\
\hline $\begin{array}{l}\text { Robotics increases student motivation and engagement } \\
\text { through "hands-on" STEM and/or cross curricular } \\
\text { learning activities. }\end{array}$ & 7 & $64 \%$ & 10 & $100 \%$ \\
\hline $\begin{array}{l}\text { Educators valued the practical classroom management } \\
\text { strategies, and experiencing the "hands-on" robotics } \\
\text { activities they can use with students covered during the } \\
\text { workshop. }\end{array}$ & 7 & $64 \%$ & 7 & $70 \%$ \\
\hline $\begin{array}{l}\text { Robotics engages students in cooperative learning, } \\
\text { which is highly valued by educators. }\end{array}$ & 6 & $55 \%$ & 7 & $70 \%$ \\
\hline $\begin{array}{l}\text { Robotics engages students by providing opportunities } \\
\text { for creative expression, asking questions, and problem } \\
\text { solving. }\end{array}$ & 6 & $55 \%$ & 6 & $60 \%$ \\
\hline $\begin{array}{l}\text { Educational robotics kits are organized and/or easy to } \\
\text { use which increase educator confidence to use with } \\
\text { students. }\end{array}$ & 6 & $55 \%$ & 6 & $60 \%$ \\
\hline
\end{tabular}

Note. Themes represented $>50 \%$ of participants. ${ }^{\mathrm{a}}$ Non-Users $(n=11) .{ }^{\mathrm{b}}$ Users $(n=10)$. 
As important as science, math, and technology standards are to educators, "a focus on creativity, critical thinking, communication and collaboration is essential to prepare students for the future" (Partnership for $21^{\text {st }}$ Century Learning, 2015, p. 1). The theme, Robotics engages students by providing opportunities for creative expression, asking questions, and problem solving was identified by $55 \%$ of non-users and $60 \%$ of users in this study. The common element is that simply introducing robotics into the K-5 environment appears to encourage student centered and student led learning. When describing how she intended to use the robotics kit, Subject 92 commented, "I'm going to and try to get the kids to use a little bit of their critical thinking skills, and be creative, and come up with their own ideas, and things of that nature, because...innovation is the key."

The majority ( $55 \%$ of non-users and $60 \%$ of users) drew attention to the organized nature of the LEGO ${ }^{\circledR}$ WeDo kit, the easy to use programming software, and the embedded video-based science content which increases the confidence of the educator to use this technology with students. (Table 7: Educational robotics kits are organized and/or easy to use which increase educator confidence to use with students). This participant captured several specifics of the educational robotics kit,

Well, it was just very easy to use. I didn't have to go through and do really hardly anything other than to make sure that I had the groups that were around each kit, you know, labeled and so I would know who had rented it out or borrowed a kit for the day. But I mean I was really amazed at how well it was labeled - each little tray had their specific parts, and everything was organized, and the sticker was on there. I liked the top tray with the paper above on the top tray that gave the diagram of what was in each. The iPads were all charged and the kit had extra batteries (Subject 102). 
Sixteen of the participants previously had been trained in the LEGO $^{\circledR}$ WeDo 1 or other LEGO $^{\circledR}$ robotics platforms, which caused them to have an even greater appreciation for the use of wireless tablet-computers to perform all the programming (via Bluetooth) as well as the easy to access science content. For example, Subject 40 asserts:

I really like the tablets - the ability for the students to program with the tablet ... I like that it's wireless because I think that the kids can really do more with it and they're already familiar with the tablet so I think that's a great way to kind of introduce them and . . to a device that they're used to (Subject 40).

Assertions. The six themes most frequently identified served as a foundation for two assertions drawn from the interview process. The first assertion is: The organized and appropriately sized kits, along with the practical classroom management strategies covered in the workshop are requirements for successful implementation of educational robotics in classrooms. This statement is supported by the majority of all participants, but is particularly valid for the group who were able to implement the activities with students. While LEGO ${ }^{\circledR}$ WeDo 2.0 is an extremely well-designed educational product, what impressed the educators appears to be some simple aspects such as:

- the sorting bins with stickers showing which LEGO ${ }^{\circledR}$ s went where;

- the extra kit the NASA ERC included to provide spare parts if some are lost;

- $\quad$ pre-charged robot batteries and tablets;

- 12 iPad tablet computers with LEGO ${ }^{\circledR}$ WeDo 2.0 software installed and updated, in kidfriendly cases that include built in stands; and

- $\quad 12 \mathrm{LEGO}^{\circledR}$ WeDo 2.0 robot kits labeled, sorted, and named (which facilitates Bluetooth pairing). 
In addition to the physical aspects, participants cited the importance of a training experience that modeled the practical and pedagogical approaches which should be used with students. Comfort with implementation would appear to be a function of knowing ahead of time what to expect.

The second assertion is: The "hands-on," technology-based, cooperative, creative nature of educational robotics, increases student engagement in STEM and/or cross-curricular learning, which is valued by educators. This assumption recognizes the nature of the learning environment that is both encouraged and supported by educational robotics, while emphasizing that this approach to STEM education is sought by educators. One participant stated,

Well, I think it's right on the target of where we need to be to stoke the kids' interests. In education, it's very hard to get the kids interested in things. Most of the time it's just books. Think about it - it's taking science on a higher, on a whole other level - it's engineering and mathematics and all that goes into it. All of that instead of just sitting in a classroom with just the text book - this is the way to go for kids to spark their interest, you know. I think it's great! (Subject 25)

While STEM was a reoccurring theme, at the elementary level it is critical that any successful initiative be cross-curricular. Several participants felt the embedded journaling tools of WeDo 2.0 software encouraged the teaching of English language arts; the open-ended nature of many projects encouraged a level of creativity; and the team-based approach supported cooperative learning. These are all $21^{\text {st }}$ century skills, which will be necessary for our students to possess no matter what type of career they aspire to. The second assertion also highlights the theoretical framework of this research, the TPACK (technology, pedagogy, and content knowledge) model. Educational robotics and well delivered professional development can shift educators into the 
middle of the TPACK diagram by providing adequate instruction in the technology and pedagogy, while connecting the activities to the educators pre-existing content knowledge.

Although the majority of comments made during the interviews reinforced the positive attributes of the robotics kit, it is important to recognize unique perspectives which if addressed, may have a disproportionately higher potential to improve the delivery of the training or aspects of the kit. Some of the categories that should be addressed are listed in rank order of frequency and include:

1. The workshop was too short, or didn't spend enough time doing hands-on activities.

2. Managing 12 stations of students can be challenging without a second instructor or an aide.

3. The school or teacher's schedule is not compatible with a project-based learning activity (gifted teachers may only meet with students once a week).

4. Fear of losing $\mathrm{LEGO}^{\circledR}$ pieces, or keeping the kit organized.

5. Challenges working with special needs learners such as those who are color-blind.

6. Having enough robotic kits for larger classrooms.

7. Kit should have clearer learning objectives, rubrics for assessment and a trouble-shooting guide.

It is apparent that most of these challenges -- with the exception of meeting the needs of some types of special needs learners -- can be addressed by: offering a longer training program; recommending schools pair teachers with an instructional aide (ideally a technology integration specialist) when using the ER kits; providing (even more) extra parts; creating a kit that has 15 robots and tablets; and, adding an additional documentation to clarify goals, assessment, and address technical problems (troubleshooting) that may arise during implementation. 
Triangulation. The quantitative data showed statistically significant gains in educator's attitudes of ability, utility and intent from the pre to the post workshop (RQ1) which is strongly reinforced by the qualitative data across all three subscales. The themes from the interviews that best aligned with the subscales from the surveys are shown along with a representative quotation from the interview data are summarized in Table 8.

Table 8

Triangulation of Themes with Subscales for RQ1

\begin{tabular}{|c|c|c|}
\hline Subscale & Emergent Theme & Representative Quotation \\
\hline Ability & $\begin{array}{l}\text { Workshop experience was positive } \\
\text { and led to increased educator } \\
\text { confidence as well ability to } \\
\text { implement robotics activities. ( } 91 \% \\
\text { of non-users; } 80 \% \text { of users) }\end{array}$ & $\begin{array}{l}\text { "I think it was great - it was very user } \\
\text { friendly for somebody who doesn't have } \\
\text { any experience. . . within the couple of } \\
\text { hours that we were there, I felt that it was } \\
\text { very usable and . . . would be accessible } \\
\text { in the classroom without having a lot of } \\
\text { training for the kids (Subject 64) }\end{array}$ \\
\hline Utility & $\begin{array}{l}\text { Robotics increases student } \\
\text { motivation and engagement through } \\
\text { "hands-on" STEM and/or cross } \\
\text { curricular learning activities. ( } 64 \% \\
\text { of non-users; } 100 \% \text { of users) }\end{array}$ & $\begin{array}{l}\text { "So it was a wonderful addition to what } \\
\text { we already teach, because we do teach } \\
\text { the sciences about mechanics and } \\
\text { engineering. . so this was an amazing } \\
\text { addition to the concepts we already teach } \\
\text { (Subject } 72 \text { )." }\end{array}$ \\
\hline Intent & $\begin{array}{l}\text { Educational robotics kits are } \\
\text { organized and/or easy to use which } \\
\text { increase educator confidence to use } \\
\text { with students. ( } 55 \% \text { of non-users; } \\
60 \% \text { of users) }\end{array}$ & $\begin{array}{l}\text { "I'm really excited about being able to } \\
\text { use it and even having the opportunity to } \\
\text { borrow them and use it to teach kids } \\
\text { (Subject 99)." }\end{array}$ \\
\hline
\end{tabular}

The analysis of the qualitative data also reinforced the findings of the survey (RQ1), with $80 \%$ (users) to $91 \%$ (non-users) indicating the experience increased their confidence (ability); 64\% (non-users) to $100 \%$ (users) agreeing that robotics increases student motivation and engagement in STEM (utility); and 55\% (non-users) to $60 \%$ of users valuing the practical strategies they can use with students (intent). 
Data from the post to post-post survey did not indicate a statistically significant difference in educator's attitudes across the three subscales (RQ2). This finding may indicate the participants have a high level of persistence in their attitudes of educational robotics. It is also consistent with participants' attitudes from the qualitative data that the workshop adequately prepared them to implement the robotics activities. One participant who used the kit with students remarked, "I felt that they were easy - the robotics kits were easy to use and the students were able to program. . . the robots with the iPads quite easily, probably easier than what I can do (Subject 72)." Another reflected, "I have been absolutely blown away at the skills that they really do have and can think through with the WeDo kit. . . you just don't realize how much they're capable of until you see them do it (Subject 66)."

Research question four (RQ4). Did any elementary educators also provide an afterschool experience, such as FIRST ${ }^{\circledR} L E G O^{\circledR}$ League $J r$., and if so what impact if any did that have on their attitudes compared to educators who did not participate in such a program? One participant (referred to as Mindy) was identified through the post-post survey and telephone interview as a fourth-grade science teacher, who was also involved as a coach for two FIRST $^{\circledR}$ LEGO $^{\circledR}$ League Jr. teams. Although Mindy is a public school teacher in an elementary school (grades kindergarten-fifth), her position is unique; as a science specialist, she was able to implement ER with every child in the fourth-grade each week during their science class. Unlike an after-school sporting team, that may be expected to only benefit the students who were able to participate, the robotics team not only allowed some students to have a richer, more meaningful experience - they also brought their enthusiasm for learning back to the classroom, becoming peer mentors and assisting students across the entire school. During the interview, Mindy explained the 11 students participating in the two IRST $^{\circledR}$ LEGO $^{\circledR}$ League Jr. teams met for an 
hour and a half, twice a week (September through December) conducting research on that year's theme about bees or animals in their environment. The teams were tasked with choosing an animal and solving a problem they identified, creating a poster presentation to share their research, and designing a diorama built using the $\mathrm{LEGO}^{\circledR}$ WeDo 2.0 kit to illustrate their solution. Through this process, Mindy reported the students developed an increased sense of responsibility and pride in their learning, self confidence in their ability to work with the robot and perform coding, demonstrated greater creativity, and improved teamwork and communication skills. What most impressed Mindy was her observation that the team members brought their experience with, knowledge of, and positive attitudes toward ER back to the whole class during the school day. These team members became peer mentors in their own classrooms, technology integration specialists for faculty and students in other classrooms, and they played a significant part in changing the culture, school-wide, toward a greater acceptance of and desire to use ER in the classroom.

A separate, second interview was conducted with Mindy, who validated via member checking the accuracy of the transcript, which provided additional technical details on her implementation of the after-school program well beyond what was conveyed in her initial guided interview. The transcript underwent content analysis through open coding to generate the codes and respective categories (Fraenkel, et al., 2015). Twenty-five codes were collapsed to form categories. Similar categories were used to generated seven themes, from which an assertion was developed (Table 9). An independent researcher and NASA Education Specialist familiar with FIRST $^{\circledR}$ LEGO $^{\circledR}$ League Jr. reviewed the codes, and she compared them to the consolidated categories, emergent themes, and the researcher's assumptions. While the independent researcher did not analyze the transcript, she validated the presence of the themes in the coded 
data and agreed the assertions were accurate representations of the themes. One theme stood alone and wasn't reflected in the assertions: Integration of ER can be limited by school structure and curriculum. When asked about the implementation of FIRST ${ }^{\circledR}$ LEGO $^{\circledR}$ League Jr. during the school day, Mindy suggested,

Right now I can only see it after school due to our time constraints during the day and the curriculum we have to cover. I know that I incorporated a lot within my classroom, because in my [science] classroom it will be throughout the whole day. But as far as pulling in the other 4th grade that will be a little more challenging because I only have them [students] four days a week for 40 minutes (Subject 55).

Table 9

Themes and Assertions of Case Study on After-School Robotics Program.

Themes

Participation in FIRST $^{\circledR}$ LEGO $^{\circledR}$ League Jr. (after-school) resulted in the inclusion of the engineering design process in the classroom.

Participation in FIRST $^{\circledR}$ LEGO ${ }^{\circledR}$ League Jr. (after-school) led to a change in the classroom culture: increased student confidence, communication, creativity, and pride in work.

Participation in FIRST $^{\circledR}$ LEGO $^{\circledR}$ League Jr. (after-school) resulted in more cross curricular learning, specifically the inclusion of research, writing, and creativity in science class.

Participation in FIRST $^{\circledR}$ LEGO $^{\circledR}$ League Jr. increased student, parent, and teacher enthusiasm, attendance during and afterschool.

Participation in FIRST $^{\circledR}$ LEGO $^{\circledR}$ League Jr. (after-school) increased interest in using robotics during school, school wide.

FIRST $^{\circledR}$ LEGO $^{\circledR}$ League Jr. students became peer mentors.

FIRST $^{\circledR}$ LEGO $^{\circledR}$ League Jr. coach training on research and dioramas enhanced classroom integration of ER.
Participation in FIRST ${ }^{\circledR}$ LEGO $^{\circledR}$ League Jr. (after-school) increased the skills, confidence, and engagement of both the teacher and students (during school) which led to: (a) the integration of engineering practices; (b) the practice of peermentoring; and (c) school-wide interest in educational robotics. 
Assertion. Participation in FIRST ${ }^{\circledR} L E G O^{\circledR}$ League Jr. (after-school) increased the skills, confidence, and engagement of both the teacher and students which led to: (a) the integration of engineering practices; (b) the practice of peer-mentoring; and (c) school-wide interest in educational robotics. During the interviews, Mindy revealed that she had received FIRST $^{\circledR}$ LEGO $^{\circledR}$ League Jr. coach training in August, 2016, prior to her elementary ER workshop hosted by the NASA ERC in December, 2017. Enthusiasm for the opportunity to be on the team was extraordinarily high. After showing the students the WeDo 2.0 robot, and explaining how FIRST $^{\circledR}$ LEGO $^{\circledR}$ League Jr. would function as an after-school program she handed out the permission forms. The response was surprising:

And the next morning when I came in I had 11 children run to me with all their forms filled out, and...I wasn't planning on having 11 children, that wasn't my plan, but you know I couldn't turn any of them away. Because they were just so excited, every one of them came to school early to be the first one to put it in my hand. (Subject 55)

Due to the requirements of the program, a team can only have 6 students, and Mindy had to form two teams. With limited resources, she approached her PTO, which then paid for a second WeDo 2.0 kit, additional LEGO ${ }^{\circledR}$ blocks, and both teams' registrations. Enthusiasm ran high for the entire season (August, 2017 through December, 2017): "None of the kids missed any of the meetings! The parents were excited. . . all of the kids came to both of the expos, even if they weren't presenting they came. (Subject 55)." According to Mindy, the teams proceeded to meet twice a week after-school, and over a four-month period, improved their ability to build and program the robot, as well as work and communicate well with others. Once the robotics kit was borrowed (February, 2017), and used with the whole classroom, "those students became kind of...role models of how to do the work, and they became helpers. If there were kids struggling I 
could say, 'you two go over there and help them."' (Subject 55). Beyond mentoring their peers, the team members also were able to assist the kindergarten through third grade classrooms, allowing the ER program to have a much broader impact in the school.

I would send over some of my FIRST $^{\circledR}$ LEGO $^{\circledR}$ League kids with those robots and they would work with the lower kids. And so I kind of took the stress off of the teacher of having to know how to do it because I was sending over students who had already had experience with it and knew how to present, and knew how to work with kids. And so you know it made a huge transition for the whole school because then I had kindergarten, first grade teachers, second grade teachers, wanting to do the robotics because they weren't afraid because they had five kids there who could help their students if there was a problem (Subject 55).

Mindy reported that her team members became more active in their own learning, developing skills to identify a problem, research solutions, and develop their own solution.

[FIRST $^{\circledR}$ LEGO $^{\circledR}$ League Jr. allowed] them to be creative, instead of me saying, "this is how you have to build it, this is how you have to do it," for me to be able to say, "here are all the materials, now you come up with something," or "you follow the directions," or "you watch the videos, you do that." Instead of me taking ownership I was able to relinquish that, and it was easier for me to relinquish it (Subject 55).

$F_{I R S T^{\circledR}}$ LEGO $^{\circledR}$ League Jr. encourages students to research a problem, document their questions, conduct research, identify possible solutions, test their ideas, analyze the results, and communicate their findings.

I learned a lot about the engineering design process, which is something that was new to me, and so then I was able to incorporate that within my curriculum, and science a lot. 
And now I'm to the point right now when I give a test I always give an engineering design question. . . I gave them a list of materials, criteria, and constraints, and they had build a bookmarker using only the materials that I gave them. And then they had to write about how did they plan for it, how did they test or it, how did they ... determine that it successfully met the criteria? And I think it gave them a whole new way of thinking about things, as well as me (Subject 55)!

The robotics teams served as role models for the rest of the school. Their interest in science, engineering, and presenting their solutions at the expositions became a source of pride for the entire school. Mindy stated, "the enthusiasm in my school greatly increased because, ... the rest of the school could see what the FIRST ${ }^{\circledR}$ LEGO $^{\circledR}$ League team is doing." One of the most unexpected outcomes was the cultural shift in the attitudes of all members of the team, the class as a whole, and on the teacher herself. Involvement in the after-school robotics program fostered a teamwork mentality that influenced not only those students' interest and engagement in learning, but the class as a whole. Mindy stated,

I know I changed as a teacher, and I know my students were excited and thrilled. I was more excited to come to school; they were excited to come to school, and that level really grew. We became more of a team than just a class, and I think that team mentality was throughout my whole year. We are a team and everybody comes and everybody has a part to play. Everybody has their strengths. Everybody needs to rely on one each other. I think that [attitude] really grew in my classroom starting at the beginning of the year with FIRST ${ }^{\circledR}$ LEGO $^{\circledR}$ League Jr.

Mindy was the only one of the 10 participants who completed all three surveys and the phone interview who also participated in FIRST $^{\circledR}$ LEGO $^{\circledR}$ League. Comparisons to other nine 
educators who also used robotics with elementary students reveal all participants experienced very successful implementations of ER in classroom settings, but none involved the cultural, emotional, and pedagogical shifts seen from the case study. One parallel in the classroom integration is that peer mentoring, when used, played a key role in the success of using the technology with students. One key difference is that participation in an after-school team requires a very committed parent or teacher to manage and coordinate team meetings, a dedicated robot for each team, as well as financial commitments for items such as registration, travel, and t-shirts for students. Until robotics earns parity with other team-based sports, teachers

\section{FIRST $^{\circ}$ LEGO $^{\circ}$ League Jr. IMPACT}

Coaches indicate that the majority of team members experienced gains on a
number of outcomes as a result of participating in FIRST LEGO League Jr.:

STEM AWARENESS, SKILLS, INTENT
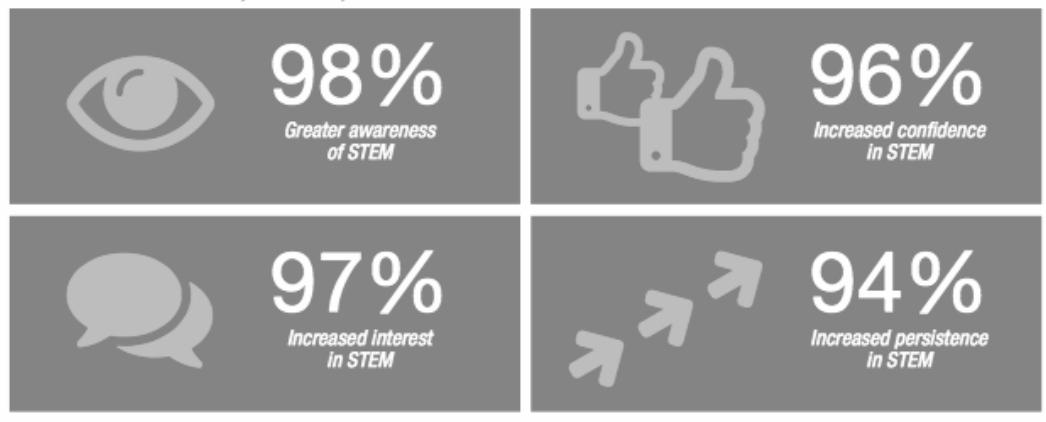

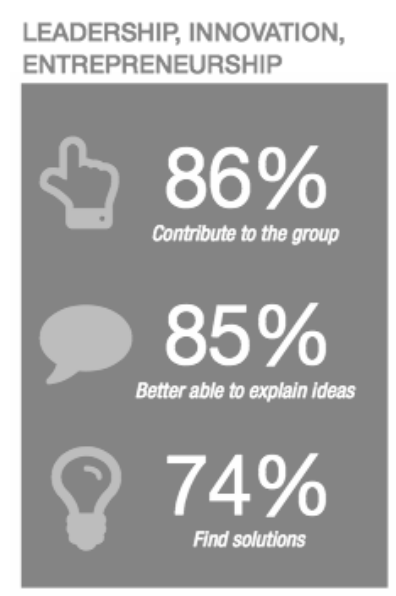

LEADERSHIP, INNOVATION,

21ST CENTURY WORK-LIFE SKILLS
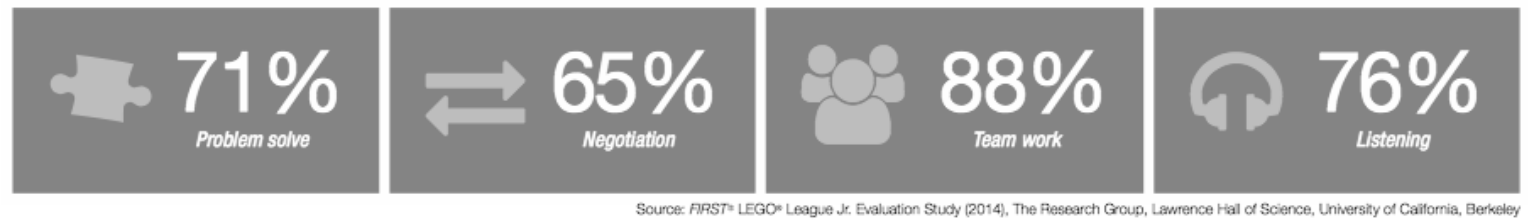

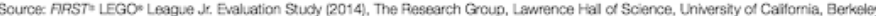

\section{NPIRST.}

FOR INSPIRATION \& RECOGNITION OF SCIENCE \& TECHNOLOGY

firstinspires.org

Figure 8. FIRST ${ }^{\circledR}$ LEGO $^{\circledR}$ League Jr. impact chart depicting gains across a number of disciplines for students participating in the program. From "FIRST ${ }^{\circledR}$ LEGO $^{\circledR}$ League Jr. Evaluation Study (2014), The Research Group, Lawrence Hall of Science, University of California, Berkeley 
who are interested in coaching a robotics team are volunteers. They don't enjoy the same access as do other coaches to school facilities, financial support from a booster club, access to a travel budget and school bussing, and other resources and incentives. Additionally, participation in these team based robotics initiatives requires attendance at Saturday events, which poses another logistical and commitment challenge for classroom educators. Most often, FIRST $^{\circledR}$ LEGO $^{\circledR}$ League Jr. teams are coached by parents outside of a school environment, which makes Mindy's experience especially unique. $F I R S T^{\circledR}$ sponsored research corroborates Mindy's experience and has shown that participation in LEGO $^{\circledR}$ League Jr. has a positive impact on students across a range of measures including: STEM awareness, skills, and intent; leadership, innovation, and, entrepreneurship; and $21^{\text {st }}$ century work-life skills (Figure 8).

Retrospective question one. Does the elementary level educational robotics workshop result in a statistically significant difference $(p<.017)$ between $K-5^{\text {th }}$ grade educators with and without prior educational robotics experience when comparing their pre-workshop attitudes of the educational utility of the technology, and their ability, and intent to use it? Analysis of the demographical data led the researcher to consider a retrospective question to understand what impact, if any, prior experience had on the participants' attitudes toward educational robotics. Both on the questionnaire and during the phone interviews, the participants were asked if they had prior experience with robotics platforms taught by the NASA ERC, including LEGO ${ }^{\circledR}$ WeDo 1.0 (older model than is used in this research), or the LEGO ${ }^{\circledR} \mathrm{NXT}$ (a larger model). While the majority of participants came to the workshop with no prior knowledge of robotics, 16 indicated they had been trained in the past on one or more of the above-mentioned platforms. This dichotomy led the researcher to question the impact of prior knowledge on the pre-workshop survey levels when comparing the two groups (users and non-users). One potential impact is that 
of a ceiling effect (Cramer \& Howitt, 2004), a serious concern for the ability to detect change in attitudes.

The purpose of addressing this question is to determine if the group with prior experience is significantly different from the group without prior experience. If a significant difference exists, the researcher will examine in which direction (higher or lower pre) does the data skew, and if that represents a risk to the reliability of this data or has implications for future research. An examination of the two groups pre-workshop averages on the 18-question survey indicated that participants with prior experience scored higher than their peers without prior experience (Table 10) for all subscales.

Table 10

Mean Scores for Pre-Workshop Survey Comparing Prior Use Versus Non-Prior Use.

\begin{tabular}{|c|c|c|c|c|c|c|}
\hline & \multicolumn{6}{|c|}{ Pre-Workshop } \\
\hline \multirow[t]{2}{*}{ Subscale } & \multicolumn{2}{|c|}{ Ability } & \multicolumn{2}{|c|}{ Utility } & \multicolumn{2}{|c|}{ Intent } \\
\hline & $M$ & $S D$ & $M$ & $S D$ & $M$ & $S D$ \\
\hline No Prior Use ${ }^{a}$ & 3.32 & .69 & 4.11 & .62 & 4.05 & .62 \\
\hline Prior Use ${ }^{b}$ & 4.02 & .71 & 4.54 & .36 & 4.46 & .46 \\
\hline$d f$ & \multicolumn{2}{|c|}{98} & \multicolumn{2}{|c|}{$34^{\mathrm{d}}$} & \multicolumn{2}{|c|}{98} \\
\hline$t$ & \multicolumn{2}{|c|}{3.71} & \multicolumn{2}{|c|}{3.81} & \multicolumn{2}{|c|}{2.50} \\
\hline$p^{c}$ & \multicolumn{2}{|c|}{$<.001$} & \multicolumn{2}{|c|}{.001} & \multicolumn{2}{|c|}{.014} \\
\hline
\end{tabular}

Note. Mean values calculated for the prior use and no-prior use groups across all three subgroups for two times, Pre-Workshop and Post-Workshop.

${ }^{\mathrm{a}} n=84$ for No Prior Use participants.

${ }^{\mathrm{b}} n=16$ for Prior-Use participants.

${ }^{\mathrm{c}}$ Significance (2-tailed) $p<.017$ for a Bonferroni correction

${ }^{\mathrm{d}}$ Pre-Workshop Utility results use Welch-Satterthwaite method

An independent-samples $t$-test (Table 10) was conducted to compare pre workshop results for each subscale comparing participants with prior robotics use $(n=16)$ to those without prior use $(n=84)$. A significant difference $(p<.017)$ was observed between the prior use and no prior use groups for each subscale (ability, utility, and intent) on the pre-workshop survey. The Pre-Utility subscale violated a test of homogeneity of variances so the Welch-Satterthwaite method was 
used which does not assume equal variances, reducing the degrees of freedom. These findings document that the educators in this study who have previous exposure to ER also have higher pre-workshop attitudes of their ability to use ER, utility value for ER, and intent to use ER with students. This statistically significant difference indicates that prior training on or experience with ER has lasting effects on teacher attitudes. Several factors may be contributing to this difference including: (a) selection effects, i.e., these educators, due to a prior positive ER experience, chose to attend this workshop while other teachers who disliked ER chose not to attend; (b) a ceiling effect, i.e., the prior experience group entered the study with average scores over 4.5 (on a scale of 1-5), suggesting that multiple exposures to ER may not improve teacher attitudes because they are already as high as possible; and, (c) the instrument is not sensitive enough to measure the range of attitudes and could be improved by increasing to a seven or nine point scale (Preston \& Colman, 2000). Future studies may need to consider a design that recruits a random sample over a convenience sample, excluding educators with prior experience, or developing a new test that addresses their persistence of attitudes toward ER.

Retrospective question 2. Does the elementary level educational robotics workshop result in a statistically significant difference $(p<.05)$ in the pre-to post-workshop attitudes of K-5th grade educators of the educational utility of the technology, and their ability, and intent to use it when grouped by 0-10,11-20, and 21+ years of teaching experience? When considering implications of the research and how they may inform policy recommendations, it is appropriate to recognize that administrators often must make decisions about how to best utilize limited resources. Given that training time for classroom educators is limited and can be costly, knowledge that professional development in the field of ER is more or less effective with certain populations can help to prioritize target audiences. Overall, the participants' pre- to post- 
workshop attitudes for the subscales ability, utility, and intent significantly increased, but to aid in identifying which educators are most likely to implement ER in their classroom, a comparison between three subgroups was conducted. Subjects with 0-10 years $(\mathrm{n}=50), 11-20$ years $(\mathrm{n}=$ $25)$, and 21 and up years $(n=21)$ of teaching experience were compared across all subscales for the pre- to post-workshop survey data (Table 11). There was a statistically significant difference for the $0-10$ years of experience sub-group across all subscales while the 11-20 and $21+$ years of experience subgroups only showed a statistically significant difference in the ability subscale.

These differences were associated with large effect sizes: $\eta_{\text {partial }}^{2} \geq .14$.

Table 11

Pre/Post Workshop Mean Values and One-Way ANOVA with Repeated Measures Comparing Years of Experience.

\begin{tabular}{llllll}
\hline Subscale (subgroup) & $M$ pre & $M$ post & $F$ & $p$ & $\eta_{\text {partial }}^{2}$ \\
\hline Ability $\left(0-10\right.$ years) $^{\mathrm{a}}$ & 3.39 & 4.28 & 77.62 & $\leq .001$ & .61 \\
Utility $\left(0-10\right.$ years) $^{\mathrm{a}}$ & 4.19 & 4.48 & 27.40 & $\leq .001$ & .36 \\
Intent $\left(0-10\right.$ years) $^{\mathrm{a}}$ & 4.16 & 4.41 & 13.01 & $\leq .001$ & .21 \\
Ability $\left(11-20\right.$ years) $^{\mathrm{b}}$ & 3.59 & 4.21 & 23.28 & $\leq .001$ & .49 \\
Utility $\left(11-20\right.$ years) $^{\mathrm{b}}$ & 4.27 & 4.46 & 3.79 & $.063 \mathrm{n} / \mathrm{s}$ & .14 \\
Intent $\left(11-20\right.$ years) $^{\mathrm{b}}$ & 4.18 & 4.37 & 3.51 & $.073 \mathrm{n} / \mathrm{s}$ & .13 \\
Ability $\left(21+\right.$ years) $^{\mathrm{c}}$ & 3.32 & 3.96 & 9.18 & .007 & .32 \\
Utility $\left(21+\right.$ years) $^{\mathrm{c}}$ & 4.11 & 4.33 & 2.12 & $.161 \mathrm{n} / \mathrm{s}$ & .10 \\
Intent $\left(21+\right.$ years) $^{\mathrm{c}}$ & 4.03 & 4.28 & 2.96 & $.101 \mathrm{n} / \mathrm{s}$ & .13 \\
\hline
\end{tabular}

Note. One-way ANOVA with repeated measures, significant at $p<.05$.

${ }^{\mathrm{a}} \mathrm{n}=50 ;{ }^{\mathrm{b}} \mathrm{n}=25 ;{ }^{\mathrm{c}} \mathrm{n}=21$.

$\mathrm{n} / \mathrm{s}=$ Not Significant

The Shapiro-Wilk test did reveal that there was a violation of the normality assumption for all the subscales and subgroups with the following exceptions: 0-10 years pre-ability; 11-20 years pre-ability, pre-intent, post-ability; 21 + years pre-ability, pre-utility, pre-intent. However, oneway repeated measures can withstand some violation to normality (Laird Statistics, 2013). 


\section{Chapter Five Summary, Conclusions, Implications \& Recommendations}

\section{Summary}

Over the past decade, growth in Science, Technology, Engineering, and Mathematics (STEM) occupations grew at a rate six times faster than non-STEM occupations, and are projected to continue outpacing non-STEM careers over the next decade (Noonan, 2017). These careers also command higher wages, experience lower unemployment, and they can help our nation stay competitive in the increasing knowledge-based economy (Economics and Statistics Administration, 2011). Despite the increased need for STEM jobs, U.S. higher education institutions are not increasing their number of STEM graduates at an adequate rate (Doershuk et al., 2016). This shortfall can be attributed partially to K-12 students' lack of adequate preparation to enter post-secondary STEM degree programs, and K-12 systems' failure to motivate students in math and science (Thomasian, 2011). In response, there has been a call to arms to engage K-12 students in STEM from the Whitehouse (President's Council of Advisors on Science and Technology, 2012) to industry leaders such as Dean Kamen (Karsten, 2016) who founded the non-profit robotics competition organization For the Inspiration and Recognition of Science and Technology $\left(\right.$ FIRST $\left.^{\circledR}\right)$. The influence of STEM can also be seen in the Next Generation Science Standards (NGSS) which integrate Science and Engineering Practices (NGSS, 2013).

In the decade since the landmark report Rising above the gathering storm: Energizing and employing America for a brighter economic future (National Academies, 2007), which served as a wake-up call to the U.S. about the importance of investing in K-12 science and mathematics education as a means to secure our economic future, there has been growing recognition among educators about what STEM is, and the importance of incorporating STEM 
into classroom instruction (Shernoff, Sinha, Bressler \& Ginsburg, 2017). This study explores one approach to preparing elementary educators to utilize robotics as a means of engaging and inspiring young minds in STEM disciplines and toward career pathways.

Educational Robotics (ER) is a rapidly expanding approach to teaching mathematics and science concepts through the application of engineering practices and computer coding to solve real-world problems. ER is based on the educational theories of Piaget's constructivism, 1972, Papert's constructionism (Papert, 1993), and computational thinking (Brennan \& Resnick, 2012). Papert's work in the field of ER directly led to the development of the LEGO ${ }^{\circledR}$ Mindstorms product line, which today provides millions of students with STEM activities that engage them in engineering practices, spatial and computational thinking, and coding (Cristóforis et al., 2013). Extant research is limited on models for integrating STEM activities into elementary education (Jaipal-Jamani \& Angeli, 2017). This lack underlies the purpose of this study: to examine the impact of an ER teacher professional development program — a workshop on LEGO ${ }^{\circledR}$ WeDo 2.0, and follow-up implementation, with elementary students on educators' attitudes of their ability to use ER, its utility in the classroom, and their intent to use it with students.

Research questions. Four research questions (RQ) were investigated (RQ1-RQ4) along with one post hoc question for RQ2, and one retrospective question:

RQ1： Does the elementary level educational robotics professional development workshop result in statistically significant $(p<.05)$ gains with at least a medium effect size $\left(\eta_{\text {partial }}^{2}>.06\right)$, in K-5 ${ }^{\text {th }}$ grade educators' attitudes about the educational utility of the technology, and their ability, and intent to use it?

RQ2: Does implementation of the elementary level educational robotics activities using the LEGO ${ }^{\circledR}$ WeDo robotics result in statistically significant $(p<.05)$ gains with at 
least a medium effect size $\left(\eta_{\text {partial }}^{2}>.06\right)$, in K-5 ${ }^{\text {th }}$ grade educators' attitudes about the educational utility of the technology, and their ability, and intent to use it compared to their post professional development experience?

Post hoc one: Do users of ER with students $(n=16)$ and non-users $(n=17)$ vary in any significant way (at the $p<.05$ level) on the subscales of ability, utility, or intent on the post-workshop survey and at the time of the post-post survey? Post hoc two: Do non-users of the elementary level ER activities result in statistically significant $(p<.05)$ gains with at least a medium effect size $\left(\eta_{\text {partial }}^{2}\right.$ $>.06)$, in $\mathrm{K}-5^{\text {th }}$ grade educators' attitudes about the educational utility of the technology, and their ability, and intent to use it compared to their post professional development experience?

RQ3: What themes emerge from the interviews with $\mathrm{K}-5^{\text {th }}$ grade educators who did/did not implement the robotics activities with students, and in what ways do they illuminate findings from the survey?

RQ4: Did any elementary educators also provide an after-school experience such as FIRST $^{\circledR}$ LEGO $^{\circledR}$ League Jr., and if so what impact, if any, did that have on their attitudes compared to educators who did not participate in such a program?

Retrospective question one: Is there a statistically significant difference between K-5th grade educators with and without prior educational robotics experience when comparing their pre-workshop attitudes of the educational utility of the technology, and their ability, and intent to use it?

Retrospective question two: Does the elementary level educational robotics workshop result in a statistically significant difference $(p<.05)$ in the pre- to post-workshop 
attitudes of K-5th grade educators of the educational utility of the technology, and their ability, and intent to use it when grouped by $0-10,11-20$, and $21+$ years of teaching experience?

Methodology. Subjects were recruited for this study from a sample of convenience and required to be formal or informal educators of students in kindergarten through fifth grade. A total of 100 participants began the study $(N=100), 33$ participated in the post-post survey $(n=$ $33)$, and 21 completed a telephone interview $(n=21)$. Subjects self-selected to attend a fourhour professional development workshop on elementary educational robotics (LEGO ${ }^{\circledR}$ WeDo 2.0) conducted at the NASA IV\&V ERC, a university extension office, a science center, one intermediate school, or three elementary schools between September 13, 2016 and March 16, 2017. All participants were asked to complete a demographics form, a pre- and post-workshop survey, and to sign up to borrow the classroom kit of robots and tablets for use with students. The quantitative instrument is an 18-question survey that measures educators' attitudes of their ability to use the technology, the utility of the technology, and their intent to use it with students. After the participants had the opportunity to borrow and use the kit with students they were asked via email to complete an online version of the instrument (referred in the study as the postpost survey). Thirty-three participants completed the post-post survey $(n=33)$ between March 15 and March 31, 2017, and approximately half $(n=16)$ indicated they were able to implement the ER activities with elementary students. Twenty-one of the 33 educators who completed the post-post survey participated in a telephone interview with approximately half $(n=10)$ indicating they had used ER with students. The demographical and survey data were tabulated and averaged using Microsoft Excel (v. 15.26) and statistical tests were conducted using IBM SPSS (v. 24). RQ1 used one-way ANOVA with repeated measures along with a Wilcoxon 
matched-pairs signed-ranks tests to determine if there were statistically significant $(\mathrm{p}<.05)$ changes in the pre- to post-workshop survey results. RQ2 used one-way ANOVA with repeated measures to determine if there were statistically significant $(p<.05)$ changes in the post- to postpost survey results as well as one-way ANOVA to answer a post hoc question comparing users and non-users. The qualitative data (RQ3-RQ4) was collected via a recorded phone interview, which was saved digitally as an .MP3 file, transcribed to Microsoft Word (Version 15.26), and coded using Microsoft Excel. Content analysis with the inclusion of frequency and inductive analysis of the interviews were employed to answer RQ3-RQ4 as well as to triangulate the qualitative and quantitative findings associated with RQ1-RQ2. The retrospective question used SPSS to conduct an independent samples (between subjects) $t$-test comparing the participants with and with-out prior robotics experience.

Findings. A one-way ANOVA with repeated measures revealed that participation in the elementary level ER workshop did have a statistically significant effect on $\mathrm{K}-5^{\text {th }}$ grade educators' attitudes, with increases across all three subscales of ability, utility, and intent $(p=<.001)$ on the pre- to post-workshop test. The effect sizes were medium to large for ability, utility and intent: $\eta_{\text {partial }}^{2}=.50, .23$, and .16 respectively (Table 2$)$. The largest gains and effect size were observed in the subscale ability to use ER $(M=3.43$ to $M=4.19)$. Method triangulation was performed with quantitative (survey) and qualitative (interview) data to increase the meaning and validity of the findings. The participants reported that: the workshop increased their confidence and ability to implement robotics ( $80 \%$ users, $91 \%$ of non-users); that hands-on robotics activities increased student motivation and engagement in STEM and/or cross curricular learning ( $100 \%$ of users, $64 \%$ of non-users); and that the kits were organized, easy to use, and increased 
their confidence to use robotics with students (60\% users, 55\% non-users). Every participant interviewed indicated they intended to use the robotics kit with students.

A one-way ANOVA with repeated measures revealed that using robotics kits with students did not have a statistically significant effect on any of the subscales (ability, utility, or intent) for the participants who had used robotics with student $(n=10)$. Qualitative data supported the theory that participants who used robotics kits with students felt adequately prepared and had positive experiences, suggesting a persistence of their already high attitudes of ER. Post-workshop mean scores for users ranged from 4.08 to 4.29 out of 5 (Table 4). Interviews with the participants indicated that $90 \%$ of students enjoy doing STEM activities with robotics; $80 \%$ responded that robotics increased student engagement through hands-on learning; and $80 \%$ suggested that they were able to implement robotics easily due to increased confidence from the workshop.

A one-way ANOVA comparing users and non-users indicated these groups differed significantly on the post-workshop test $(p<.025)$ with non-users mean scores higher for all three subscales. No statistical significance was found for the comparison of users and non-users on the post-post test comparison across all three subscales.

Qualitative data was assessed with both frequency and inductive analysis for emergent themes and revealed general consistency across the two groups with the greatest variance between users and non-users in observations of student engagement. The transcripts provided hundreds of codes which were combined to form 14 categories, and further consolidated to seven themes, each representing over $50 \%$ of participants, which were used in closed coding. Examination of the results led to two assertions: (a) The organized and appropriately sized kits, along with the practical classroom management strategies covered in the workshop are 
requirements for successful implementation of educational robotics in classrooms; and (b) The "hands-on", technology-based, cooperative, creative nature of educational robotics, increases student engagement in STEM and/or cross-curricular learning, which is valued by educators. Triangulation of the qualitative and quantitative findings demonstrated data convergence, affirming that the workshop had a significant impact on educators' attitudes of ability to use ER, the utility of the technology, and their intent to use it with students.

One participant from this study also coached two FIRST ${ }^{\circledR}$ LEGO $^{\circledR}$ League Jr. teams in an after-school setting. Data from both interviews with this teacher revealed one overarching assertion: Participation in FIRST $^{\circledR}$ LEGO $^{\circledR}$ League Jr. (after-school) increased the skills, confidence, and engagement of both the teacher and students (during school) which led to: (a) the integration of engineering practices; (b) the practice of peer-mentoring; and (c) school-wide interest in educational robotics.

An independent-samples $t$-test revealed that previous experience did result in a statistically significant difference between participants who entered the study with prior experience $(n=16)$ compared to their peers who had not been trained in or used educational robotics $(n=84)$ before the workshop. Mean scores across all three subscales of ability, utility, and intent were higher for participants with prior experience.

Years of teaching experience is a predictor for educators' attitudes of utility of the technology and intent to use it. A one-way ANOVA with repeated measures revealed a statistically significant difference for the $0-10$ years of experience sub-group $(n=50)$ across all subscales, while the 11-20 and $21+$ years of experience subgroups $(n=25 ; n=21$ respectively) only showed a statistically significant difference in the ability subscale. The increases in attitudes of ability were associated with large effect sizes: $\eta_{\text {partial }}^{2} \geq .14$. 


\section{Conclusions}

Conclusions for this study based on the major findings are presented by research question. Each subsection will address rationale and interpretation connected to each finding.

Research question one. Research question one asks: Does the elementary level educational robotics professional development workshop result in statistically significant ( $p<$ .05) gains with at least a medium effect size $\left(\eta_{\text {partial }}^{2}>.06\right)$, in $K-5^{\text {th }}$ grade educators' attitudes about the educational utility of the technology, and their ability, and intent to use it? It was concluded that the ER workshop results in statistically significant gains $(p<.001)$ for the subscales of ability, utility, and intent, with medium to large effect sizes $\eta_{\text {partial }}^{2}=.50, .23$, and .16 respectively. The largest gains and effect size were observed in the subscale ability to use ER $(M=3.43$ to $M=4.19)$, which was an expected response to a four hour, hands-on training, particularly when the majority of the participants $(n=84)$ were using robotics for the first time. Teachers' ability to use the ER technology is consistent with Bandura's (1997) concept of selfefficacy, in that teachers' belief in their capabilities to organize and execute a course (i.e. teach robotics) was evident. (Watts, 1996). Bandura describes four means of improving self-efficacy: performance accomplishments, vicarious experience, verbal persuasion, and psychological states (Bandura, 1997). Throughout the workshop, the instructor provided a positive vicarious experience to teachers by demonstrating how to successfully assemble the WeDo 2.0 robot, pair the robot and iPad (via Bluetooth), and use the software to access the training materials as well as how to program the robot. As pairs of educators succeeded in the activities around the room, the participants observed their own peers experiencing success as well, reinforcing this positive vicarious experience. As the educators worked through the various activities, the instructor also provided continual and timely encouragement (verbal persuasion). She intentionally scaffolded 
the experience in such a way that early success was almost certain, as she led activities that enabled teachers to build Milo the Science Rover (performance accomplishments).

The instructor shared on numerous occasions that, "The teachers entered the workshop quiet and timid, but by the first build [Milo] they were laughing and having fun. This happened in almost every workshop" (NASA Education Specialist, personal communication, June 6, 2017). Bandura (1997) suggests that moods, emotions, physical reactions, and stress levels may influence how we feel about our personal abilities. The workshop environment was relaxed, jovial, and at the same time rewarding, and likely affected the participants' positive attitudes of their ability including their familiarity with $\mathrm{LEGO}^{\circledR} \mathrm{s}$ and the Apple iPad operating system (iOS 10.3) and the well-designed programming environment. Triangulation from the qualitative data converged on the measurement of ability and nearly all workshop participants agreed that the, "workshop experience was positive and led to increased educator confidence as well ability to implement robotics activities," acknowledged by $80 \%$ of users and $91 \%$ of non-users.

The statistically significant gains in utility and intent are particularly noteworthy, as the participants self-selected based on their pre-existing personal interest in learning about elementary ER, and were motivated in part by the lure of being able to borrow the pre-organized and charged classroom kit of 12 robots, 12 Pads, and additional instructional materials. The mean pre-workshop values for utility and intent were 4.19 and 4.13 respectively, leaving little room for improvement on a one through five Likert scale. Qualitative data triangulation supports the positive gains in utility, notably in the theme, "Robotics increases student motivation and engagement through 'hands-on' STEM and/or cross curricular learning activities," recorded for $100 \%$ of users and $64 \%$ of non-users. The subscale intent is reinforced by the theme, 
"Educational robotics kits are organized and/or easy to use which increase educator confidence to use with students," which was specifically referenced by $60 \%$ of users and $55 \%$ of non-users.

Research Question Two. Research question two asks: Does implementation of the elementary level activities using robotics result in statistically significant $(p<.05)$ gains with at least a medium effect size, $\left(\eta_{\text {partial }}^{2}>.06\right)$ in $K-5^{\text {th }}$ grade educators' attitudes about the educational utility of the technology, and their ability, and intent to use it compared to their post professional development experience? Implementation of elementary level educational robotics activities does not result in statistically significant change $(p<.05)$ in the attitudes of the educators $(n=15)$ completing the post-post survey, and those who were able to implement ER with their students. This result was initially unexpected for the researcher who theorized that use of the robots with students would increase the attitudes of the educators. Upon further reflection, the result of no significant change supports the theory that the participants experienced a high level of persistence, which could be a result of their opinions being accurately measured in the post-workshop survey and the workshop adequately preparing them to use ER with students. Training appeared to match teachers' classroom implementation experience. Triangulation of qualitative data supports this theory, with the theme, 'Educators valued the practical classroom management strategies, and experiencing the "hands-on" robotics activities they can use with students covered during the workshop," which was reflected by $70 \%$ of users.

A post hoc question asked: Do users of ER with students $(n=16)$ and non-users $(n=17)$ vary in any significant way (at the $p<.05$ level) on the subscales of ability, utility, or intent on the post-workshop survey and at the time of the post-post survey? It was concluded that these groups did vary significantly at the post-workshop, but not at the post-post test (after using robots with students). In contrast to the investigator's assumption, the subgroups were not 
distinguishable on the post-workshop survey, and ER users were not different from non-users as a result of the classroom experience. Non-users scored significantly higher at the post-workshop but at the post-post, both groups were equivalent. However, non-ER users expressed more confidence and ability compared to ER users. Qualitative data triangulation suggests that nonusers frequency was higher for the theme, "The workshop experience was positive and led to increased educator confidence as well as ability to implement robotics activities," with non-ER users at $91 \%$ and ER users at $80 \%$. Loan of the classroom kits for use with students operated on a first-come, first-served basis. The NASA ERC initially only had two kits, leaving one for loans while one was maintained for training. Later in the study, the ERC obtained two additional kits which increased the rate of loans, but still there was a long waiting list, making this (insufficient number of kits available for loan) one of the most significant limitations of the study.

A second post hoc question asked: Do non-users of the elementary level ER activities result in statistically significant $(p<.05)$ differences with at least a medium effect size $\left(\eta_{\text {partial }}^{2}\right.$ $>$.06), in $K-5^{\text {th }}$ grade educators' attitudes about the educational utility of the technology, and their ability, and intent to use it compared to their post professional development experience? RQ2 sought to determine if using ER with students made a significant gain. Post hoc 1 examined if the two groups (users and non-users) varied at the time of post-workshop and postpost. Post hoc two conducted the same test as the ER users by comparing their post to post-post scores for all three subscales to see if that group performed the same as the users. It was concluded that non-ER users leave the workshop with a (significantly) higher and persistent selfefficacy of their ability to use ER than their peers who had the opportunity to implement ER with students. When afforded the opportunity to use ER with students, non-users attitude toward their 
ability would likely decrease, becoming insignificant when compared to their post-workshop survey results.

Research Question Three. Research question three asks: What themes emerge from the interviews with $\mathrm{K}-5^{\text {th }}$ grade educators who did/did not implement the robotics activities with students, and in what ways do they illuminate findings from the survey? The investigator concluded that the process of inductive and frequency analysis of the transcribed interview data (Fraenkel, et al., 2015; Patton, 2002), combined with analyst triangulation (Saldana, 2011; Cresswell et al., 2003; Merriam, 1998) generated 14 categories (Table 5) and seven emergent themes (Table 6) which gave voice to the participants and supported the quantitative findings from the survey data. The emergent themes from the qualitative data illuminated the results of RQ1, that participation in the elementary level ER workshop: (a) increased the participants' ability and confidence to use and teach ER with students; (b) demonstrated pedagogical and organizational strategies which increased the utility of the technology; and (c) increased intent to use ER with students by providing the opportunity to borrow a classroom kit from NASA, or prepared participants to utilize their own kit. All participants intended to borrow robotics kits, or had received funding through a grant to purchase their own kits, further supporting the pre- to post-workshop statistically significant finding that intent to use ER with students increased.

The two assertions, derived through analyst triangulation represent the most relevant and pertinent opinions of the participants. The first assertion states, "The organized and appropriately sized kits, along with the practical classroom management strategies covered in the workshop are requirements for successful implementation of educational robotics in classrooms." It is clear that while the goals of the training are to present an emerging educational robotics platform to teach STEM topics such as engineering design and computer 
coding, the participants identified the very basic classroom and equipment management topics as critical to their success. This reinforces the importance of including these topics in the workshop, and warrants the development of additional resources to further clarify and support educators as they implement ER with students. The second assertion states, “The 'hands-on', technology-based, cooperative, creative nature of educational robotics, increases student engagement in STEM and/or cross-curricular learning, which is valued by educators." The data indicated that ER inspires and engages students to work together in teams, expand their creative thinking, blurs the lines between academic subjects by infusing writing with science and technology, and to help students through peer mentoring. This reinforces the researcher's belief that ER can be a transformative instructional technology, shifting the focus of instruction from the teacher to the student through a constructionist pedagogical approach, and redefining the way students learn. Effective professional development can help move educators towards the center of the TPACK model (Figure 10) where they possess the technological knowledge to use ER with comfort, the ability to use the pedagogical framework of constructionism in their teaching, and the understanding of how to connect ER with their content knowledge in science, mathematics, engineering, language and creative arts, and more.

Although the majority of comments made during the interviews reinforced the positive attributes of the robotics kit, it is important to recognize unique perspectives which if addressed, may have a disproportionately higher potential to improve the delivery of the training or aspects of the kit. Suggestions to provide more hands-on activities and to address methods of assessing the teaching goals are addressed further under the implications for practice.

Research Question Four: Research question four asks: Did any elementary educators also provide an after-school experience, such as FIRST ${ }^{\circledR} L E G O^{\circledR}$ League Jr., and if so what 
impact, if any, did that have on their attitudes compared to educators who did not participate in such a program? One teacher's after-school utilization of ER had an observable impact on her attitudes of educational robotics. FIRST ${ }^{\circledR}$ LEGO $^{\circledR}$ League Jr., as with most robotics program, traditionally serves a relatively small group of students who are able to stay after-school (Barker \& Ansorge 2007; Chung et al. 2014; Karp \& Maloney, 2013; Nugent et al., 2010; Williams et al. 2007). Students benefit by spending extended time deepening their understanding and knowledge of computer coding, problem solving, working as a team, and communicating ideas to others. Only one participant in the study was identified as being involved in leading such a program for students.

Subject 55 (referred to as Mindy) met twice a week after-school with two teams of students from September through December, culminating in presentations at two expositions held at the larger and older FIRST ${ }^{\circledR}$ LEGO $^{\circledR}$ League (ages 9-14) tournaments. The teams attended two expositions where they presented their student generated research project and diorama (model) to a group of judges, and received recognition in front of an audience of parents, faculty, middle school students, and their peers.

Mindy participated in all three surveys, shifting her attitudes from an initial ability, utility, and intent of $4.40,3.83$, and 4.43 respectively on the pre-workshop survey to 5.0 for all three subscales on the post-post. Compared to her peers who did not participate in an afterschool program, Mindy showed a level of enthusiasm for ER shared by only handful of other educators, but most significant was the observed transformation in both herself as a teacher, and her students as active learners. This experience is reflective of a shift from a direct instruction model where the teacher and her knowledge are the focus of the classroom, to a constructionist model that puts the student in charge of building their knowledge through inquiry-based 
activities, and sharing those ideas and what they constructed (Ucgul \& Cagiltay, 2014; Papert, 1999; Ackerman, 1996; Papert \& Harel, 1991). Two interviews with this Mindy revealed seven themes with one overarching assertion. Participation in FIRST ${ }^{\circledR}$ LEGO $^{\circledR}$ League Jr. (afterschool) increased the skills, confidence, and engagement of both the teacher and students (during school) which led to: (a) the integration of engineering practices; (b) the practice of peermentoring; and (c) school-wide interest in educational robotics. The implication is that while both an after-school program as well as a classroom initiative support the integration of STEM, together, the two experiences support one another and can magnify their effects on teaching, learning, and culture. While after-school programs such as $F I R S T^{\circledR}$ LEGO $^{\circledR}$ League Jr. provide a rich experience for a limited number of students $\left(\mathrm{FIRST}^{\circledR}\right.$ LEGO $^{\circledR}$ League Jr. Evaluation Study, 2014), curricular programs such as integrating the $\mathrm{LEGO}^{\circledR}$ WeDo 2.0 kits into a classroom can provide an introductory base-line opportunity for many students. When combined, the afterschool students become peer mentors in their own classroom and technology integration specialists school-wide, thus increasing the effectiveness ER experience for all. Additionally, the students serve as role-models inspiring even more students to seek out participation in the after-school program.

Retrospective question one: The first retrospective question asked: Is there a statistically significant difference between $K-5^{\text {th }}$ grade educators with and without prior educational robotics experience when comparing their pre-workshop attitudes of the educational utility of the technology, and their ability, and intent to use it? Prior experience was concluded to bias the participants pre-workshop attitudes toward the "strongly agree" on all three subscales. Prior training on, or experience with ER, may have lasting effects on educators' attitudes towards ER, as well as possible implications for future research. These participants, unlike their peers 
who were experiencing ER for the first time, entered the study with significantly higher attitudes due to their experience with a similar programming environment, classroom management, and pedagogical approaches which are similar for alternate ER workshops offered by the NASA ERC (LEGO ${ }^{\circledR}$ WeDo 1 and the LEGO $^{\circledR}$ NXT platforms). Triangulation with the qualitative data indicated that prior experience limited the perspective of some participants to drawing comparisons with other versions of ER over observations of this workshop, e.g.,

The WeDo 1.0's - the problem is, everything has to - the cords - sometimes the cords get away, because you have to connect the. . motor . . . to a USB port directly into the computer and sometimes you know the kids - those come out, they come loose, they get damaged; so that's the only thing I didn't like about the WeDo 1.0's. The WeDo 2.0 is Bluetooth technology - Bluetooth capability. We can use it on a lot more different platforms. The WeDo 1.0's we have to have a USB port, it has to be hooked to a laptop, you can't use. . . any Apple iPads (Subject 92).

While the comparison is constructive to illustrate the benefits of the newer platform, it is clear that a separate set of questions for interviews, and possibly a separate survey instrument should be employed for participants with prior experience.

Retrospective question two: The second retrospective question asked: Does the elementary level educational robotics workshop result in a statistically significant difference ( $p$ $<.05)$ in the pre-to post-workshop attitudes of K-5th grade educators of the educational utility of the technology, and their ability, and intent to use it when grouped by 0-10, 11-20, and 21+ years of teaching experience? Regardless of the tenure of the educator, the subscale ability increased significantly with large effect sizes as a result of the workshop. However, this was not the case for utility and intent, in which only those with 0-10 years of experience realized 
statistically significant increases. Therefore, in this study, the conclusion is that years of teaching experience makes a difference as to the extent to which participants' increase their attitudes about the utility of and intent to use ER. This finding may assist administrators in prioritizing staff members with $0-10$ years of experience to receive training in ER, and further may indicate that the most effective time to provide ER training is during their early years as an educator or even at the preservice level. Possible explanations for this result are that the experienced educators have more successful techniques and methods of covering the required standards, and are resistant to changing what they know works well. Educators with less experience tend to be younger and have grown up using technology, which may contribute to positive attitudes towards using an emerging tool such as ER.

\section{Implications for Practice and Policy}

This study examined the impact of a four-hour professional development workshop on educational robotics on $\mathrm{K}-5^{\text {th }}$ grade educators' attitudes of their ability to use the technology, the perceived utility of the technology, and teachers' intent to use ER with students. The research questions were designed to gain an understanding of how the educators' attitudes changed over time, as well as how factors such as prior experience and use of ER with students affected their attitudes. Findings from this study may assist in refining the delivery of future professional development, identifying additional instructional resources or approaches which may improve the effectiveness of the robotics kit for most effective classroom use, and addressing implications for policy such as how ER can align to the Next Generation Science Standards.

Educational robotics programs have been shown to increase K-12 students' understanding of STEM concepts, and can develop students' self-confidence and interest in STEM (Nugent et al. 2015). As educators struggle to adapt their current science teaching 
practices to meet the new interdisciplinary requirements of the Next Generation Science

Standards, ER has the potential to simultaneously engage and inspire students in science, integrate the STEM disciplines, and build connections to STEM careers. One challenge is a lack of validated models for preparing educators, particularly at the elementary level, to effectively use robotics in their classrooms (Jaipal-Jamani \& Angeli, 2017). The lack of research on uses of appropriate robotics platforms for elementary learners, reliable techniques for delivering professional development in ER, or standardized instruments that can reliably measure elementary educators' self-efficacy (Watts, 2017) for robotics instruction motivated this research project.

Professional development workshop. The elementary educator workshop was delivered as consistently as possible for the 13 sessions that were the focus of this study (Appendix F). Going forward, it is important to identify areas for improvement based on the input of the educators' comments and observations captured through the 21 interviews conducted with users and non-users. Although the majority of comments made during the interviews reinforced the positive attributes of the robotics kit, it is important to recognize unique perspectives, which if addressed, may have a disproportionately higher potential to improve the delivery of the training.

Participants comments indicated that the workshop was too short and did not devote sufficient time to doing hands-on activities. This concern can be addressed by reducing the amount of introductory materials about NASA and the various ERC programs, and by extending the workshop by 30 minutes for participants who have never attended a NASA ER workshop. The early-start time will allow an opportunity for this important material to be covered, while giving some who may have covered it several times previously the chance to start a bit later. 
Other concerns included the need for attention to participants' special needs (e.g. difficulty distinguishing the colors of the programming blocks) and the need to access the Apple iPad's accessibility features of the iPad at the beginning of each workshop.

While only one participant indicated that the kit should have clearer learning objectives, rubrics for assessment, and a trouble-shooting guide, this may be the most valuable suggestion to improving the effectiveness of both the workshop and the kit. Fortunately, LEGO ${ }^{\circledR}$ Education has recently made all of their training materials freely available for download, which includes a 217-page teacher guide that contains specific learning objectives, rubrics, correlations to standards, and more. Troubleshooting resources are available at the LEGO $^{\circledR}$ Education website (https://education.lego.com/en-us/support/wedo-2).

Connections to the instructional models and pedagogical approaches employed by ER need to be more explicitly addressed to improve educators' metacognitive awareness of TPACK and constructionism. The potential impact, and thus the importance of starting an after-school robotics team and how create one should also be addressed during the workshop. Figure 9 depicts the Technological, Pedagogical and Content Knowledge (TPACK) model on the left, with the phases of implementation as a result of participation in the ER workshop on the right. Starting at the bottom, most educators enter the workshop with content knowledge but little knowledge of this technology or the pedagogical approaches aligned with ER. As participants complete the workshop and move into implementation with students, they progress toward the center of the TPACK diagram. Based on this research, a high level of constructionist learning occurred in the site that participated in the after-school team-based program. The students who were exposed to ER prior to classroom use not only took charge of their own learning, but they served as peer mentors and instructional aides. While too limited to draw clear conclusions, this 
result is an encouraging outcome that warrants greater research.

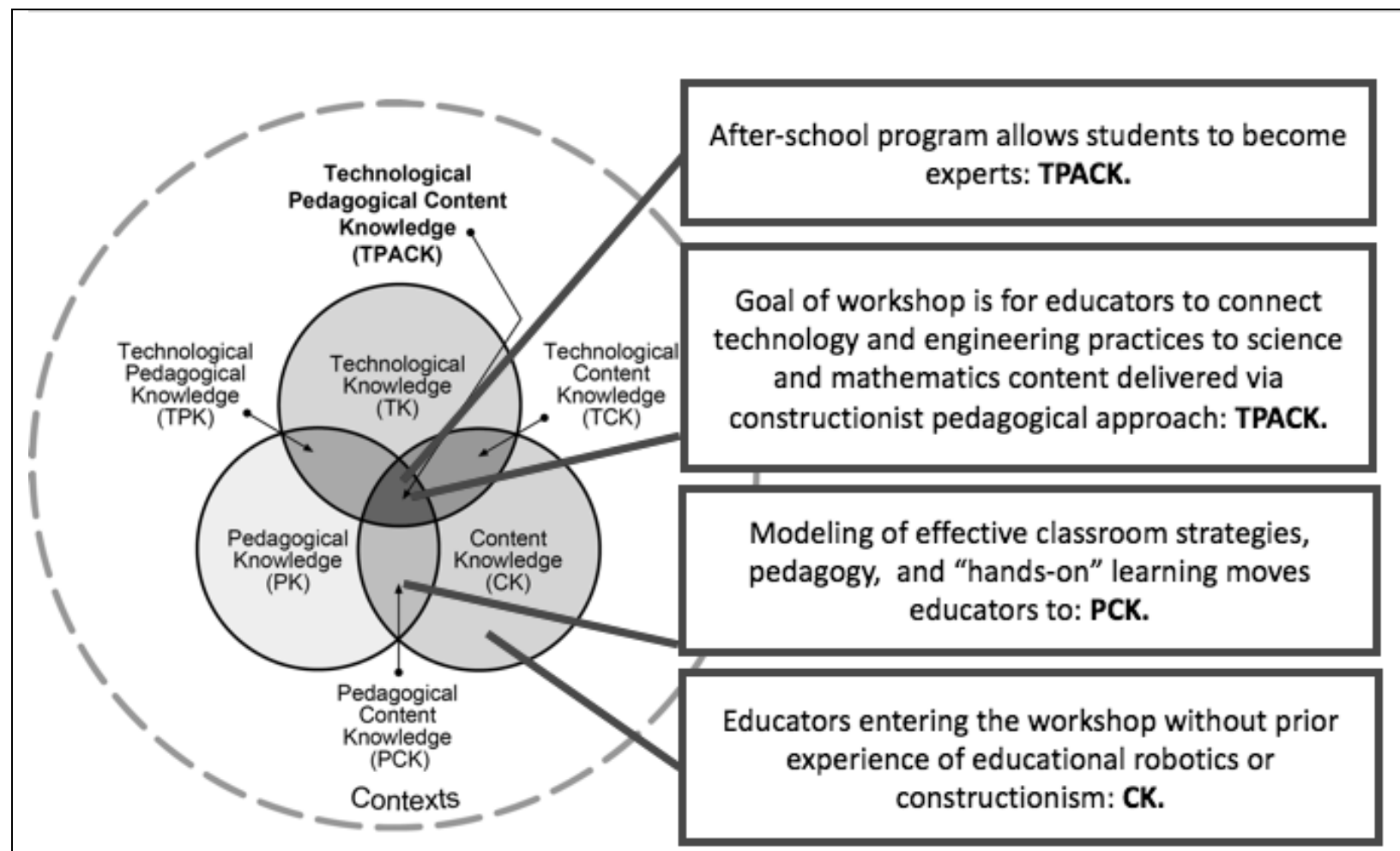

Figure 9. Educational Robotics Workshop Objectives with TPACK.

TPACK model. Adapted from “TPACK Model” by TPACK.org, 2012, Retrieved April 17, 2016 from http://tpack.org. (Reproduced by permission of the publisher, (C) 2012)

Given the greater potential for shifting the attitudes of educators with less experience, the workshop opportunity and limited classroom kits could be targeted towards preservice through those with 10 years of experience. While not part of this study, the same LEGO ${ }^{\circledR}$ WeDo 2.0 workshop was delivered to a university science methods class $(n=17)$ and in their final course evaluation the preservice teachers indicated the most useful and likely to be implemented topic of the semester was robotics (J. Rye, personal communication, July 11, 2017).

Educational robotics classroom kit. The NASA ERC loans classroom kits to educators who successfully complete the professional development workshop: a model that has been used successfully by the ERC for almost two decades. While the approach is sound, qualitative data from the interviews identified numerous ways the elementary ER classroom kits could be 
modified or improved.

Several participants reflected in the interview that managing 12 stations of students can be challenging without a second instructor or an aide. The educators who reported this concern largely solved it by scheduling an aid, additional teacher, technology integration specialist, or teacher of the gifted to accompany the kit: This solution will be shared at future ER workshops.

Educators who did not teach a traditional schedule, such as teachers of the gifted who travel school to school identified the NASA ERC's loan period of two-weeks as too short when they are only able to meet with a group of students once a week. For these educators, who most often don't need a classroom kit of 12 robots and tablets, a solution is to create two smaller kits with a set of six, that may be signed out for a longer duration. This concern can also be solved by assisting the school district in writing a grant to obtain their own equipment, thus eliminating the need to borrow a kit and providing a year-round ER program with potential for after-school programming for those students. A related concern is that some classrooms have as many as 30 students, and a class set of 12 robots and tablets causes groups of three and shortages of materials. To meet this need, a classroom kit of 15 robots will be developed that can be loaned to schools.

A common concern was a fear of losing $\mathrm{LEGO}^{\circledR}$ pieces, or keeping the kit organized. To address this, the kits loaned by the NASA ERC are already clearly labeled with robots paired to iPads and a storage container with pictures depicting which cubby is for each part (Figure 4). While the class set provided by the NASA ERC already contains one additional WeDo 2.0 kit that is used for spare parts, this can be expanded for very little expense to help reduce this fear of implementation. 
Alignment with NGSS. Educational robotics can engage students and connect STEM disciplines through a constructionist pedagogical approach, which aligns with the Next Generation Science Standards (NGSS)'s three dimensional learning: practices, crosscutting concepts, and disciplinary core ideas (Ortiz, Bos, \& Smith, 2015; NGSS, 2013). One of the strengths of the LEGO ${ }^{\circledR}$ WeDo 2.0 curriculum (The LEGO Group, 2016) that is included with the programming software, is that it was built from the ground up to support teachers in states that have adopted NGSS. Educational robotics, like STEM, is not just a what, it is a what and how. Using ER and STEM with students describes an approach to teaching and learning -not a subject or a standard - a method. Educational robotics is a tool to provide students with opportunities to develop the science and engineering practices which lay the groundwork for the NGSS (NGSS, 2013). Looked at through one of the guided activities on Speed in the WeDo 2.0 curriculum (The LEGO Group, 2016) it is easy to see how well ER fits with the 8 practices of this experiential approach to learning.

1. Asking questions and defining problems-How can a car go faster?

2. Developing and using models-Students build a working model of a car.

3. Planning and carrying out investigations-Students change the power to the motor or the ratio of motor to the wheel to change speed.

4. Analyzing and interpreting data-Students measure, record, and graph time and distance to understand velocity as well as proportionalities and energy.

5. Using mathematics and computational thinking-Students use logic, patterns, and mathematics to change the program and model different simulations using the computer. Proportional ratios can be calculated to solve for specific distances.

6. Constructing explanations and designing solutions-Explain why car changed speed. 
7. Engaging in argument from evidence-Students use observations and data explain how to make the car go faster, slower, and why this works.

8. Obtaining, evaluating, and communicating information-Students use the journal tool to take photos and make notes of your car and experiments, then present their findings to the class.

NGSS's crosscutting concepts are an organizational strategy to help students understand how knowledge from separate scientific fields fits together. They include patterns; cause and effect; scale, proportion, and quantity; systems and system models; energy and matter; structure and function; and stability and change. (NGSS, 2013). Applied to the above example of building a motorized car with $\mathrm{LEGO}^{\circledR}$ WeDo 2.0, students would be able to observe: patterns in the software code; cause and effect relationships in the speed of the motor to the distance travelled; how proportion can describe a change in speed based on the size of the wheel; that energy stored in the battery can change forms causing motion; understand that each part of the car has a function; and that the model performs in a stable manner unless effected by change. Not all the crosscutting concepts would apply to every lesson or activity in any science lesson, but it is easy to see that ER facilitates the creation of these schema.

Disciplinary core ideas in NGSS are the broad domains of: physical sciences; life sciences; earth and space sciences; and engineering, technology and applications of science. With the example of the lesson on speed, which is targeted at grades three and four, it addresses multiple disciplinary core ideas. In physical science this lesson meets the following performance standards: Make observations and/or measurements of an object's motion to provide evidence that a pattern can be used to predict future motion (3-PS2-2); and Use evidence to construct an explanation relating the speed of an object to the energy of that object (4-PS3-1; The LEGO 
Group, 2016; NGSS, 2013). In engineering, technology and applications of science this lesson meets the performance engineering design standards: Define a simple design problem reflecting a need or a want that includes specified criteria for success and constraints on materials, time, or cost (3-5-ETS1-1); Generate and compare multiple possible solutions to a problem based on how well each is likely to meet the criteria and constraints of the problem (3-5-ETS1-2); and Plan and carry out fair tests in which variables are controlled and failure points are considered to identify aspects of a model or prototype that can be improved (3-5-ETS1-3; NGSS, 2013).

Triangulation with the qualitative data shows the obvious connections to NGSS were not lost on the participants of this study. Subject 61 stated:

I'm assessing the West Virginia Next Generation Science Standards that have the engineering, technology, and science core standards in grade level band. . . So you're seeing the scientific practices and scientific method of asking questions and solving problems - powerful!

Given the ability of ER to support the shift from a teacher to a student centered, from a textbookbased to an inquiry-based learning environment, future workshops must make this more obvious, so all educators see the benefit of using the approach. The implication for practice and policy is that ER is a "powerful" tool to help teachers span learning across the three dimensions of NGSS, and while doing so, engage and challenge their students to think and act like engineers, while using science and mathematics to address authentic problems, even if they are only about how fast your $\mathrm{LEGO}^{\circledR}$ car can go.

\section{Recommendations for Research}

Educational Robotics (ER) has been shown to increase student engagement in STEM, aid educators in meeting the demands of new standards such as NGSS, and at times, transform 
classrooms into student-centered learning environments. Recommendations for increasing reliability of future research are made, suggestions for using additional instruments are proposed, and the need to initiate a series of case studies is made.

Research instruments. Refinement of the current instruments used in this study can improve the quality of the data, strengthen triangulation, and better lead to an increased understanding of the impact on educators and students. The 18-question survey of ability, utility, and intent is validated, and shown to be effective for measuring pre-service, classroom, and informal educators' attitudes and should continue to be utilized. But, this study demonstrated that there is a risk of a ceiling effect when evaluating participants who self-select and have been previously trained as evidenced by the retrospective question. To avoid this, a recommendation is to identify those participants with prior training or experience before conducting the research, and provide an alternate quantitative test (yet to be developed) that allows them to compare and rank the multiple ER platforms they are trained on, which would benefit the broader body of research and improve the reliability of the 18-question pre- to post-workshop assessment by limiting it to those participants who are approaching ER for the first time.

This study could be improved by pairing participants who attend the ER workshop with a similar educator who did not. This may be accomplished by requesting those participants who are in the study to identify a teacher in their school or organization who teaches an equivalent grade level, has a similar amount of experience, but will not be attending the ER workshop or using ER with students. This paired comparison group could demonstrate that the increase in perception of ability, utility, and intent are due to the treatment and not other factors. This study can serve as a baseline and foundation for funding proposals that will have greater financial support to continue and expand ER research in the future. 
The researcher determined that the interview questions could be tailored better to reflect the experiences (or lack thereof) of two audiences (users and non-users) as they potentially limited the responses of the participants, and that analysis would be strengthened by asking participants directly about ability, utility, and intent. Greater effort needs to be taken to identify which participants used ER with students and to ask them more appropriate questions tailored to their group (users and non-users). Likely due to the low cost of entry for the WeDo 2.0, more schools purchased their own kits to use with pre-existing tablet computers than expected, and one question that should be moved near the top of the interview should be phrased, "Have you been able to borrow the NASA ERC's WeDo 2.0 kit with students, or have you been able to use WeDo 2.0 purchased by your school organization with students?" To improve analysis of users, a question should be added that subdivides this group by the type of "use". For example, "Please select if you used ER with students for: (a) one day or class period; (b) more than one day but less than a week; (c) at least one week; or (d) greater than one week." This could be further enhanced by asking the participants to define how many hours of contact the students had with ER. For both groups, the first open ended question should be phrased, "Tell me about your experience so far with WeDo 2.0. For example, did you like the workshop, what thoughts did you have afterwards about using ER with students, what impacts did it have, or do you think ER will have in your classroom or school?" The final recommendation to improve the interview and the researcher's ability to perform triangulation is to refine the questions to specifically address the educator's ability to use ER (their own self-efficacy), the utility of the technology, and their intent to use it with students.

Triangulation would be enhanced if initial closed coding was conducted with the transcripts to permit a frequency analysis of the three subscales of ability, utility, and intent. The 
interview questions could be edited to elicit greater reflection on the subscales by the participants. Closed coding would allow the qualitative data to more strongly support the quantitative data.

Student instruments should be deployed with the kits that allow educators to become part of an ongoing action-research initiative. There are preexisting instruments used by $F I R S T^{\circledR}$ as part of a longitudinal study (www.firstinspires.org/about/impact) on the impact of participation in after-school robotics teams that could be leveraged for this purpose. Installing software or a link to an online version of a student assessment on the iPads could facilitate easy and rapid data collection.

Case studies of transformational schools. Ongoing research in elementary educational robotics is necessary to provide the sound footing that administrators and policy makers need to make the investment in this technology so it can be made available to all students, not kept largely in the domain of after-school clubs and teams as it is today (Barker \& Ansorge 2007; Chung et al. 2014; Karp \& Maloney, 2013; Nugent et al., 2010; Williams et al. 2007). Particularly important is the need to develop and test effective models for implementation across multiple grades and throughout the curriculum. Educational robotics holds a key that can unlock the transformation of a classroom, or an entire school from teacher to student centered, from direct instruction to constructionism, from substitution to redefinition, and from C to TPACK. The role of ER in this metamorphosis of our $\mathrm{K}-5^{\text {th }}$ educational system can be described by Mindy,

The kids actually take control of their own learning and I think that in elementary schools sometimes the teachers are wanting to be control focused; you know, they want to be in control - they want to guide. Whereas you go into the robotics and into their teams, and 
you give them a project, and they're working on the project, and they're writing about the projects -you're not really the focus of the classroom. You're the liaison who kind of goes around and trouble shoots if you need to and I think sometimes I think that's a little frightening for the teacher. But the kids are really growing and they're taking on a lot of responsibility that sometimes I think we're afraid to relinquish to them (Subject 55).

To achieve this shift in more schools, professional development models that can be replicated at the elementary level need to be shared broadly. Through effective professional development, educators can move to the center of TPACK.

Research question four illustrated a single case where classroom opportunities for ER were paired with an after-school team-based experience. It was observed by the participant that the robotics teams provided an avenue for students to dive much deeper into the content, coding, and communication and teamwork, creativity, and ultimately a high level of confidence. These youth on the robotics team brought their experience with them when ER was integrated during the school day. Through their emergent roles as peer-mentors in their classroom and technology integration specialists for younger grades, these students served as a key to unlocking the redefinition of the role of technology in the classroom. While this process was only observed at one site in this study, school-wide transformation has been previously documented in other K-12 schools across the U.S. when after-school robotics programs have been established (Malachowski, 2015; Powell, 2014; McIntyre, 2012; Bascomb, 2011; Oppliger, 2002). Classroom integration of ER, when paired with after-school team-based opportunities, have the potential to transform STEM education. But more research is needed. Recruitment of additional schools to participate can be achieved through training, grants, and promotion of the potential benefits to students, staff, and the community. Taken alone, it is the story of one extraordinary 
teacher and her students. But, if documented, these sites will collectively become a model for other schools to replicate.

Educational robotics has the potential to engage and inspire young learners by shifting the focus of the classroom from the teacher to the student, from the content to the process; and from a subject to a solution of a real-world problem. Woodie Flowers, co-creator of FIRST ${ }^{\circledR}$, has been a champion for evolving our educational system through challenges, competition, and innovation for more than 40 years. In a 2014 interview, Flowers described the current challenge of education:

Our education system is largely structured around the process of imparting information and, to some extent, building students' skills. Even in schools that are embracing a more holistic view of learners, we are still using structures inherited from a centuries-old model: teacher as expert, rather than coach; and pacing based on efficiency and uniformity, rather than individual learners' needs. New technologies are starting to allow us to question these orthodoxies, but only when we really consider our users' needs will we succeed in changing the system for the better (Flowers, Greenberg, Plattner, Miller \& Arthur, 2014, p. 7).

Educational robotics is one of the "new technologies" Flowers is describing that can unlock the potential of our students. Born from the "Mindstorms" of theorists such as Papert, educational robotics is not only changing the way we learn, but is fundamentally altering what our relationship is with knowledge. From his 1980 book, Mindstorms: Children, Computers, and Powerful Ideas, Papert expressed:

In my vision, space-age objects, in the form of small computers, will cross these cultural barriers to enter the private worlds of children everywhere. They will do so not as mere 
physical objects. This book is about how computers can be carriers of powerful ideas and of the seeds of cultural change, how they can help people form new relationships with knowledge that cut across the traditional lines separating humanities from sciences and knowledge of the self from both of these (p. 230).

In 1980, Papert envisioned the reality we exist in today where millions of small computers, in the form of educational robots, are literally in the hands of children worldwide due to the popularity of competitive programs started by Flowers, Kaman and others. The challenge for our generation is to harness this technology to change the culture of education, and in doing so, immeasurably better the lives of our children who must possess powerful ideas if they are to succeed in the knowledge economy of tomorrow. 


\section{References}

Ackermann, E. K. (1996). Perspective-taking and object construction: Two keys to learning. In Y. Kafai \& M. Resnik (Eds.), Constructionism in practice: Designing, thinking and learning in a digital world (pp. 25-37). Mahwah, NJ: Lawrence Erlbaum.

Ackerman, E.K. (2004). Constructing knowledge and transforming the world. In Tokoro, M., \& Steels, L. (Eds.), A learning zone of one's own: Sharing representations and flow in collaborative learning environments (pp. 15-37). Washington DC: IOS Press.

ACT. (2012). The Condition of College \& Career Readiness 2012. Retrieved from Www.act.org/readiness/2012

Alimisis, D. (2012). Robotics in Education \& Education in Robotics: Shifting Focus from Technology to Pedagogy. Paper presented at 3rd International Conference on Robotics in Education, Prague, CZ.

Bandura, A. (1994). Self-efficacy. In V. S. Ramachaudran (Ed.), Encyclopedia of human behavior (Vol. 4, pp. 71-81). New York: Academic Press. (Reprinted in H. Friedman [Ed.], Encyclopedia of mental health. San Diego: Academic Press, 1998).

Bandura, A. (1997). Self-efficacy: The exercise of control.

Bandura, A., Barbaranelli, C., Caprara, G. V., \& Pastorelli, C. (2001). Self-efficacy beliefs as shapers of children's aspirations and career trajectories. Child Development, 72, 187 206.

Barker, B. (2012). Robots in k-12 education: A new technology for learning. Hershey PA: Information Science Reference. 
Barr, V., \& Stephenson, C. (2011). Bringing computational thinking to K-12: What is involved and what is the role of the computer science education community? ACM Inroads, 2(1), 48- 54.

Barker, B., \& Ansorge, J. (2007). Robotics as Means to Increase Achievement Scores in an Informal Learning Environment. Journal of Research on Technology in Education, 39(3), 229-243.

Bascomb, N. (2011). The new cool: A visionary teacher, his FIRST robotics team, and the ultimate battle of smarts. New York, NY: Crown Publishers.

Benitti, F. B. V. (2012). Exploring the educational potential of robotics in schools: A systematic review. Computers \& Education, 58(3), 978-988. doi:10.1016/j.compedu.2011.10.006

Bers, M., Portsmore, M., (2005). Teaching Partnerships: Early Childhood and Engineering Students Teaching Math and Science Through Robotics. Journal of Science Education and Technology, Vol. 14, No. 1.

Bers, M. U., Seddighin, S., \& Sullivan, A. (2013). Ready for robotics: Bringing together the T and E of STEM in early childhood teacher education. Journal of Technology and Teacher Education, 21(3), 355-377.

Bloom, L. (2017, March 28). The 10 Most (And 10 Least) Innovative States In The U.S.. Forbes. Retrieved from https:/www.forbes.com/sites/laurabegleybloom/2017/03/28/the-10-mostand-10-least-innovative-states-in-the-u-s/\#7f45a76110a6

Bonarini, A. \& Romero M. (2013). Robotics and Design: An Interdisciplinary Crash Course. IEEE Transactions on Education, Vol. 56, NO. 1.

Bouvier, S. (2011). Increasing student interest in science, technology, engineering, and math (STEM): Massachusetts STEM Pipeline Fund programs using promising practices. 
Prepared by the UMass Donahue Institute Research and Evaluation Group for the Massachusetts Department of Higher Education. Retrieved from http://www.mass.edu/stem/documents/Student\%20Interest\%20Summary\%20Report.pdf

Bradley, E. H., Curry, L. A., \& Devers, K. J. (2007). Qualitative Data Analysis for Health Services Research: Developing Taxonomy, Themes, and Theory. Health Services Research, 42(4), 1758-1772. http://doi.org/10.1111/j.1475-6773.2006.00684.x

Brand, B., Collver, M., \& Kasarda, M. (2008). Motivating students with robotics. Science Teacher, 75(4), 44-49.

Brennan, K., \& Resnick, M. (2012). New frameworks for studying and assessing the development of computational thinking. Paper presented at AERA, Vancouver, BC. Retrieved from: http://web.media.mit.edu/ kbrennan/files/Brennan_Resnick_AERA2012_CT.pdf

Brown, J. (2012). The current status of STEM education research. Journal of STEM Education, 13(5), 7-11.

Caron, D. (2010). Competitive robotics brings out the best in students. Tech Dir 69(6):21-23

Charmaz, K. (2008). Grounded Theory as an Emergent Method. In S.N. Hesse-Biber \& P. Leavy (eds), Handbook of Emergent Methods (pp 155-172). New York: The Guilford Press

Chung, C., Cartwright, C. \& Cole, M. (2014). Assessing the impact of an autonomous robotics competition for STEM education. Journal of STEM Education: Innovations and Research 15(2):24.

Clements, D. (1999). Young children and technology. In G. D. Nelson (Ed.), Dialogue on early childhood science, mathematics, and technology education. Washington, DC: American Association for the Advancement of Science. 
Cohn, D., \& Caumont, A., (2016, March 31). 10 demographic trends that are shaping the U.S. and the world. Retrieved from the Pew Research Center Website http://www.pewresearch.org/fact-tank/2016/03/31/10-demographic-trends-that-areshaping-the-u-s-and-the-world/

Committee on Science, Technology, Engineering, and Mathematics Education (CoSTEM). (2013). Federal STEM Education 5-Year Strategic Plan. Retrieved from The White House Website https://obamawhitehouse.archives.gov/sites/default/files/microsites/ostp/stem_stratplan_2 013.pdf

Cramer, D., \& Howitt, D. (2004). The Sage dictionary of statistics: A practical resource for students in the social sciences. London: SAGE Publications.

Creswell, J., Plano Clark, V., Gutmann, M., \& Hanson, W. (2003). Advanced Mixed Methods Research Designs. In Clark, V. L. P., \& Creswell, J. W. (Eds.). (2008). The mixed methods reader. (p. 161-195) Thousand Oaks, CA: Sage Publications.

Cristóforis, P., Pedre, S., Nitsche, M., Fischer, T., Pessacg, F., \& Di, P. C. (February 01, 2013). A Behavior-Based Approach for Educational Robotics Activities. IEEE Transactions on Education, 56, 1, 61-66.

Cuny, J., Snyder, L., \& Wing, J.M. (2010). Demystifying computational thinking for noncomputer scientists. Unpublished manuscript in progress, referenced in http://www.cs.cmu.edu/ CompThink/resources/TheLinkWing.pdf

DeCoster, J. (2005). Scale Construction Notes. Retrieved June 4, 2017 from http://www.stathelp.com/notes.html 
Dill, K. (2016, July 13). The Companies With The Most STEM Job Openings Right Now. Forbes. Retrieved from https://www.forbes.com/sites/kathryndill/2016/07/13/thecompanies-with-the-most-stem-job-openings-right-now-3/\#72300e3f7f82

Doerschuk, P., Bahrim, C., Daniel, J., Kruger, J., Mann, J., \& Martin, C. (August 01, 2016). Closing the Gaps and Filling the STEM Pipeline: A Multidisciplinary Approach. Journal of Science Education and Technology, 25, 4, 682-695.

Eccles, J. (2005). Studying gender and ethnic differences in participation in math, physical science, and information technology. New Directions for Child and Adolescent Development, (110), 7 - 14. Education Week, Vol. 27, Issue 29, Pages 1,14,

Eccles, J., \& Wigfield, A. (2002). Motivational beliefs, values, and goals. Annual Review of Psychology, 53(1), 109-132. doi:10.1146/annurev.psych.53.100901.135153

Economics and Statistics Administration. (2011). STEM: Good Jobs Now and for the Future. United States Department of Commerce, Washington, D.C. Retrieved from http://www.esa.doc.gov/sites/default/files/stemfinalyjuly14_1.pdf

Ensign, T., Rye, J., \& Luna, M. (2015, October). Embedding Probeware Technology in Science Methods Courses for Preservice Elementary Teachers: Analysis of Ability, Utility, and Intent over 3 years, Paper presented at the annual meeting of the Mid-Atlantic Association for Science Teacher Educators, Cambridge, $\mathrm{OH}$.

Ensign, T., Rye, J., \& Luna, M. (in press). Embedding Probeware Technology in the Context of Ocean Acidification in Elementary Science Methods Courses. Journal of Science Education and Technology. DOI 10.1007/s10956-017-9704-2. 
Falloon, G. (December 01, 2016). An analysis of young students' thinking when completing basic coding tasks using Scratch Jnr. On the iPad. Journal of Computer Assisted Learning, 32, 6, 576-593.

Family Educational Rights and Privacy Act of 1974, 20 U.S.C. $§ 1232$ g (1974).

FIRST $^{\circledR}$ LEGO $^{\circledR}$ League Jr. Evaluation Study (2014), The Research Group, Lawrence Hall of Science, University of California, Berkeley. Retrieved from https://www.firstinspires.org/sites/default/files/uploads/resource_library/impact/firstimpact-infographic-sep16-flljr.pdf

Fischetti, M., (2014, July 1). Foreign Companies grab increasing share of U.S. patents. Scientific American. Retrieved from https://www.scientificamerican.com/article/foreigncompanies-grab-increasing-share-of-u-s-patents/

Flannery, L., \& Bers, M. (January 01, 2013). Let's dance the "Robot Hokey-Pokey!": Children's programming approaches and achievement throughout early cognitive development. Journal of Research on Technology in Education, 46, 1, 81-101.

Fleischman, H., Hopstock, P., Pelczar, M., \& Shelley, B. (2010, December 7). Highlights From PISA 2009: Performance of U.S. 15-Year-Old Students in Reading, Mathematics, and Science Literacy in an International Context. (NCES 2011004). Retrieved from NCES https://nces.ed.gov/pubs2011/2011004.pdf

Flowers, W., Greenberg, S. S., Plattner, H., Miller, R. K., \& Arthur, S. M. D. (June 06, 2014). Q\&A. Design Management Review, 25, 1, 4.

Fraenkel, J., Wallen, N., \& Hyun, H. (2015). How to design and evaluate research in education. New York: McGraw-Hill Education 
Frankfort-Nachmias, C., \& D. Nachmias. (1996). Research methods in the social sciences. New York: St. Martin's Press.

Gado, I., Ferguson, R., \& Van 'T Hooft, M. (2006). Using Handheld-Computers and Probeware in a Science Methods Course: Preservice Teachers' Attitudes and Self-Efficacy. Journal of Technology \& Teacher Education, 14 (3), 501-529.

Gardner, H. (1991). The unschooled mind: How children think and how schools should teach. New York: BasicBooks.

Global educational robots market 2016-2020 - market to grow at a CAGR of 21.5\% - research and markets. (2016, Jun 14). Business Wire Retrieved from https://search.proquest.com/docview/1796252092?accountid=2837

Grubbs, M. (2013). Robotics intrigue middle school students and build STEM skills. Technology, Engineering \& Teaching. 72(6):12-16 .

Harris Interactive. (2011). STEM Perceptions: Student \& Parent Study Parents and Students Weigh in on How to Inspire the Next Generation of Doctors, Scientists, Software Developers and Engineers. Retrieved from http://news.microsoft.com/download/archived/presskits/citizenship/docs/STEMPerceptio nsReport.pdf

Ivey, D. \& Quam, G. (2009). 4-H and tech ed partnership gets students geeked about STEM. Tech Dir 69(3):19-21

Jacobson, J. (Dec 17, 2016). "Next Generation Science Standards-Based Assessments Are Coming. How Should Teachers Prepare?’. EdSurge. Retrieved from https://www.edsurge.com/news/2016-12-17-next-generation-science-standards-basedassessments-are-coming-how-should-teachers-prepare 
Jaipal-Jamani, K., \& Angeli, C. (April 01, 2017). Effect of Robotics on Elementary Preservice Teachers' Self-Efficacy, Science Learning, and Computational Thinking. Journal of Science Education and Technology, 26, 2, 175-192.

Karp, T., Maloney, P. (2013). Exciting young students in grades K-8 about STEM through an afterschool robotics challenge. American Journal of Engineering Education. 4(1):39-54.

Karsten, J. (May 10, 2016). "Make STEM education exciting and engaging”. TechTank. The Brookings Institution. Retrieved from https://www.brookings.edu/blog/techtank/2016/05/10/make-stem-education-exciting-andengaging/

Kazakoff, R., Sullivan, A. \& Bers, U. (2013). The effect of a classroom- based intensive robotics and programming workshop on sequencing ability in early childhood. Early Childhood Education Journal 41(4):245-255.

Koballa, J. \& Glynn, S. (2007). Attitudinal and motivational constructs in science learning. In S. Abell \& N. G. Lederman (Eds.), Handbook of research in science education (pp. 75102). Mahwah, NJ: Erlbaum.

Langdon, D., McKittrick, G., Beede, D., Khan, B., Doms, M. (July, 2011). STEM: Good Jobs Now and for the Future. ESA Issue Brief \#013-11.

Laerd Statistics (2013). ANOVA with repeated measures using SPSS statistics. Lund Research Ltd. Accessed 2/8/17 at https://statistics.laerd.com/spss-tutorials/one-way-manova-usingspss-statistics.php

Lee, I., Martin, F., Denner, J., Coulter, B., Allan, W., Erickson, J. \& Werner, L. (2011). Computational thinking for youth in practice. ACM Inroads, 2(1), 32-37. doi:10.1145/1929887.1929902 
LEGO $^{\circledR}$ WeDo. (n.d.). Retrieved March 27, 2016, from https://education.lego.com/enus/products/lego-education-wedo-construction-set/9580.

Leonard, J., Buss, A., Gamboa, R., Mitchell, M., Fashola, O., Hubert, T., \& Almughyirah, S. (2016). Using robotics and game design to enhance children's self-Efficacy, sTEM attitudes, and computational thinking skills. Journal of Science Education and Technology, 25(6), 860-876

Levitt, K. (2002). An analysis of elementary teachers' beliefs regarding the teaching and learning of science. Science Education, 86(1), 1-22. doi:10.1002/sce.1042

Linn, C., Hsi, S. (2000). Computers, teachers, peers: science learning partners. LEA, Mahwah Martin, M., Mullis, I., Foy, P. \& Stanco, G. (2012). Chestnut Hill, MA: TIMSS \& PIRLS International Study Center, Boston College.

Malachowski, J. (November 27, 2015). LEGO League inspires area middle schoolers. Telegram \& Gazette.

Matson, E., DeLoach, S. \& Pauly, R. (2004) Building interest in math and science for rural and underserved elementary school children using robotics. Journal of STEM Education $5(3 \& 4): 35-46$

McIntyre, N. (August 01, 2012). A Day at FIRST Lego League. Learning \& Leading with Technology, 40, 1, 17-19.

Merriam, S. (1998). Qualitative research and case study applications in education. San Francisco: Jossey-Bass Publishers. Metz, S. (2014). Science Teaching and Learning in the 21st Century. Science Teacher, 81(6), 6. 
Llinares, S. \& Krainer, K. (2006). Mathematics (Student) Teachers and Teacher Educators as Learners. In Gutiérrez, A., \& Boero, P. (Ed.), Handbook of research on the psychology of mathematics education : Past, present and future. (pp. 429-459). Rotterdam: Sense.

Melchior, A., Burack, C., Hoover, M. \& Marcus, J., (2017), FIRST Longitudinal Study: Findings at 36 Month Follow-Up (Year 4 Report). The Center for Youth and Communities Heller School for Social Policy and Management Brandeis University. Retrieved from https://www.firstinspires.org/resource-library/first-impact

Metz, S. (2007). Attracting the engineering of 2020 today. In R. Burke \& M. Mattis (Eds.), Women and minorities in science, technology, engineering and mathematics: Upping the numbers (pp. 184-209). Northampton: Edward Elgar Publishing.

Mioduser, D., Levy, T. \& Talis, V. (2009). Episodes to scripts to rules: concrete-abstractions in kindergarten children's explanations of a robot's behavior. International Journal of Technology Des Education. 19(1):15-36

Mishra \& Koehler. (2006). Technological pedagogical content knowledge: A framework for teacher knowledge. Teachers College Record, 108(6), 1017-1054.

National Academy of Sciences, National Academy of Engineering, and Institute of Medicine. (2007). Rising Above the Gathering Storm: Energizing and Employing America for a Brighter Economic Future. Washington, DC: The National Academies Press. https://doi.org/10.17226/11463.

National Center for Education Statistics. (2012). The Nation's Report Card: Science 2011. (NCES 2012-465). Institute of Education Sciences, U.S. Department of Education, Washington, D.C. Retrieved from https://nces.ed.gov/nationsreportcard/pdf/main2011/2012465.pdf 
National Research Council. (2011). Assessing 21st Century Skills: Summary of a Workshop. J.A. Koenig, Rapporteur. Committee on the Assessment of21st Century Skills. Board on Testing and Assessment, Division of Behavioral and Social Sciences and Education. Washington, DC: The National Academies Press.

National Science Board. (2016). Science and Engineering Indicators 2016. Arlington, VA: National Science Foundation (NSB-2016-1).

National Science Foundation (NSF) Division of Science Resources Statistics. (2011). Women, Minorities, and Persons with Disabilities in Science and Engineering: 2011. (Special Report NSF 11-309). Retrieved from https://www.nsf.gov/statistics/wmpd/archives/wmpd_2011.zip

NGSS Lead States. (2013). Next generation science standards: For states, by states.

Noonan, R. (March 30, 2017). STEM Jobs: 2017 Update (ESA Issue Brief \# 02-17). Office of the Chief Economist, Economics and Statistics Administration, U.S. Department of Commerce. Retrieved from http://www.esa.gov/reports/stem-jobs-2017-update.

Nugent, G., Barker, B., Grandgenett, N., \& Adamchuk, V., (2010). Impact of Robotics and Geospatial Technology Interventions on Youth STEM Learning and Attitudes, Journal of Research on Technology in Education, Vol. 42, No. 4, pp. 391-408.

Nugent ,G., Barker, B., Welch, G., Grandgenett, N., Wu, C., Nelson, C. (2015). A model of factors contributing to STEM learning and career orientation. International Journal of Science Education 37(7):1067-1088.

Oppliger, D. (January 01, 2002). Using FIRST ${ }^{\circledR}$ LEGO $^{\circledR}$ League to Enhance Engineering Education and to Increase the Pool of Future Engineering Students. Proceedings Frontiers in Education Conference, 3. 
Ortiz, A. M., Bos, B., \& Smith, S. (2015). The Power of Educational Robotics as an Integrated STEM Learning Experience in Teacher Preparation Programs. Journal of College Science Teaching, 44(5), 42-47.

Papert, S. (1993). Mindstorms: Children, computers, and powerful ideas. New York, NY: Basic Books.

Papert, S. (1991). Situating Constructionism. In S.Papert and I.Harel (eds.) Constructionism, Norwood, NJ, Ablex Publishing Corporation.Patton (2002). Qualitative research and evaluation methods. Thousand Oaks, CA: Sage Publications.

Papert, S. (1999). What is Logo? And who needs it? Logo philosophy and implementation (pp. iv-Xvi). Logo Computer Systems, Inc.

Papert, S., \& Harel, I. (1991). Situating constructionism. Constructionism. Norwood, NJ: Ablex Publishing. Retrieved from http://www.papert.org/articles/SituatingConstructionism.html

Park, J. (2015). Effect of robotics-enhanced inquiry-based learning in elementary science education. Journal of Computer, Mathematics, and Science Teaching. 34(1):71-95

Partnership for 21st Century Skills (2015). P21 Framework Definitions. Washington D.C. Retrieved from http://www.p21.org/

Patton. (2002). Qualitative research and evaluation methods. Sage Publications, Thousand Oaks Powell, M. (March 12, 2014). Changing a School's Culture, From the Ground Up. Education Week. Published online. Retrieved from http://www.edweek.org/tm/articles/2014/03/12/ctq-powell.html

President's Council of Advisors on Science and Technology (PCAST). (2012). Engage to Excel: Producing One Million Additional College Graduates with Degrees in Science, Technology, Engineering, and Mathematics. Retrieved from The White House Website 
https://obamawhitehouse.archives.gov/sites/default/files/microsites/ostp/pcast-engage-toexcel-final_2-25-12.pdf

Preston, C., \& Colman, A., (2000). “Optimal number of response categories in rating scales: reliability, validity, discriminating power, and respondent preferences". Acta Psychologica 104, 1-15. Retrieved from https://www2.le.ac.uk/departments/npb/people/amc/articles-pdfs/optinumb.pdf

Rehmat, A. \& Bailey, J. (2014). Technology Integration in a Science Classroom: Preservice Teachers' Perceptions. Journal of Science Education and Technology, Volume 23, Issue 6, 744-755.

Reeve, E. (2015). STEM thinking! Technology and Engineering Teacher, 74(4), 8-16.

Richardson, J. (2011). Eta squared and partial eta squared as measures of effect size in educational research. Educational Research Review 6, 135-47.

Riggs, I., \& Enochs, L. (1990). Toward the development on an elementary science teachers' science teaching efficacy belief system. Science Education, 74, 625-635.

Rinke, C., Gladstone-Brown, W., Kinlaw, C. R. \& Cappiello, J. (October 01, 2016). Characterizing STEM Teacher Education: Affordances and Constraints of Explicit STEM Preparation for Elementary Teachers. School Science and Mathematics, 116, 6, 300-309.

Rogers, C., \& Portsmore, M. (2004). Bringing engineering to elementary school. Journal of STEM Education, 5(3-4), 17-28.

Rye, J. (2011, September). Elementary Preservice Teachers Perceptions of Probeware Technology for Science Instruction. 2011 Mid-Atlantic Association for Science Teacher Educators Conference. 
Saldana, J. (2011). Fundamentals of qualitative research. Retrieved from http://ebookcentral.proquest.com

Shernoff, D. J., Sinha, S., Bressler, D. M., \& Ginsburg, L. (December 01, 2017). Assessing teacher education and professional development needs for the implementation of integrated approaches to STEM education. International Journal of Stem Education, 4, 1, 1-16.

Skamp, K., \& Mueller, A. (2001). A longitudinal study of the influences of primary and secondary school, university and practicum on student teachers' images of effective primary science practice. International Journal of Science Education, 23(3), 227-45.

Somyürek, S. (February 01, 2015). An effective educational tool: construction kits for fun and meaningful learning. International Journal of Technology and Design Education, 25, 1, 25-41.

Steele, C. (1997). A threat in the air: How stereotypes shape intellectual identity and performance. American Psychologist, 52, 613-629.

Sullivan, R. (2008). Robotics and science literacy: thinking skills, science process skills and systems understanding. Journal of Research in Science Teaching 45(3): 373-394.

Sullivan, A., Bers, M. (2016). Robotics in the early childhood classroom: learning outcomes from an 8-week robotics curriculum in pre-kindergarten through second grade. International Journal of Technology and Design Education. Volume 26. Pages 3-20

Sutcher, L., Darling-Hammond, L., \& Carver-Thomas, D. (2016). A Coming Crisis in Teaching? Teacher Supply, Demand, and Shortages in the US. Learning Policy Institute. Retrieved from https://learningpolicyinstitute.org/product/solving-teacher-shortage May 30, 2017. 
Tai, R., Qi, L., Maltese, A. \& Fan, X. (January 01, 2006). Career choice. Planning early for careers in science. Science (new York, N.y.), 312, 5777, 1143-4.

The LEGO Group. (2016). LEGO ${ }^{\circledR}$ Education WeDo 2.0 Curriculum Pack. Retrieved from https://education.lego.com/en-us/support/wedo-2/curriculum-preview

Thomasian, J. (2011). "Building a Science, Technology, Engineering, and Math Education Agenda: An Update of State Actions.” National Governors Association Center for Best Practices,. Retrieved from https://www.nga.org/files/live/sites/NGA/files/pdf/1112STEMGUIDE.PDF

Tsupros, N., Kohler, R. \& Hallinen, J. (2009). STEM education: A project to identify the missing components. Intermediate Unit 1: Center for STEM Education and Leonard Gelfand Center for Service Learning and Outreach, Carnegie Mellon University, Pennsylvania. Ucgul, M. \& Cagiltay, K. (2014). Design and Development Issues for Educational Robotics Training Camps. Int. Journal of Technology Design Education 24:203-222.

Watters, A. (2015, April 10). Lego Mindstorms: A History of Educational Robotics. Retrieved April 21, 2016, from http://hackeducation.com/2015/04/10/mindstorms

Watts, R. (24 June 2017). "Self-Efficacy in Changing Societies." Journal of Cognitive Psychotherapy 10.4 (1996): 313-5. ProQuest.

Weems, G. \& Onwuegbuzie, A. J. (2001). The Impact of Midpoint Responses and Reverse Coding on Survey Data. Measurement \& Evaluation In Counseling \& Development (American Counseling Association), 34(3), 166.

Welch, A. \& Huffman, D. (January 01, 2011). The Effect of Robotics Competitions on High School Students' Attitudes Toward Science. School Science and Mathematics, 111, 8.) 
Williams, D., Ma, Y., Prejean, L. \& Ford, MJ. (2007). Acquisition of physics content knowledge and scientific inquiry skills in a robotics summer camp. Journal of Research in Technology Education. 40:201-216 


\section{Appendix A}

Announcement of Workshop Opportunity

Dear K-5 Educators,

The NASA IV\&V Educator Resource Center (ERC) has recently added two new sets of $12 \mathrm{LEGO}^{\circledR}$ WeDo 2.0 robots and iPad Air 2 computers to our classroom kit program! We invite you to set up a FREE (4 hour) workshop at your school or attend one of the workshops scheduled at the ERC for K-5 classroom or out-of-school time educators. Once you complete the workshop, you may sign out the kit to use with your students.

The new WeDo 2.0 platform has numerous enhancements over the current version used by the ERC that we believe will make it much more accessible to younger students:

- The programming software has been updated and is easier to use!

- We now program using iPads, which are more user friendly for young learners!

- The WeDo robots are now wireless, avoiding the need for cables, and allowing student creations to move freely around the classroom!

- New activities and lessons you can use to meet Next Generation Science Standards, and integrate Technology and Engineering concepts in your Science or Mathematics class!

To set up a workshop at your school, contact us via email at: erc@ivv.nasa.gov or 304-367-8436.

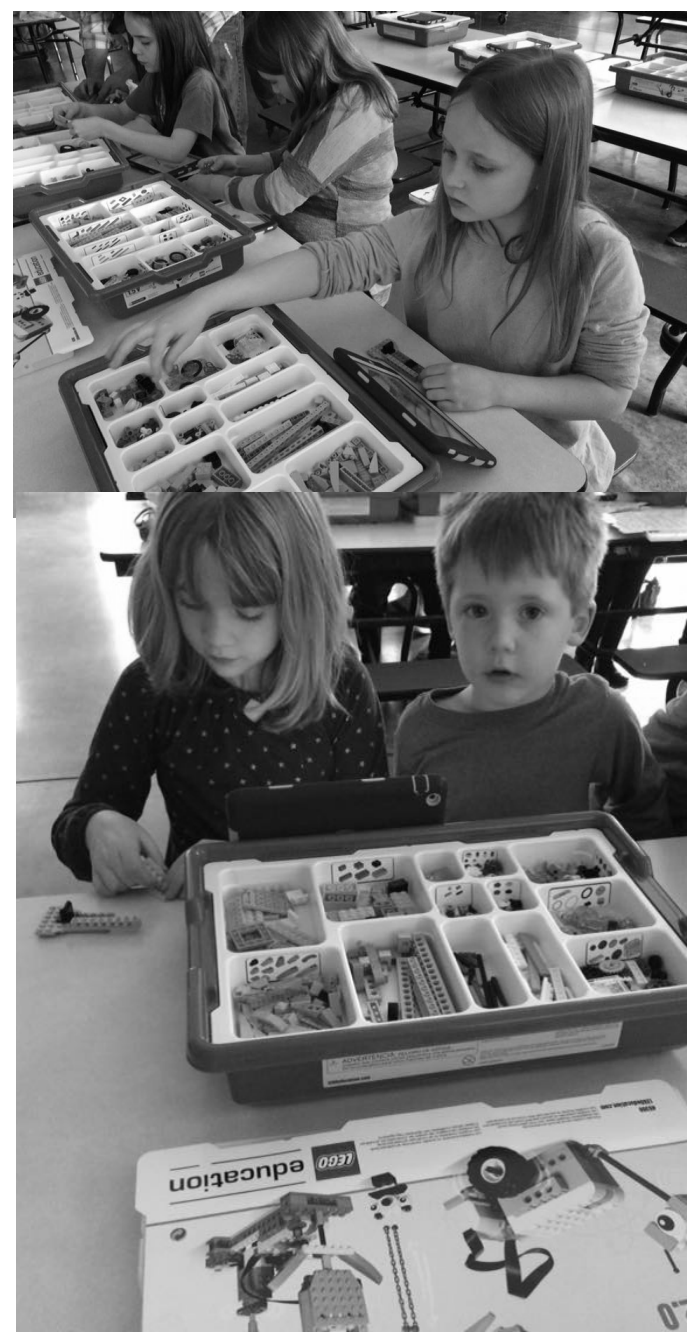

Or Register for one of our on-site workshops at the NASA ERC in Fairmont. Click HERE for dates and to sign up.

Note: These trainings are being offered in conjunction with Todd Ensign's graduate research on elementary educators' attitudes of robotics. Voluntary participation in the research project will enter you in a drawing to win a free $L E G O^{\circledR}$ WeDo robot set. If you have questions about the research,you may contact tensign@mix.wvu.edu or 304-685-3146. 


\section{Appendix B}

\section{Cover Letter.}

Date

\section{Subject \#}

Dear Participant:

My name is Todd Ensign and I am a graduate student in the Curriculum and Instruction / Literacy Studies department at West Virginia University's College of Education and Human Services. For my doctoral dissertation I am examining educators' perceptions of using robotics with elementary students. Because you are a classroom or out-of-school time elementary educator attending a NASA IV\&V Educator Resource Center (ERC) LEGO ${ }^{\circledR}$ WeDo 2.0 robotics training, I am inviting you to participate in this research study by completing the attached form and surveys.

The initial questionnaire and 18 question survey will require approximately 10 minutes to complete. Following the workshop the 18 question survey will be administered for a second time, which will require approximately 5 minutes to complete. Please return the questionnaire and pre and post workshop surveys to the NASA ERC instructor.

Either at your workshop, or within 1 week, you will be contacted to set up a loan of the classroom kit. With the kit will be a third (voluntary) survey that should be completed when you are finished using the kit with students. Return this survey along with the classroom kit to the ERC.

Finally, 20 educators who completed all 3 surveys will be selected to participate in a follow up phone interview. Again, participation is voluntary and your personal information will be kept confidential. You may indicate your intent to complete a phone interview on the questionnaire.

There is no compensation for responding, nor is there any known risk, but completion of each survey and the interview will enter you in a drawing for a free $\mathrm{LEGO}^{\circledR} \mathrm{WeDo}$ robotics set. The more surveys you complete, the better your chance of winning!

If you choose to participate in this project, please answer all questions as honestly as possible. Participation is strictly voluntary and you may refuse to participate at any time.

Thank you for taking the time to assist me in my educational endeavors. The data collected will provide useful information regarding how to best deliver and support robotics in K-5 education. If you would like a summary copy of this study please check the Request for Information box on the demographic form and provide your email address. Completion and return of the form and surveys will indicate your willingness to participate in this study. If you require additional information or have questions, please contact me at the number listed below.

If you are not satisfied with the manner in which this study is being conducted, you may report any complaints to Dr. Jim Rye at Jim.Rye@mail.wvu.edu or 304-293-0982.

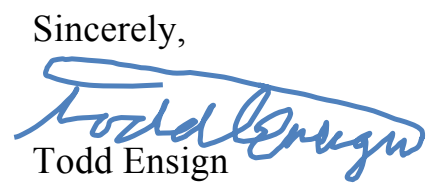

tensign@mix.wvu.edu or 304-685-3146 


\section{Appendix C}

Demographical Information Collected About Subjects

\section{Subject ID \#}

Directions: Please answer the following questions by putting a check mark with the appropriate response, or filling in the information requested. This information optional, but will be separated from your survey data to maintain anonymity and is only used to enter you in the drawing for a free $L E G O^{\circledR}$ WeDo set and for a possible follow up phone interview.

1. Name:

2. School or Organization:

3. Phone \# (used if you are selected for an interview) (

4. Gender: __ Male __ Female __ Other

5. Age:

6. I teach students in grades: _ Pre-K, _ $\mathrm{K}, \ldots 1, \ldots 2, \ldots 3, \ldots 4, \ldots 5$, _ Other

7. I teach:__ During the school day in a traditional classroom.

During the school day working with spec. ed. (gifted or high needs). During the school day in another setting. Please describe:

After school

Other. Please describe:

8. I have been teaching / instructing students for years.

9. $\square$ I have been trained in the use of $\mathrm{LEGO}^{\circledR}$ WeDo robotics by the NASA ERC or another provider.

$\square$ I would like to receive a summary of the study results send to the email listed below.

Email Address: (a) 


\section{Appendix D}

\section{Survey About Educational Robotics for Instruction}

\section{SURVEY ABOUT EDUCATIONAL ROBOTICS FOR INSTRUCTION}

Directions: Below are 18 statements about the use of Educational Robotics (specifically the LEGO WeDo) for instruction. For each statement, there is a scale of responses that ranges from "strongly disagree" to "strongly agree." There are no correct or incorrect responses. For each statement, please darken the circle (only one) that corresponds to your response: strongly disagree, agree, not sure, agree, or strongly agree. After you have responded to the 18 statements, please use the back side of this survey to respond to the question at the bottom of the survey. Place the survey in the envelope when you are finished. Thank you.

\begin{tabular}{|c|c|c|c|c|c|}
\hline Statement & $\begin{array}{l}\text { Strongly } \\
\text { Disagree }\end{array}$ & Disagree & Not Sure & Agree & $\begin{array}{c}\text { Strongly } \\
\text { Agree }\end{array}$ \\
\hline $\begin{array}{l}\text { 1. Robotics sounds like problematic instructional technology } \\
\text { to me. }\end{array}$ & $r$ & $r$ & $r$ & $r$ & $r$ \\
\hline $\begin{array}{l}\text { 2. I don't know how to use Robotics (i.e., Robotics is } \\
\text { unfamiliar to me). }\end{array}$ & $r$ & $r$ & $r$ & $r$ & $r$ \\
\hline 3. Some day, I will use Robotics in my classroom. & $r$ & $c$ & $r$ & $c$ & $r$ \\
\hline $\begin{array}{l}\text { 4. If given the opportunity, I would like to learn to use } \\
\text { Robotics for instructional activities. }\end{array}$ & $r$ & $r$ & $r$ & $r$ & $r$ \\
\hline $\begin{array}{l}\text { 5. Children should be introduced to Robotics in elementary } \\
\text { school }\end{array}$ & $r$ & $c$ & $r$ & $r$ & $r$ \\
\hline 6. I am confident that I could learn how to use Robotics. & $r$ & $r$ & $r$ & $r$ & $r$ \\
\hline $\begin{array}{l}\text { 7. The challenge of using Robotics for instruction does not } \\
\text { appeal to me. }\end{array}$ & $r$ & $r$ & $r$ & $r$ & $r$ \\
\hline $\begin{array}{l}\text { 8. I will hesitate to use Robotics for fear of making mistakes } \\
\text { I cannot correct. }\end{array}$ & $r$ & $r$ & 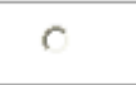 & $r$ & $r$ \\
\hline $\begin{array}{l}\text { 9. I am unsure of my ability to integrate Robotics in my } \\
\text { classes. }\end{array}$ & $r$ & $r$ & $r$ & $r$ & $r$ \\
\hline 10. I will do as little work with Robotics as possible. & $r$ & 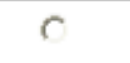 & C & $r$ & $r$ \\
\hline $\begin{array}{l}\text { 11. I think that integrating Robotics with teaching would } \\
\text { take too much time. }\end{array}$ & $r$ & $r$ & $r$ & $c$ & $r$ \\
\hline $\begin{array}{l}\text { 12. I am willing to spend time setting up Robotics for } \\
\text { instruction. }\end{array}$ & $r$ & $r$ & $c$ & $c$ & $r$ \\
\hline $\begin{array}{l}\text { 13. I am sure I could do instructional activities with } \\
\text { Robotics. }\end{array}$ & $r$ & $r$ & $c$ & $r$ & $r$ \\
\hline 14. I would feel at ease using Robotics in my classes. & $r$ & $r$ & $r$ & $r$ & $r$ \\
\hline $\begin{array}{l}\text { 15. I think working with Robotics in class would be } \\
\text { enjoyable and stimulating. }\end{array}$ & $r$ & $c$ & $r$ & $r$ & $r$ \\
\hline $\begin{array}{l}\text { 16. I think using Robotics in class would be very hard for } \\
\text { me. }\end{array}$ & $c$ & $r$ & $r$ & $r$ & $r$ \\
\hline $\begin{array}{l}\text { 17. Robotics can create more learning opportunities for } \\
\text { students. }\end{array}$ & $C$ & $r$ & $c$ & $r$ & $r$ \\
\hline 18. Robotics is a valuable educational tool. & $r$ & $r$ & $r$ & $r$ & $C$ \\
\hline
\end{tabular}

Acknowledgement: Adapted with permission from Appendix C in Gade et al. (2006), Journal of Technology and Teacher Education, 14 (3), 501-529.

POST WORKSHOP QUESTION: On the back side of this survey, please provide suggestions/ideas for improving the Robotics experiences in this course. 


\section{Appendix E}

Interview Protocol*

Subject ID \#:

Date: Time: Interview performed by:

1. Please state your name, school, and grade level that you teach or work with.

2. Do you have any prior experience using WeDo 1 or NXT or another robotics platform?

3. When and where was your workshop? Thinking back on it, what thoughts, observations, or suggestions do you have about the workshop on elementary robotics? Any improvements you may suggest? Anything that was especially good?

4. What is your perception of educational robotics use in the elementary classroom? Good or bad idea? Positive or negative for kids?

5. Did you borrow the classroom kit or have your own kit you used with students? If not, why did you not borrow the kit? Was it not available when you needed it, or do you plan to use it later in the year? Or, do you not want to use it? If not, then why?

6. When, and for how long did you (or do you plan to) borrow the kit? How many days or times did (or will) you use it with students and for how long? What successes or challenges did (or do you think) you have?

7. What do you like about the $\mathrm{LEGO}^{\circledR}$ WeDo 2.0 platform and our kit including the iPads, travel boxes, etc.?

8. What problems/issues have you (or do you think you'll) encountered in the use of this platform and/or kit?

9. How did (or will) the activities demonstrated in the workshop help you when using it with students?

10. Beyond what was demonstrated, what other uses did you find (or do you anticipate) for the kit?

11. How does this kit need to be changed to make it more useful for teaching and learning in elementary education?

12. Why did you attend the WeDo 2.0 workshop?

13. Do you have any additional suggestions for the platform, training, loan kit, or in general about your experiences, or to assist in my research about using educational robotics?

*Updated March 3, 2017 to reflect how the order of the questions were modified to improve the flow of the interview. 


\section{Appendix F}

Workshop Agenda

ERC Elementary Educational Robotics LEGO ${ }^{\circledR}$ WeDo 2.0 Workshop

\section{Welcome/Introductions/Restrooms}

Educational Robotics (ER) Research Project:

- Read cover letter aloud.

- Fill out Demographic Sheet.

- Complete ER Pre-Workshop Survey.

\section{Educational Robotics Training:}

- Introduction to WeDo 2.0.

- WeDo 2.0 in the elementary curriculum.

- Assessment with WeDo 2.0.

- How our kits are organized to facilitate classroom use:

1. Box, lit, robot brain, iPad, and charger of same number stays together.

2. Spare parts box and multi-charger included as well.

3. Batteries (spares included, don't mix with rechargeable).

4. Clear portfolios and programs from iPads before returning.

- Classroom Management Techniques:

1. No dumping parts out of kits.

2. Students work in pairs (trios only if necessary).

3. Assign roles (engineer, programmer) and ensure they switch.

4. Make sure each student contributes to the portfolio.

5. Explain special parts and how the kit organizes them by function.

6. All classes start with Milo, then add the light sensor to cover basics.

7. Younger students work together as a class until they are comfortable.

- Educators build Milo, add light sensor, sound, complete portfolio with photo and written entry.

- Educators build object of choice from guided activities, modify the program to make it work differently, complete portfolio.

- Educators share build with the class.

- Discuss standards addressed and cross-curricular connections.

- Sort all parts, clean programs and portfolios from iPads, return to kit.

\section{Complete ER Post-Workshop Survey.}


Appendix G

Example Interview Transcript

Name:

Subject 55

School:

DATA REMOVED FOR PRIVACY

Grade:

$4^{\text {th }}$ grade

Timestamp

(2) [Did not directly ask question\#2 regarding any prior experience with robotics as researcher knows this participant had prior experience, had borrowed the kit, and was a LEGO $^{\circledR}$ League Jr. coach.]

When did you attend the WeDo 2.0 workshop?

I attended a WeDo 2.0 for First Lego League in September and I attended again, I think in January.

The January was with Pam, right? Yes.

So I'm interested in the workshop with Pam. Oh, okay.

What thoughts, observations, or suggestions do you have on the workshop that Pam delivered on the WeDo 2.O for elementary robotics?

Really I don't have any. It was very enjoyable. I learned a lot. It made me less afraid to attempt to try it with my class because she let us experiment with it and showed us that there wasn't anything to be afraid of; so really I don't have any suggestions or improvements - I've just been trying to tell everybody else to go and do it! Great!

What is your perception of educational robotics in general?

I just see the huge advantage of doing it because the kids have learned so much beyond what I thought they would. I mean they've learned a lot of science which you know, because we did a lot with the earthquake machines and flood gates and that kind of thing so that they could learn the science and how scientists could reduce the impact of natural disasters and those kinds of things and so they learned a lot in science. They learned about engineering design. They learned a lot about cooperation - working in a group and I've also found that they're starting to read manuals, so their informational reading has improved and then I've even found that they're - when they discuss with each other, their vocabulary is a lot higher, and that the way they talk to each other, and they problem solve and they figure out: "Well this is what I did," and "This is what happened," or "Let's try something else" and I feel that they're generally improving in everything. In math they're learning about angles, and they're learning about speed, and what motion and force can do - and so I think that all around they're learning lots of different things. Great - so now just to follow up on that, you're suggesting that they're doing that while they're using the robotics or they're gaining that in all other areas? (2:30-4:00) They're actually doing it more when they're using the robotics because when I put them in the groups and we talk about you know, what do scientist do? And then I have them build a flood gate; you know build the earth quake machine; and then when 
they're working together, we assigned them roles, you know - "You're the person controlling the iPad," it goes from step to step - "You're the person who gets the pieces out of the box," "You're the person who puts the pieces together" and the last person in our group is the quality control - they make sure that it's built correctly. I just find that the communication between the four of them is really improving, and then they're looking back and they're reading what Milo is saying and different things. They're watching the videos to try to figure out the answers to the questions that are on there and then they write about it and so they discuss and then they write it - "How did this work?" "What weather made the flood gate open?" "What made it close?" And the discussions that they're having is just increasing in every aspect.

Do you have different perspectives on robotics when considering the elementary classroom?

I think a lot of the teachers are afraid of it because they're technology and they're afraid they won't know how to teach the children; you know - how to use it. I think what I'm seeing is, now that I'm using it and a lot of teachers are seeing me use it - is that the students are so familiar with technology - really it's not something that they're afraid of. It's something that we as adults who haven't had as much exposure to it - we are more afraid of it than the kids are. The kids actually take control of their own learning and I think that in elementary schools sometimes the teachers are wanting to be control focused; you know, they want to be in control - they want to guide. Whereas you go into the robotics and into their teams, and you give them a project, and they're working on the project, and they're writing about the projects -you're not really the focus of the classroom. You're the liaison who kind of goes around and trouble shoots if you need to and I think sometimes I think that's a little frightening for the teacher. But the kids are really growing and they're taking on a lot of responsibility that sometimes I think we're afraid to relinquish to them. Wonderful!

When did you borrow the kit and how long did you have it?

I borrowed it in February and I had it for two weeks.

Can you tell me about - and I think you've already been doing this so this question may seem a little out of order but I was wondering if you could tell me about the experience you had with the kit - like did you use it every day or did you use it just every several days - I mean how did you implement it? (5:30-7:05) We had just finished up a unit - I just did a whole science unit on the way rocks and the land forms. We had been talking about flooding, and earthquakes, and volcanoes, and natural disasters and how quickly our land forms change and what scientists do to reduce the impact of those kinds of situations. We just finished a whole unit on that so when I borrowed the kit I used them every day. I had two science classes $-4^{\text {th }}$ grade; I just had the kids work in groups of four and on the first we talked about, you know, flooding and the other things we talked about in class. Then they built the floodgates in their groups of four, and then they had to write about how the flood gates change how natural disasters impact us; how can it be effective; what did they notice about when it opened and when it closed - so those kinds of things. Then we went from there after they finished building it and writing about it, which went much quicker than I thought it would. The kids built it, 
in like 15 minutes - it was amazing! I thought it would take me days to get through it it did not [laughter]; so then I - So that's great - the building part, which I think would be something people consider a stumbling block, you said that they really went through that quickly.

Oh yeah! They were building and programming in a 40 minute period. It was - you know, the kids are so familiar with that kind of stuff that it doesn't even faze them. After we did the first one, then the next day I had them build the earth quake detector or the earth quake simulator - they were even quicker the second day because they had gone through it the first day and they knew exactly where to go on the iPad and they knew exactly what to do and they wrote about that and it went even quicker. And so then that went a couple days because we did some experiments with trying different types of houses and things. Then the next time, we built the volcano alarm and so we talked about the tilt meters and different things like that and they built that and then wrote about it and then we did some experiments with it. So one week I did one whole science class and the second week I did my other science class, so that we got through two weeks and both of my science classes got to build all three things.

what grade are you teaching again? Fourth.

What do you like about the WeDo 2.0 platform?

I think that there's just so much that I can do with it, like I can do science, I can do math, I can talk about systems and I think that there's so much versatility in it and so many different ways that I can incorporate it into the curriculum that I teach and it's easy. The kids love it. The pieces, you know - everything is organized and so that it doesn't seem like chaos. It seems - I don't know - there's such a flow and the kids are so motivated they can't wait to get into my class.

It's actually one of the, it's not a downside I guess, but we have often have a teacher return the kit and say, "Please take it back - I can't get rid of the kids. They keep coming in before and after school."

Oh yeah. I've ended up - I've wrote a couple of grants and I got a couple of kits, but I only have like two or three so it's not enough to do my whole class, but at recess time, that's all they want to do - they want to build. It's just that amazing.

What problem or issues have you encountered with the WeDo 2.0 kit?

The only thing that - and you know Pam actually addressed this in the meeting which I'm really glad that she did when we went to the workshop; you know the kids losing the pieces and finding them on the floor; but she talked to us about putting out the little bin that says, "extra pieces," and then when they find a piece then they put it in there and at the end of the week I had the kids inventory and make sure everything was put back. You know if anything was missing they had to come up to me and tell me about the missing pieces. That was the hardest part, you know, maintaining all of the little pieces. But since she talked about that in the workshop it made it so much easier for me because I already had a system before I was going to do it and before I handed them out. I talked to the kids about how much these cost and how much they don't belong to us. If we wanted to 
borrow them again we would need to take really good care of them and that kind of stuff; and really I didn't have any problems. That's wonderful to hear.

I had students who have never done anything for me like written anything for me and they did it and wrote about it. I was amazed!

I think you preempted this question also, but how did the activities demonstrated in the workshop help you when using the kits with the students?

I think because she allowed us to build things and us to experiment and you know go through the iPad and kind of, even with your partner and build, talk, and experiment; it took away the fear factor of it. I think that was the biggest part - whether I could build something, whether I could understand how it works, and her taking us through that you know, letting us play with instead of just talking to us about it - we had the kit in our hands, we had the iPad in our hands. We were able to build and see what it did. I think that (a) it motivated me to say, "Oh my kids will love this!" and (b) took the away the fear of doing it.

(10) Beyond what we demonstrated did you find any other uses for the kit?

Well, after she talked us through a couple - we, you know, got to go into the iPad and looked at the different activities that they had in there - that gave me a lot of ideas that I didn't realize. We could build a frog, do metamorphosis with it - I didn't realize I could do that. So I think just getting into the iPad and seeing all the different projects that already are in there kind of spurred my creativity - "Well, I could tie this into math and we could talk about Richter scale and force and do some of those equations with it. That kind of spurred me into - How can I tie this into English? How can I tie this into - it really made it come alive when I saw all the different projects that were in there. okay - yeah, so even more than we were able to cover? Yeah.

(11) Do you think the kit needs to be changed or modified in any way to make it more useful for teaching and learning with elementary students?

I don't think so; I mean I was very successful and very happy and my students were thrilled and I thought that they learned a lot.

(12) [Did not directly ask question\#12 regarding motivation for attending workshop]

(13) That was it - that was all my questions unless you have any additional suggestions for the workshop itself, the loan kit, or any other thoughts about how this could help improve teaching and learning - or help teachers themselves and with integration.

I think for me, I've been talking about it a lot with teachers because they've seen what my kids are doing - now everybody wants to get the kits and I'm kind of like - that kind puts me at a downfall because I'd only get them only once a year - so having access to them more often would be helpful. Other than that I haven't seen anything else - other than me going around talking to everybody about them and everybody else signing up, 
you know makes it harder to get a hold of the kits when I'm at the end of my unit. Oher than that, no I don't have anything. I think she did an awesome job and made it really accessible to me and easy to do. I felt really comfortable. Great! Thank so much for your time - I really appreciate it; and as always if you have any questions or concerns either about our workshops, or our kits, or my research you can always let me know.

Okay, thanks so much.

Have a wonderful day.

You too. Bye-bye 